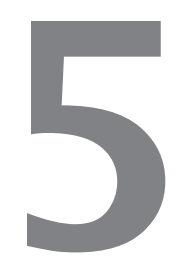

\title{
Investigação experimental em modelos
}

Para aferir a formulação proposta neste trabalho para o cálculo da frequência do primeiro modo de vibração, desenvolvida no capítulo 4, foram desenvolvidos ensaios dinâmicos em laboratório utilizando modelos de barras. A investigação foi realizada nas dependências do Gabinete de Dinâmica Não-Linear de Estruturas da Escola Politécnica da USP.

Dois conjuntos de testes foram conduzidos visando aferir a proposta para o cálculo da frequência e avaliar a influência da rigidez geométrica na frequência de vibração dos sistemas estruturais em balanço. O primeiro grupo estava submetido, além do seu peso próprio, 
a uma força normal aplicada na extremidade. O segundo grupo estava sujeito exclusivamente ao seu peso próprio.

Para acompanhar os cálculos analíticos e os resultados experimentais, foram feitas duas análises numéricas por meio do Método dos Elementos Finitos (MEF) utilizando o programa SAP2000. A primeira foi realizada sob condições lineares (MEFL) e a segunda sob as condições de não-linearidade geométrica (MEFNL), essa última processada com base nos resultados provenientes de uma análise estática não-linear. Essa análise pode ser realizada com objetivos comparativos, pois é possível especificar no programa SAP2000 para que se utilize do processo de cálculo que leva em consideração o efeito da força normal sobre a rigidez do sistema. Nos dois casos, as análises foram feitas por autovalores.

Para o segundo grupo de testes, acrescentou-se à análise dinâmica, a análise estática da carga crítica de flambagem, pela formulação numérica de autovalores e pela solução de Euler-Greenhill.

Nas análises numéricas, os parâmetros empregados foram os referidos nos itens relativos aos corpos-de-prova, tendo sido lançadas nos modelos numéricos as características do material, geometrias e massas dos modelos físicos.

As análises numéricas e analíticas, mencionadas anteriormente, foram descritas no capítulo 3.

\subsection{INSTRUMENTOS E SISTEMAS EMPREGADOS}

Os instrumentos, entre eles os equipamentos eletrônicos, utilizados foram: extensômetros elétricos; acelerômetros piezoelétricos; sistema de aquisição de dados ADS-2000, com placa conversora AI-2161 e placa controladora AC-2122VA, e programas AqDados e AqDAnalysis para aquisição e análise de dados, da LYNX informática; microcomputador; pré-amplificadores para o sinal dos acelerômetros; calibrador manual de acelerômetro; paquímetro; régua metálica; balança eletrônica; grampos metálicos; nível de bolha com base magnética e trena metálica. 


\subsection{CARACTERÍSTICAS DOS SENSORES}

Foram utilizados extensômetros elétricos de resistência de 120 $\Omega$ e fator 2,1; fabricados pela Excel Sensores (Excel Sensores, 2006). O arranjo adotado para a ligação dos extensômetros ao sistema de aquisição de dados foi de $1 / 4$ de ponte a três fios.

Foram também utilizados acelerômetros do tipo piezoelétricos. Os acelerômetros piezoelétricos foram de fabricação Bruel \& Kjaer modelos 4393 e 4371, cujas características, respectivamente, são: sensibilidade - 3,1 pC/g e 10 pC/g, intervalo de frequência - 0,1 Hz à $16.500 \mathrm{~Hz}$ e $0,1 \mathrm{~Hz}$ à $12.600 \mathrm{~Hz}$, frequência de ressonância - $55 \mathrm{kHz}$ e $42 \mathrm{kHz}$, nível de ruído residual - 0,52 g e 0,24 g, nível operacional máximo - 5000 g e 6000 g, massa 2,4 gramas e 11 gramas (BRUEL \& KJAER, 2005). Os acelerômetros foram calibrados usando um calibrador excitador manual da Bruel \& Kjaer tipo 4294.

A ligação dos acelerômetros ao sistema de aquisição de dados foi precedida da ligação do acelerômetro ao amplificador modelo 2525 da própria Bruel \& Kjaer (SERRIGDE \& LICHT, 1995).

\subsection{SISTEMA DE AQUISIC̣ÃO DE DADOS}

O sistema de aquisição automático de dados empregado foi o ADS-2000 (AqDados) com placa conversora AI-2161 e placa controladora AC-2122VA, da LYNX informática, de 16 bits de resolução, cuja interface com microcomputador é feita através de rede Ethernet, (AqDados 7.02, 2003). A ligação dos sensores ao sistema de aquisição de dados é feita por meio dos conectores de entrada, que estão localizados na parte traseira do equipamento e obedeceram às seguintes configurações:

- $\quad$ extensômetros: $1 / 4$ de ponte a $120 \Omega$ com 3 fios, ganho 2000 , tensão de excitação de 5 volts;

- $\quad$ acelerômetros: tensão diferencial, ganho 1.

Durante a aquisição dos sinais foram usados filtros passa baixa de $20 \mathrm{~Hz}$ para os ensaios de maior frequência e $5 \mathrm{~Hz}$ para os demais.

Inicialmente usou-se uma taxa de amostragem de $1000 \mathrm{~Hz}$ para prospectar o experimento. Como as frequências mais elevadas fica- 
ram abaixo de $10 \mathrm{~Hz}$, optou-se por baixar a frequência de aquisição para $100 \mathrm{~Hz}$, em alguns casos a aquisição foi feita a uma frequência de $500 \mathrm{~Hz}$. Os pré-amplificadores 2525 foram ajustados conforme a sensibilidade de cada acelerômetro.

\subsection{ESQUEMA ESTRUTURAL}

O esquema estrutural adotado para os ensaios foi o de uma barra engastada em uma extremidade e livre na outra, conforme visto na Figura 4.1.

\subsection{CORPOS-DE-PROVA}

O corpo-de-prova (CP) do primeiro grupo de testes era constituído por uma barra metálica chata de seção nominal de 1/2" $(12,70 \mathrm{~mm})$ por 1/8" (3,17 mm) ao qual foram fixadas, por pressão lateral, duas massas metálica na extremidade livre, que somadas às massas dos acelerômetros e suas bases magnéticas resultaram no valor total de 1,595 gramas no topo da haste.

Por ser uma peça de aço, o módulo de elasticidade longitudinal do material foi assumido como sendo de $205 \mathrm{GPa}$. A determinação da densidade do material da haste foi feita experimentalmente no laboratório de materiais do PCC/USP usando a técnica de picnometria com gás Helio. A densidade relativa obtida foi de $8,19\left(8190 \mathrm{~kg} / \mathrm{m}^{3}\right)$, conforme se vê no Anexo A. As demais massas envolvidas foram medidas na balança eletrônica do laboratório de materiais da USP.

O corpo-de-prova foi instrumentado com três extensômetros e dois acelerômetros, conforme a disposição mostrada na Figura 5.1. Os extensômetros foram colados à superfície da barra, enquanto que os acelerômetros ficaram aderidos a essa por meio de bases magnéticas que fazem parte do seu estojo de acessórios. 


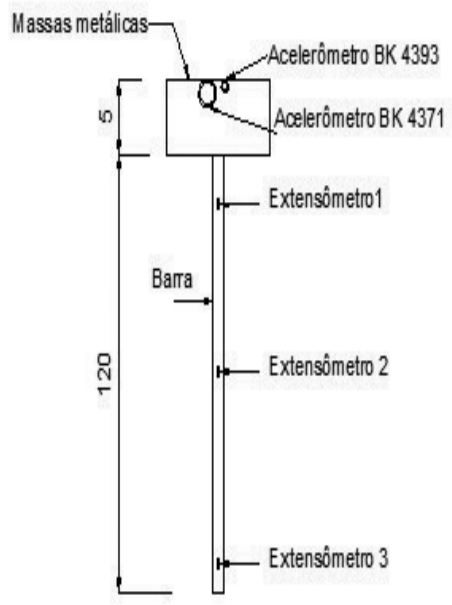

Figura 5.1 - Instrumentação do corpo-de-prova - medidas em centímetros.

O corpo-de-prova do segundo grupo ensaiado era constituído por um tubo metálico de diâmetro externo nominal de 3/8" (9,525 mm) e espessura da parede de 1,2 mm. Para esse corpo-de-prova, o módulo de elasticidade longitudinal do material foi também assumido como sendo de $205 \mathrm{GPa}$. Para esses ensaios, o corpo-de-prova foi instrumentado com o acelerômetro modelo 4371 fabricado pela Bruel \& Kjaer. Os ensaios do segundo grupo foram realizados apenas para a força normal de compressão devida ao peso próprio dos modelos.

\subsection{DESCRIC̣ÃO DOS ENSAIOS}

Com as massas metálicas adicionadas à haste foram adotadas três posições de ensaio para o primeiro grupo de testes, relativas às possíveis influências da carga axial na rigidez no sistema. A primeira posição considerou a influência da força axial de compressão, logo, posicionou-se o conjunto de forma ser comprimido pelo peso próprio da barra e pela carga vertical produzida pela massa no topo. A segunda posição considerou a influência da força axial de tração, de forma que o conjunto foi posicionado de maneira a gerar força de tração no sistema e o corpo-de-prova foi posto na posição inversa à anterior. A terceira 
posição analisou a ausência da influência da carga axial na frequência fundamental do modelo, por essa razão, o conjunto foi instalado na posição horizontal. Um quarto ensaio considerou exclusivamente a compressão devido ao peso próprio da barra e será descrito mais adiante. A Figura 5.2 ilustra as posições empregadas nos testes do primeiro grupo.

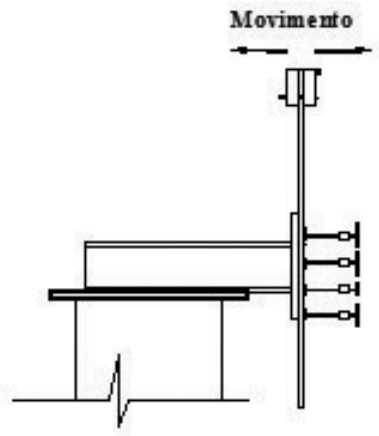

(a) compressão

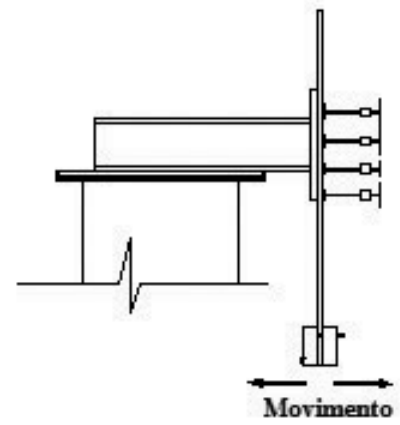

(b) tração

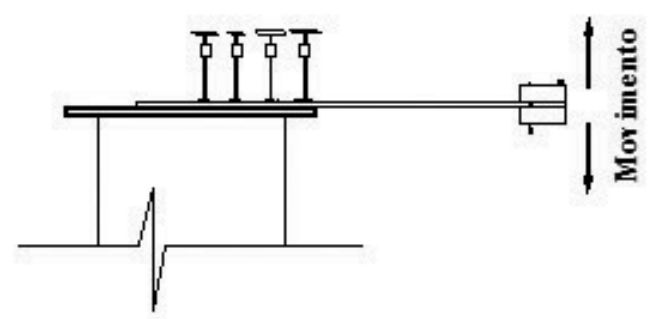

(c) ausência do esforço normal

Figura 5.2 - Posições adotadas nos ensaios. 
A realização dos ensaios obedeceu aos passos descritos a seguir. Antes do inicio dos ensaios, os acelerômetros foram calibrados com o calibrador excitador B\&K modelo 4294 (Bruel \& Kjaer, 2005). Os acelerômetros ficaram aderidos ao corpo-de-prova por meio das bases magnéticas com a disposição mostrada na Figura 5.3.
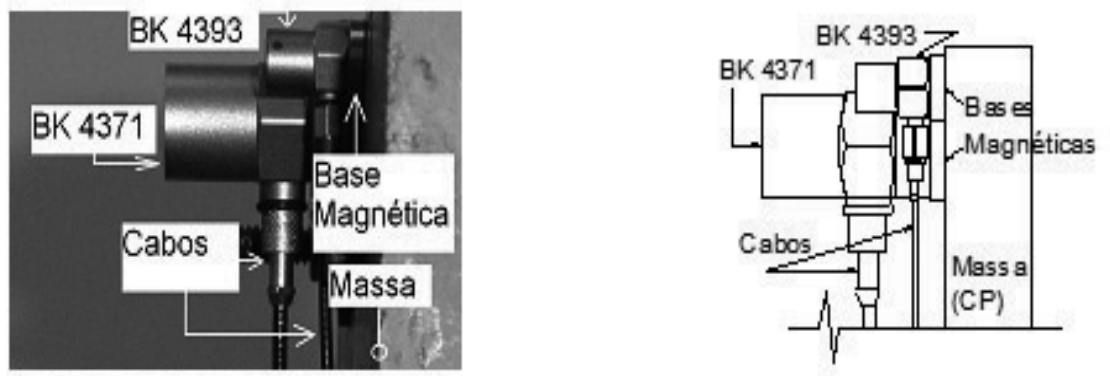

Figura 5.3 - Detalhe da fixação dos acelerômetros no CP.

Após serem fixados, tanto o aparelho de apoio quanto os modelos foram nivelados horizontal e verticalmente com nível de bolha (Figura 5.4).
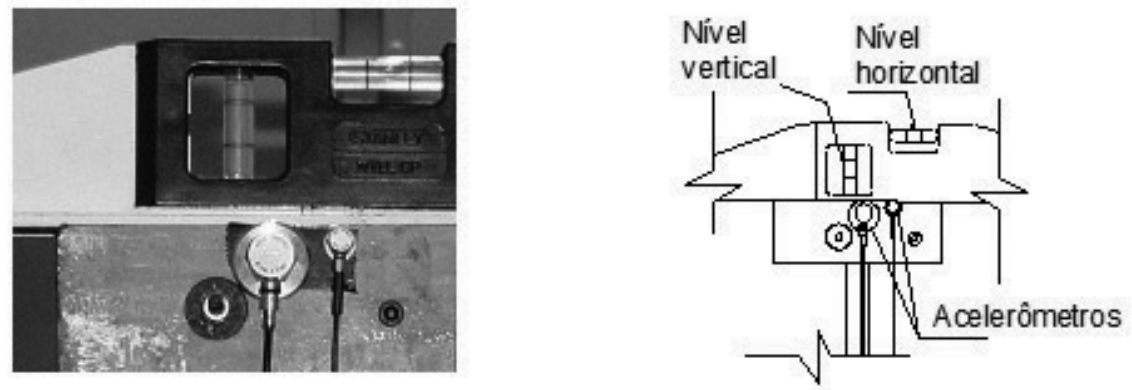

Figura 5.4 - Nivelamento dos corpos-de-prova.

O corpo-de-prova foi fixado ao aparelho de apoio por meio de grampos metálicos conhecidos comumente como grampos tipo sargento. Buscou-se manter o mesmo padrão de fixação para todos os modelos, como o tamanho e a posição dos grampos em relação aos CP e a pressão de aperto. 
O comprimento experimental de referência foi controlado visualmente e a sua determinação foi feita por meio de uma trena metálica. As mesmas referências foram mantidas para as diferentes posições. Variou-se o comprimento de $5 \mathrm{~cm}$ em $5 \mathrm{~cm}$ até o limite físico de fixação possível ou até a posição de máxima estabilidade oferecida pelo conjunto. A Figura 5.5 mostra o sistema de fixação empregado nos ensaios e as referências para controle do comprimento dos corpos-de-prova.
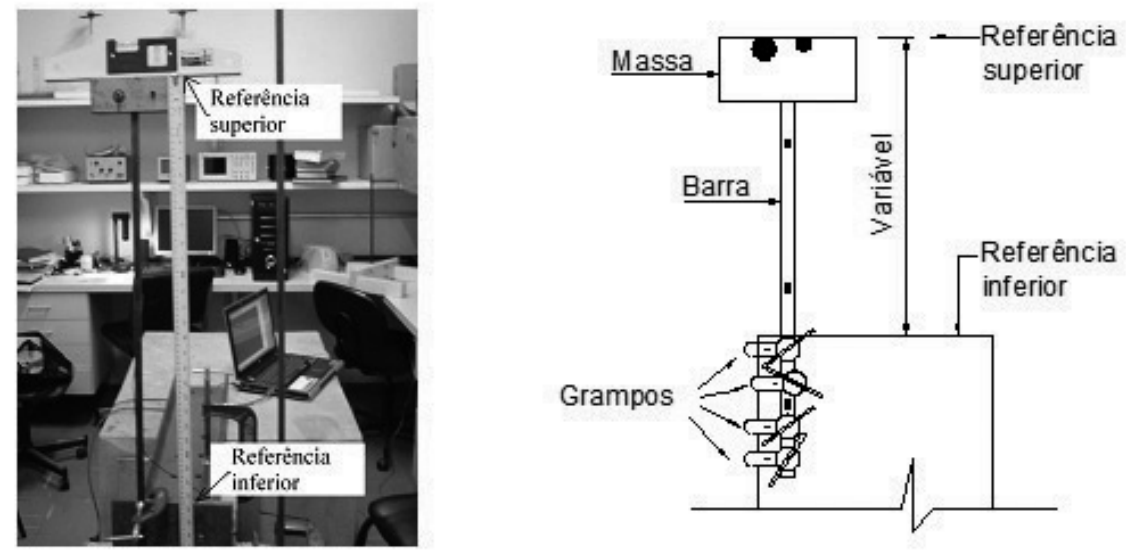

Figura 5.5 - Controle do comprimento dos modelos.

Os corpos-de-prova do grupo que estava submetido exclusivamente ao peso próprio foram fixados a um pórtico metálico por meio de uma base e uma placa metálica que permitia a mudança do comprimento ao aliviar-se a pressão exercida pelos parafusos. Buscou-se manter o mesmo padrão de aperto na fixação da barra com os diversos comprimentos adotados.

Antes de serem excitados os modelos eram verticalmente nivelados, operação que se tornava mais difícil à medida o comprimento dos modelos aumentava. O conjunto de apoio conferia uma condição inercial segura para a realização dos ensaios.

A Figura 5.6 mostra o sistema de apoio e fixação utilizado e a verificação da verticalidade dos corpos-de-prova. 

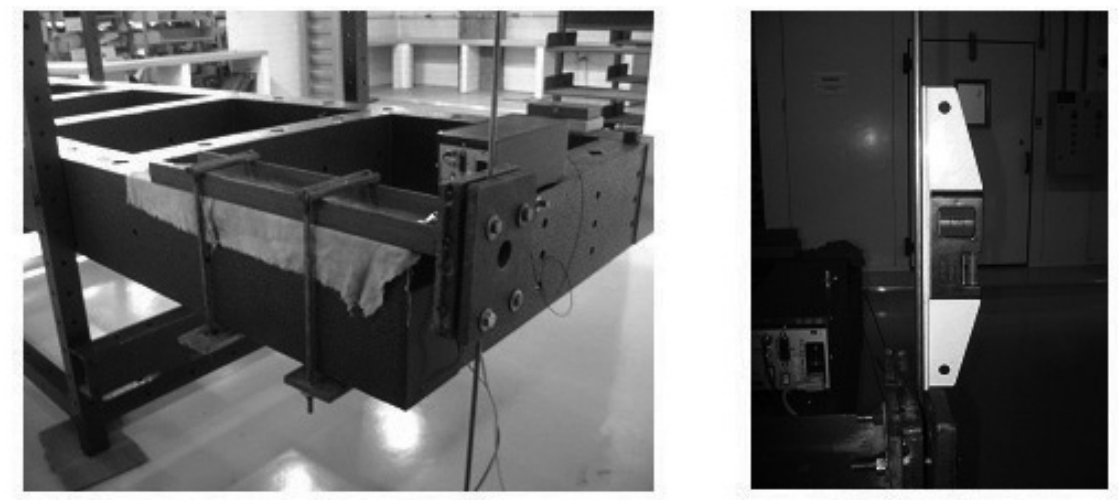

Figura 5.6 - Sistema de fixação e nivelamento do CP - Ensaios com o tubo metálico.

Em todos os ensaios, os cabos dos acelerômetros foram fixados ao sistema de apoio com fita adesiva para evitar interferência na aquisição dos sinais.

Em ambos os ensaios, os modelos, nas diversas posições e comprimentos, foram excitados por uma força aleatória com magnitude necessária e suficiente para por o sistema em movimento oscilatório. Depois de excitados, os sistemas oscilavam em torno da sua posição inicial.

Os sinais, no domínio do tempo, foram então gravados e analisados posteriormente.

\subsection{ANÁLISE DOS RESULTADOS}

Como afirma Lobo Carneiro (1993), as vibrações livres, excitadas inicialmente a partir de um deslocamento inicial, são amortecidas por efeito histérico, por atritos, ou pela resistência de um meio viscoso. A taxa de amortecimento é uma constante física característica do material do corpo e/ou do meio que o cerca, proporcional à dissipação de energia por ciclo ou ao decréscimo relativo da amplitude de vibração.

Quanto se refere ao decréscimo da amplitude de vibração, Lobo Carneiro (1996) recomenda que o amortecimento crítico seja calculado pela Eq. (5.1). 


$$
\zeta=\frac{1}{2 \pi} \cdot(\text { decréscimo relativo da amplitude por ciclo }) \text {. }
$$

No caso de pequenas amplitudes, tanto a experiência quanto as soluções teóricas mostram que a influência do deslocamento inicial em relação ao comprimento do corpo é desprezível e que também a influência do amortecimento sobre o período de vibração pode, em geral, ser desprezado. $\mathrm{O}$ amortecimento relativo medido nos ensaios por decremento logarítmico de duas amplitudes consecutivas para o corpo-de-prova em compressão com $50 \mathrm{~cm}$ de altura foi de 0,00724 (0,724\%), corroborando as afirmações de Lobo Carneiro (1993).

É interessante mencionar que nos ensaios de compressão e sem a consideração da influência do esforço normal, os modelos mais longos apresentaram uma configuração inicial de equilíbrio estático bastante deformada em relação à posição reta do eixo da barra, chegando mesmo a ocorrer a plastificação localizada em alguns modelos. A Figura 5.7 ilustra a plastificação mencionada para o comprimento de $90 \mathrm{~cm}$.
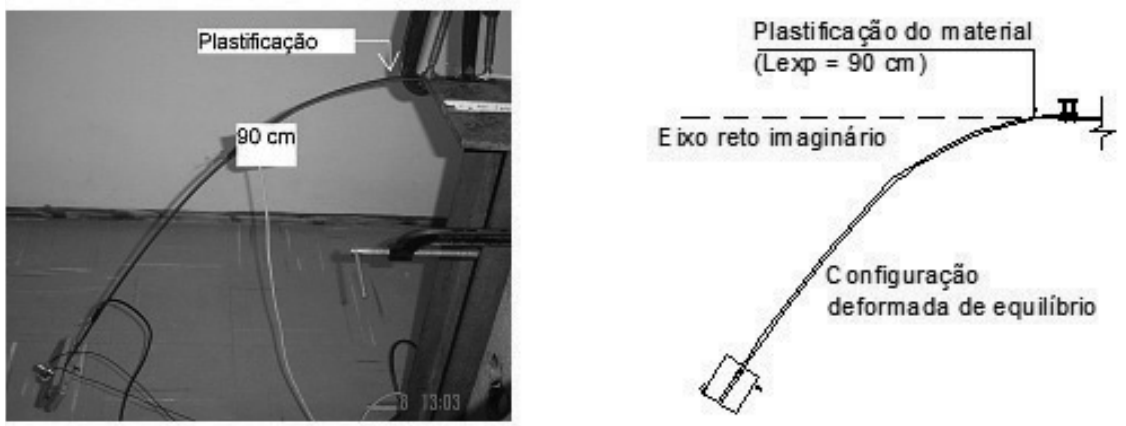

$\left(\mathrm{L}_{\text {exp }}=\right.$ comprimento experimental de referência)

Figura 5.7 - Plastificação do material.

A situação descrita anteriormente está fora do escopo deste trabalho. No entanto, por tratar-se de atividades de prospecção, optou-se por conduzir os ensaios até onde fosse possível sua a rea- 
lização. A condição relatada anteriormente representa um caso de vibração a partir da configuração inicial deformada, sendo necessário, portanto, considerar que devido à grande deformação da peça, a força $\mathrm{F}$ inicialmente alinhada ou perpendicular ao eixo da barra, produz uma componente axial $\mathrm{N}$ e gera uma força tangencial $\mathrm{V}$ que variam ao longo do comprimento em função da seção considerada, conforme se vê na Figura 5.8.
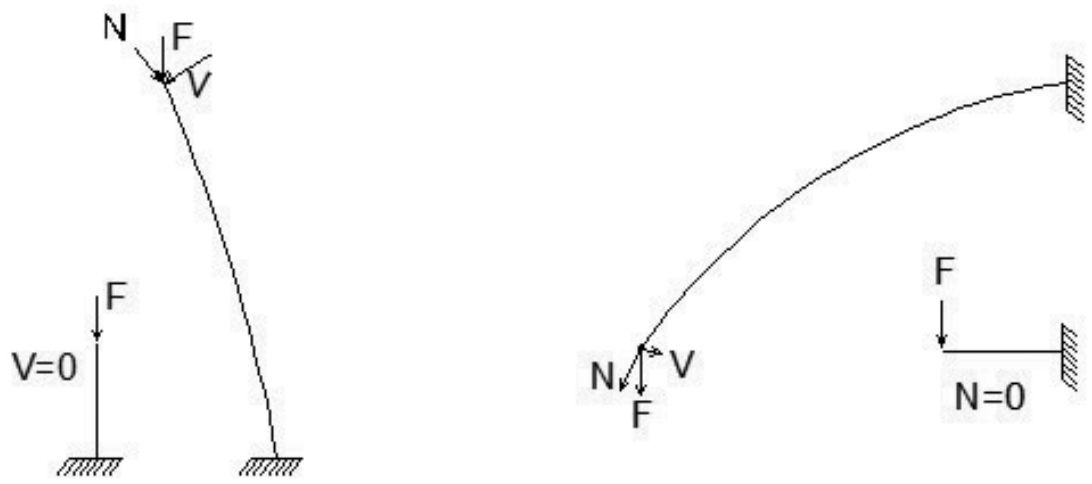

Figura 5.8 - Componentes normal e tangencial devido à curvatura acentuada da barra.

A obtenção da frequência do modo fundamental de vibração dos modelos foi feita pela transformada de Fourier no programa AqDAnalysis 7 (AqDAnalysis 7, 2004). Para isso, a análise de auto-espectro disponibilizada pelo programa foi configurada para uma janela de compensação do tipo Hanning, com uma janela de dados para o cálculo do espectro médio; zoom da FFT (Transformada Rápida de Fourier) igual a 1; e com a máxima resolução permitida para a quantidade de amostras aquisitadas. A resposta apresentada pelos modelos representa o movimento harmônico, conforme se vê na Figura 5.9, que exemplifica os sinais dos sensores no domínio do tempo e a transformada de Fourier correspondente ao acelerômetro B\&K 4371. 


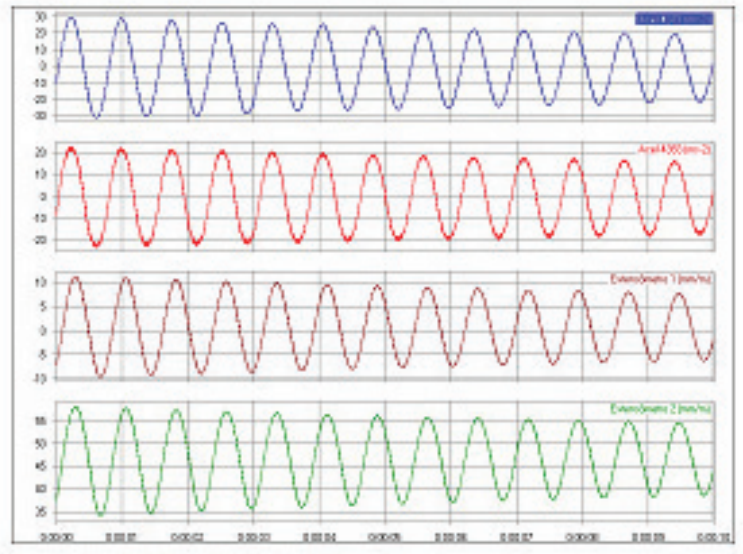

(a) No domínio do tempo.

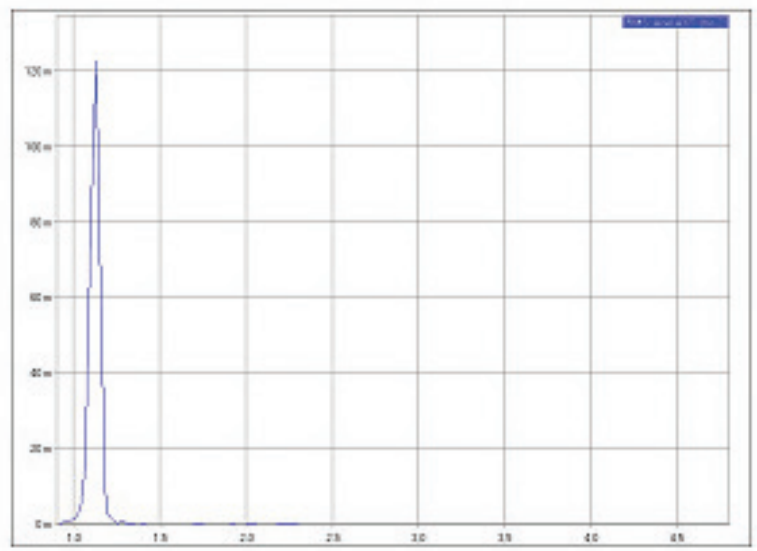

(b) No domínio da frequê̂ncia.

\section{Figura 5.9 - Resposta dinâmica experimental.}

O comprimento máximo alcançado no ensaio de compressão foi de $85 \mathrm{~cm}$, além do qual, o sistema não mais se manteve em equilíbrio. Os resultados dos ensaios serão discutidos mais adiante.

No que se refere às análises pelo Método dos Elementos Finitos, é oportuno salientar que:

- às frequências obtidas sob a hipótese de comportamento linear independem da natureza do esforço, pois não levam em conta a mudança na rigidez geométrica dos modelos, e, portanto, podem ser comparadas com os resultados ex- 
perimentais e com os da solução proposta neste trabalho para o esforço de compressão;

- a análise dinâmica não-linear esteve baseada na matriz de rigidez de uma prévia análise estática não-linear como descrito no início deste capítulo.

Para os modelos do primeiro grupo de testes, os resultados obtidos na análise dinâmica não-linear pelo Método dos Elementos Finitos foram os seguintes:

Tabela 5.1 - Resultados da análise não-linear por Elementos Finitos.

\begin{tabular}{|c|c|c|c|}
\hline \multicolumn{4}{|c|}{ Análise não-linear - Frequências $(\mathrm{Hz})$} \\
\hline Comprimento (m) & Compressão & Tração & Sem esforço axial \\
\hline 0,20 & 6,2810 & 6,5146 & 6,3989 \\
\hline 0,25 & 4,4405 & 4,7022 & 4,5733 \\
\hline 0,30 & 3,3281 & 3,6155 & 3,4749 \\
\hline 0,35 & 2,5940 & 2,9053 & 2,7543 \\
\hline 0,40 & 2,0783 & 2,4121 & 2,2517 \\
\hline 0,45 & 1,6983 & 2,0536 & 1,8848 \\
\hline 0,50 & 1,4077 & 1,7839 & 1,6073 \\
\hline 0,55 & 1,1783 & 1,5751 & 1,3915 \\
\hline 0,60 & 0,9925 & 1,4096 & 1,2198 \\
\hline 0,65 & 0,8383 & 1,2760 & 1,0805 \\
\hline 0,70 & 0,7073 & 1,1664 & 0,9657 \\
\hline 0,75 & 0,5936 & 1,0751 & 0,8698 \\
\hline 0,80 & 0,4924 & 0,9981 & 0,7886 \\
\hline 0,85 & 0,3994 & 0,9325 & 0,7192 \\
\hline 0,90 & 0,3104 & 0,8760 & 0,6593 \\
\hline
\end{tabular}

Graficamente tem-se o comportamento apresentado na Figura 5.10. 


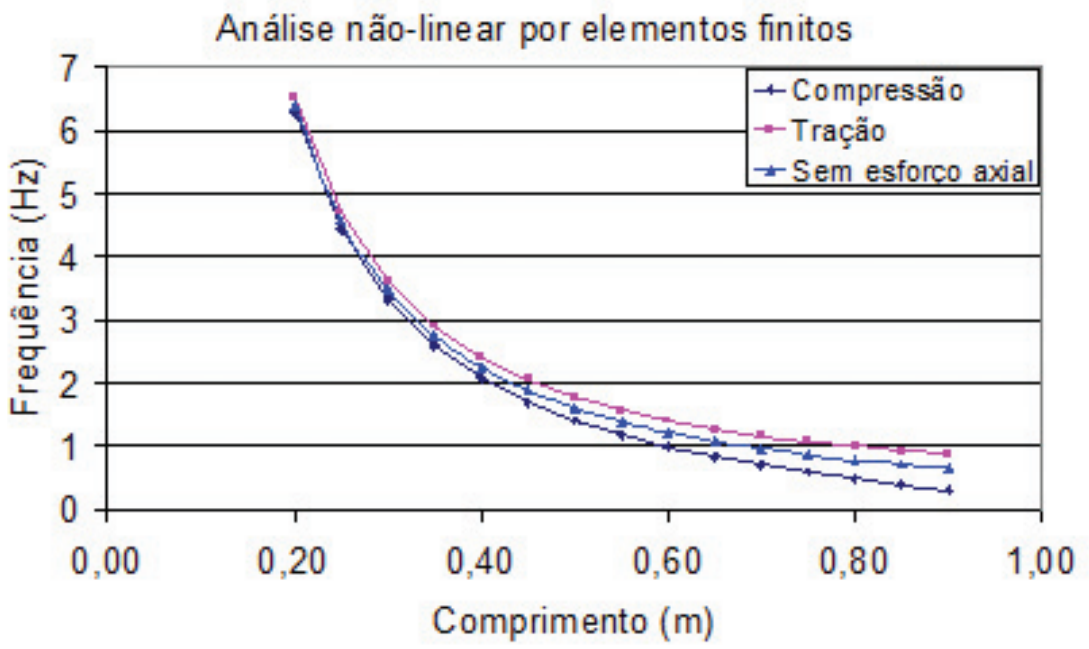

Figura 5.10 - Análise não-linear pelo Método dos Elementos Finitos.

As análises numéricas com a inclusão da não-lineridade geométrica forneceram três diferentes resultados para a frequência de vibração dos modelos. Esses resultados revelam influência que a natureza do esforço normal produz na frequência de vibração dos modelos, tornam-se, para esses sistemas, mais evidente à medida que aumenta a esbeltez dos modelos e diminui a frequência de vibração.

Os resultados obtidos pela análise dinâmica dos modelos não-lineares pelo Método dos Elementos Finitos foram comparados aos resultados experimentais e aos da solução proposta para o cálculo da frequência, desenvolvida no capítulo 4, e serão apresentados no decorrer deste capítulo.

\subsubsection{Análise dos ensaios para o esforço de compressão}

As diferenças percentuais entre os valores experimentais e a solução de referência, Eq. (4.19), ficaram em torno de 3,17\% nos 
comprimentos iniciais, passando para $5,98 \%$ ao ser alcançado o comprimento de $70 \mathrm{~cm}$. A partir desse instante já se percebia uma configuração estática de equilíbrio acentuadamente deformada, e a plastificação do material já se manifestava perceptível.

A média das diferenças entre o total dos resultados experimentais e a solução proposta neste trabalho foi de 8,69\%. Os resultados obtidos no ensaio de compressão estão dispostos na Tabela 5.2 com os correspondentes resultados da solução proposta neste trabalho, dados pela Eq. (4.19).

Tabela 5.2 - Esforço de compressão: resultados experimentais e solução proposta.

\begin{tabular}{|c|c|c|c|c|}
\hline \multicolumn{5}{|c|}{ Esforço de compressão } \\
\hline \multirow{2}{*}{$\begin{array}{l}\text { Comprimento } \\
\text { (m) }\end{array}$} & \multicolumn{2}{|c|}{ Frequências $(\mathrm{Hz})$} & \multicolumn{2}{|c|}{ Diferenças } \\
\hline & $\begin{array}{c}\text { Resultados } \\
\text { experimentais }\end{array}$ & $\begin{array}{l}\text { Solução } \\
\text { proposta }\end{array}$ & $\mathrm{Hz}$ & $\%$ \\
\hline 0,20 & 6,3477 & 6,3276 & 0,020 & 0,32 \\
\hline 0,25 & 4,4556 & 4,4729 & $-0,017$ & 0,39 \\
\hline 0,30 & 3,2959 & 3,3520 & $-0,056$ & 1,67 \\
\hline 0,35 & 2,5024 & 2,6122 & $-0,110$ & 4,20 \\
\hline 0,40 & 1,9836 & 2,0925 & $-0,109$ & 5,20 \\
\hline 0,45 & 1,6479 & 1,7096 & $-0,062$ & 3,61 \\
\hline 0,50 & 1,3428 & 1,4167 & $-0,074$ & 5,21 \\
\hline
\end{tabular}




\begin{tabular}{|c|c|c|c|c|}
\hline \multicolumn{5}{|c|}{ Esforço de compressão } \\
\hline \multirow{2}{*}{$\begin{array}{l}\text { Comprimento } \\
\text { (m) }\end{array}$} & \multicolumn{2}{|c|}{ Frequências $(\mathrm{Hz})$} & \multicolumn{2}{|c|}{ Diferenças } \\
\hline & $\begin{array}{c}\text { Resultados } \\
\text { experimentais }\end{array}$ & $\begin{array}{l}\text { Solução } \\
\text { proposta }\end{array}$ & $\mathrm{Hz}$ & $\%$ \\
\hline 0,55 & 1,1292 & 1,1855 & $-0,056$ & 4,75 \\
\hline 0,60 & 0,9155 & 0,9983 & $-0,083$ & 8,29 \\
\hline 0,65 & 0,7935 & 0,8429 & $-0,049$ & 5,86 \\
\hline 0,70 & 0,6104 & 0,7110 & $-0,101$ & 14,15 \\
\hline 0,75 & 0,4883 & 0,5965 & $-0,108$ & 18,14 \\
\hline 0,80 & 0,3662 & 0,4946 & $-0,128$ & 25,95 \\
\hline 0,85 & 0,3052 & 0,4011 & $-0,096$ & 23,90 \\
\hline
\end{tabular}

As respostas do ensaio de compressão revelaram o comportamento presente na Figura 5.11, na qual é possível ver que os resultados obtidos pela solução analítica do método proposto, Eq. (4.19), ajustam-se bem aos resultados experimentais.

Portanto, é possível afirmar, com os ensaios realizados, que dentro do intervalo de validade da equação (4.19), até o comprimento de $65 \mathrm{~cm}$, os resultados experimentais confirmam o correto cálculo da frequência propiciado pela solução desenvolvida neste trabalho. 
Esforço de compressão

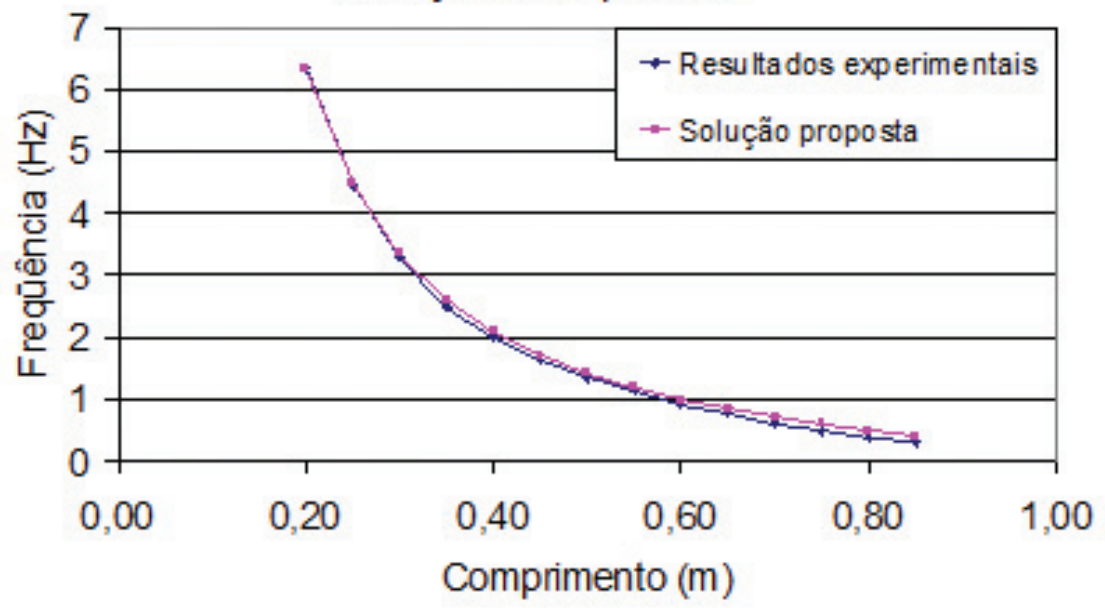

Figura 5.11 - Compressão: Resultados experimentais e solução proposta.

As frequências obtidas pelo Método dos Elementos Finitos, sob a hipótese de comportamento linear, são apresentadas na Tabela 5.3.

Tabela 5.3 - Comparativo dos resultados da análise linear pelo Método dos Elementos Finitos.

\begin{tabular}{|c|c|c|c|}
\hline \multicolumn{4}{|c|}{ Frequências (Hz) } \\
\hline $\begin{array}{c}\text { Comprimento } \\
(\mathbf{m})\end{array}$ & $\begin{array}{c}\text { Elementos Finitos } \\
\text { Linear }\end{array}$ & $\begin{array}{c}\text { Resultados } \\
\text { experimentais }\end{array}$ & $\begin{array}{c}\text { Solução } \\
\text { proposta }\end{array}$ \\
\hline 0,20 & 6,3989 & 6,3477 & 6,3276 \\
\hline 0,25 & 4,5733 & 4,4556 & 4,4729 \\
\hline 0,30 & 3,4749 & 3,2959 & 3,3520 \\
\hline
\end{tabular}




\begin{tabular}{|c|c|c|c|}
\hline \multicolumn{4}{|c|}{ Frequências $(\mathrm{Hz})$} \\
\hline $\begin{array}{l}\text { Comprimento } \\
\text { (m) }\end{array}$ & $\begin{array}{l}\text { Elementos Finitos } \\
\text { Linear }\end{array}$ & $\begin{array}{c}\text { Resultados } \\
\text { experimentais }\end{array}$ & $\begin{array}{l}\text { Solução } \\
\text { proposta }\end{array}$ \\
\hline 0,35 & 2,7543 & 2,5024 & 2,6122 \\
\hline 0,40 & 2,2517 & 1,9836 & 2,0925 \\
\hline 0,45 & 1,8848 & 1,6479 & 1,7096 \\
\hline 0,50 & 1,6073 & 1,3428 & 1,4167 \\
\hline 0,55 & 1,3915 & 1,1292 & 1,1855 \\
\hline 0,60 & 1,2198 & 0,9155 & 0,9983 \\
\hline 0,65 & 1,0805 & 0,7935 & 0,8429 \\
\hline 0,70 & 0,9657 & 0,6104 & 0,7110 \\
\hline 0,75 & 0,8698 & 0,4883 & 0,5965 \\
\hline 0,80 & 0,7886 & 0,3662 & 0,4946 \\
\hline 0,85 & 0,7192 & 0,3052 & 0,4011 \\
\hline
\end{tabular}

Graficamente tem-se: 
Esforço de compressão

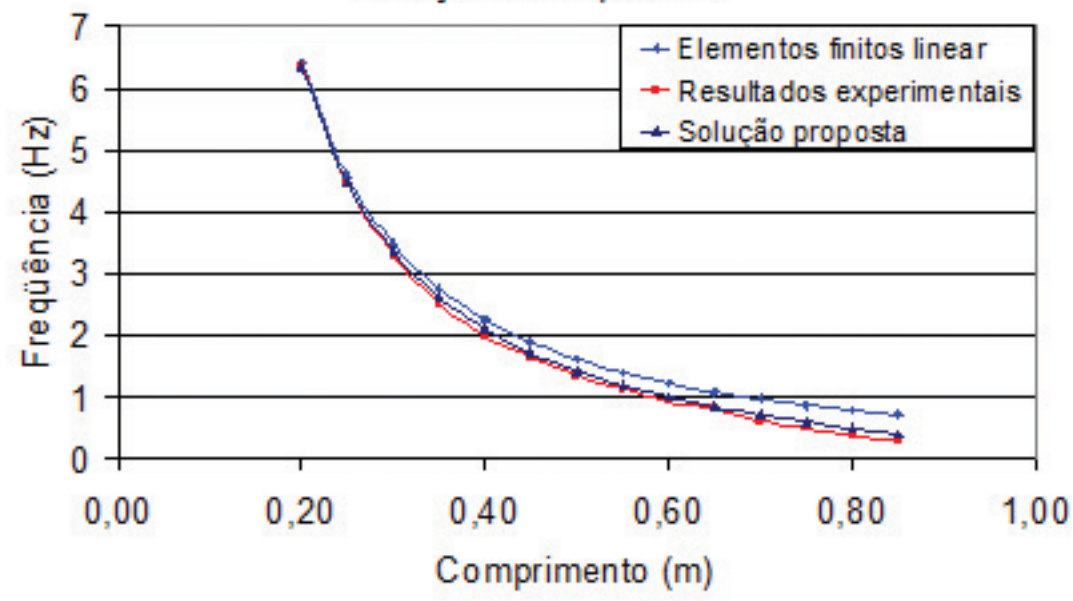

Figura 5.12 - Análise linear por elementos finitos, experimental e proposto.

Quando comparados aos resultados da formulação proposta e aos valores experimentais, para o esforço de compressão, situação em que, na prática, se encontram as estruturas civis em estudo, a análise linear apresenta diferenças importantes nas primeiras frequências.

As diferenças da análise linear pelo Método dos Elementos Finitos entre os valores experimentais e os da solução proposta podem ser encontradas na Tabela 5.4.

Tabela 5.4 - Diferenças da análise linear pelo Método dos Elementos Finitos.

\begin{tabular}{|c|c|c|c|c|}
\hline \multicolumn{5}{|c|}{ Esforço de compressão } \\
\hline $\begin{array}{c}\text { Comprimento } \\
(\mathbf{m})\end{array}$ & Com resultados experimentais & Com a solução proposta \\
\cline { 2 - 5 } & $\mathbf{H z}$ & $\%$ & $\mathbf{H z}$ & $\%$ \\
\hline 0,20 & 0,0512 & 0,80 & 0,0713 & 1,11 \\
\hline 0,25 & 0,1177 & 2,57 & 0,1004 & 2,20 \\
\hline 0,30 & 0,1790 & 5,15 & 0,1230 & 3,54 \\
\hline
\end{tabular}




\begin{tabular}{|c|c|c|c|c|}
\hline \multicolumn{5}{|c|}{ Esforço de compressão } \\
\hline \multirow{2}{*}{$\begin{array}{c}\text { Comprimento } \\
\text { (m) }\end{array}$} & \multicolumn{2}{|c|}{ Com resultados experimentais } & \multicolumn{2}{|c|}{ Com a solução proposta } \\
\hline & $\mathrm{Hz}$ & $\%$ & $\mathrm{~Hz}$ & $\%$ \\
\hline 0,35 & 0,2519 & 9,15 & 0,1421 & 5,16 \\
\hline 0,40 & 0,2681 & 11,90 & 0,1592 & 7,07 \\
\hline 0,45 & 0,2369 & 12,57 & 0,1752 & 9,30 \\
\hline 0,50 & 0,2645 & 16,46 & 0,1907 & 11,86 \\
\hline 0,55 & 0,2623 & 18,85 & 0,2060 & 14,80 \\
\hline 0,60 & 0,3043 & 24,95 & 0,2215 & 18,16 \\
\hline 0,65 & 0,2870 & 26,56 & 0,2377 & 21,99 \\
\hline 0,70 & 0,3553 & 36,79 & 0,2547 & 26,38 \\
\hline 0,75 & 0,3815 & 43,86 & 0,2733 & 31,42 \\
\hline 0,80 & 0,4224 & 53,56 & 0,2940 & 37,28 \\
\hline 0,85 & 0,4140 & 57,56 & 0,3181 & 44,23 \\
\hline
\end{tabular}

Quando comparada aos resultados experimentais, a análise linear pelo Método dos Elementos Finitos alcança um máximo de $57,56 \%$. Para o mesmo intervalo de validade considerado para a validade da Eq. (4.19), essa diferença se aproxima de 13\%.

Para melhor comparar os resultados obtidos, na Tabela 5.5 são novamente apresentadas frequências da análise não-linear pelo Método dos Elementos Finitos, para o esforço de compressão. 
Tabela 5.5 - Resultados da análise não-linear pelo MEF para o esforço de compressão.

\begin{tabular}{|c|c|}
\hline \multicolumn{2}{|c|}{ Análise não-linear - Frequências $(\mathrm{Hz})$} \\
\hline Comprimento (m) & Compressão \\
\hline 0,20 & 6,2810 \\
\hline 0,25 & 4,4405 \\
\hline 0,30 & 3,3281 \\
\hline 0,35 & 2,5940 \\
\hline 0,40 & 2,0783 \\
\hline 0,45 & 1,6983 \\
\hline 0,50 & 1,4077 \\
\hline 0,55 & 1,1783 \\
\hline 0,60 & 0,9925 \\
\hline 0,65 & 0,8383 \\
\hline 0,70 & 0,7073 \\
\hline 0,75 & 0,5936 \\
\hline 0,80 & 0,4924 \\
\hline 0,85 & 0,3994 \\
\hline 0,90 & 0,3104 \\
\hline
\end{tabular}


No gráfico da Figura 5.13 são mostradas as frequências dos modelos não-lineares obtidas pelo Método dos Elementos Finitos, juntamente com os respectivos valores experimentais e analíticos da solução proposta.

Na Figura 5.13, é possível ver a boa aproximação entre as curvas dos três resultados: não-linear pelo $\mathrm{MEF}$, experimental e proposto, confirmando o caráter não-linear do problema e a validade da solução desenvolvida neste trabalho.

As diferenças existentes entre a análise não-linear por Elementos Finitos, com a análise linear, com a solução proposta e com os resultados experimentais são apresentadas na Tabela 5.6.

Em termos absolutos há uma significativa diferença entre a análise não-linear e a análise linear pelo Método dos Elementos Finitos, quando a primeira é superada em 0,4088 Hz. Em termos relativos, essa diferença representa um percentual de 44,46\%.

\section{Esforço de compressão}

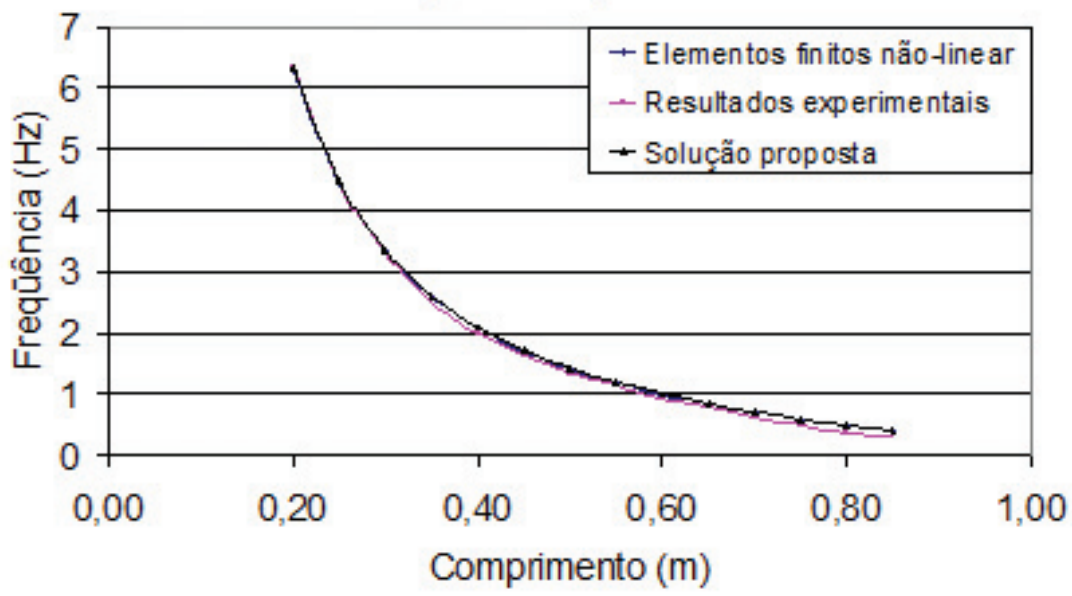

Figura 5.13 - Compressão: elementos finitos não-linear, experimental e proposto. 
Tabela 5.6 - Compressão - Diferenças percentuais da análise não-linear pelo MEF.

\begin{tabular}{|c|c|c|c|}
\hline $\begin{array}{c}\text { Comprimento } \\
\text { (m) }\end{array}$ & $\begin{array}{c}\text { Com linear pelo } \\
\text { MEF }\end{array}$ & $\begin{array}{c}\text { Com } \\
\text { experimental }\end{array}$ & $\begin{array}{c}\text { Com } \\
\text { proposto }\end{array}$ \\
\hline 0,20 & 1,88 & 1,05 & 0,74 \\
\hline 0,25 & 2,90 & 0,34 & 0,72 \\
\hline 0,30 & 4,22 & 0,98 & 0,71 \\
\hline 0,35 & 5,82 & 3,66 & 0,70 \\
\hline 0,40 & 7,70 & 4,77 & 0,68 \\
\hline 0,45 & 9,89 & 3,06 & 0,66 \\
\hline 0,50 & 12,42 & 4,83 & 0,63 \\
\hline 0,55 & 15,32 & 4,35 & 0,61 \\
\hline 0,60 & 18,64 & 8,41 & 0,58 \\
\hline 0,65 & 22,42 & 5,64 & 0,55 \\
\hline 0,70 & 26,76 & 15,88 & 0,51 \\
\hline 0,75 & 31,75 & 21,57 & 0,48 \\
\hline 0,80 & 37,56 & 34,46 & 0,44 \\
\hline 0,85 & 44,46 & 30,88 & 0,40 \\
\hline
\end{tabular}


Em situação contrária à descrita anteriormente, os resultados da análise não-linear pelo MEF guardam desprezível diferença relativa com os resultados obtidos pela solução proposta. Nas análises realizadas pelo MEF, os resultados obtidos, tanto nos modelos lineares quanto nos modelos não-lineares, obedeceram à discretização mais densa presente na Tabela 5.7, na qual podem ser encontradas as diferenças de resultados para modelos com diferentes discretizações.

Para avaliar a influência que a técnica de discretização dos modelos pelo Método dos Elementos Finitos exerce sobra a frequências de vibração, foram processadas modelagens contendo 1, 10, 40, 100, 500 e 1000 elementos. A simulação foi realizada para o esforço de compressão e os resultados estão na Tabela 5.7. A Tabela 5.8 apresen- 


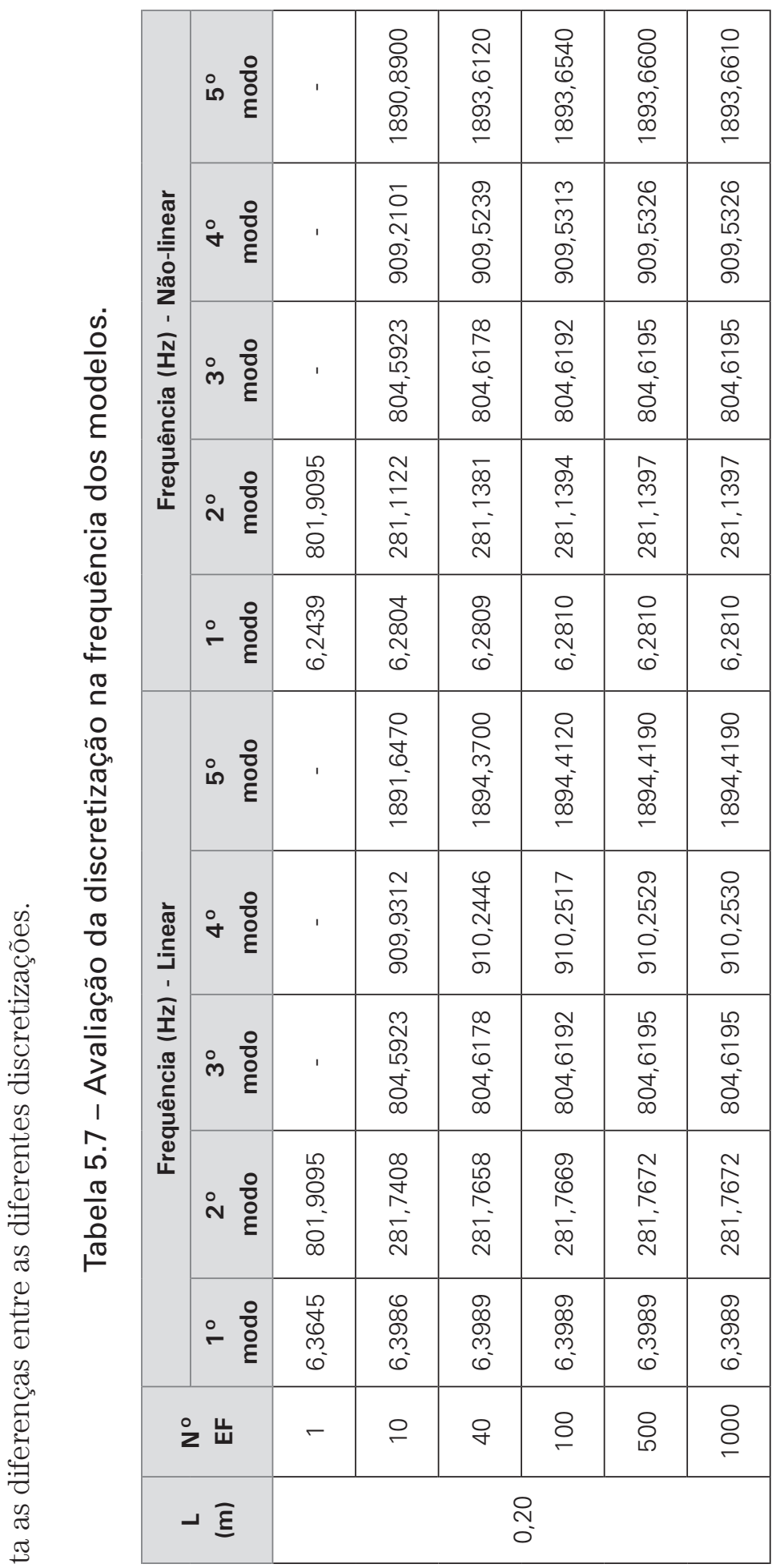




\begin{tabular}{|c|c|c|c|c|c|c|c|}
\hline \multirow{5}{*}{ 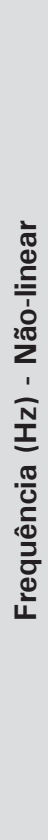 } & 요 & & 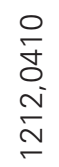 & 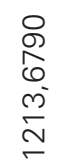 & 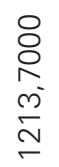 & 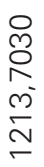 & 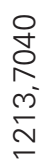 \\
\hline & 용 & I & $\begin{array}{l}\underset{\mathcal{Y}}{+} \\
\stackrel{+}{+} \\
\frac{\infty}{\pi}\end{array}$ & $\begin{array}{l}\stackrel{L}{\sim} \\
\underset{7}{f} \\
\infty \\
\frac{1}{\pi}\end{array}$ & \begin{tabular}{l}
$\bar{g}$ \\
\multirow{J}{*}{} \\
$\infty$ \\
$\frac{1}{\pi}$
\end{tabular} & 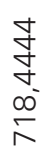 & $\begin{array}{l}\frac{8}{d} \\
\frac{J}{2} \\
\frac{\infty}{i}\end{array}$ \\
\hline & 용 & I & $\begin{array}{l}\underset{N}{N} \\
\underset{\sim}{\sim} \\
\infty \\
\infty \\
\sim\end{array}$ & 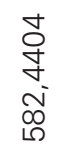 & 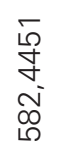 & 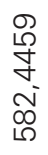 & 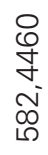 \\
\hline & 유ํ & 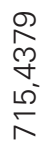 & 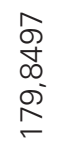 & 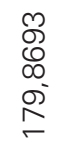 & 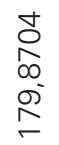 & 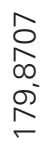 & 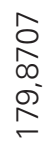 \\
\hline & $\stackrel{\circ}{\circ} \stackrel{\circ}{\circ}$ & $\begin{array}{l}\overline{8} \\
\vdots \\
+ \\
-\end{array}$ & 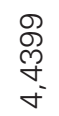 & 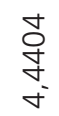 & 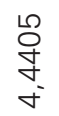 & 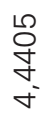 & 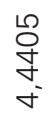 \\
\hline \multirow{5}{*}{ 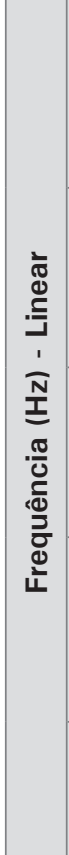 } & 요 & ' & 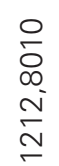 & 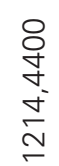 & 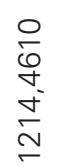 & 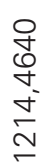 & 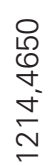 \\
\hline & 용 & ' & $\begin{array}{l}\underset{J}{\sim} \\
\underset{+}{+} \\
\frac{\infty}{\pi}\end{array}$ & $\begin{array}{l}\stackrel{L}{\mathcal{N}} \\
\underset{+}{+} \\
\stackrel{\infty}{\pi}\end{array}$ & 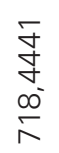 & $\begin{array}{l}\underset{8}{J} \\
\stackrel{8}{J} \\
\frac{0}{1}\end{array}$ & $\begin{array}{l}\underset{8}{J} \\
\frac{8}{2} \\
\frac{0}{\pi}\end{array}$ \\
\hline & 용 융 & , & $\begin{array}{l}\bar{\infty} \\
0 \\
\mathscr{0} \\
\sim \\
\infty \\
\infty \\
⺊\end{array}$ & 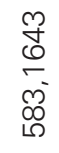 & $\begin{array}{l}0 \\
\infty \\
0 \\
\infty \\
\infty \\
\infty \\
\llcorner\end{array}$ & $\begin{array}{l}\text { वे } \\
0 \\
0 \\
0 \\
0 \\
0 \\
0\end{array}$ & $\begin{array}{l}\text { वे } \\
0 \\
0 \\
\infty \\
0 \\
0 \\
0\end{array}$ \\
\hline & $\stackrel{\circ}{\stackrel{\circ}{\circ}}$ & 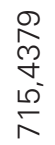 & $\begin{array}{l}\underset{N}{N} \\
\stackrel{0}{0} \\
\circ \\
\infty \\
\infty\end{array}$ & $\begin{array}{l}0 \\
8 \\
\circ \\
\circ \\
0 \\
\infty \\
-\end{array}$ & $\begin{array}{l}\llcorner 0 \\
\llcorner \\
\llcorner \\
\circ \\
\infty \\
\infty\end{array}$ & $\begin{array}{l}\hat{0} \\
\tilde{\delta} \\
0 \\
0 \\
\infty\end{array}$ & 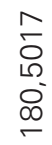 \\
\hline & $\stackrel{\circ}{-} \stackrel{\circ}{\circ}$ & \begin{tabular}{l}
$\hat{N}$ \\
जै \\
\multirow{2}{*}{}
\end{tabular} & 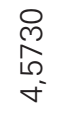 & 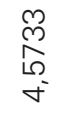 & 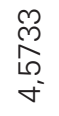 & 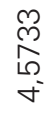 & 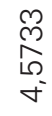 \\
\hline \multicolumn{2}{|c|}{ 足 } & $r$ & 으 & 아 & 음 & 웅 & 음 \\
\hline \multicolumn{2}{|c|}{\lrcorner$\overline{\underline{\xi}}$} & \multicolumn{6}{|c|}{ 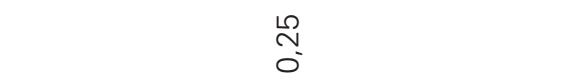 } \\
\hline
\end{tabular}




\begin{tabular}{|c|c|c|c|c|c|c|c|}
\hline \multirow{5}{*}{ 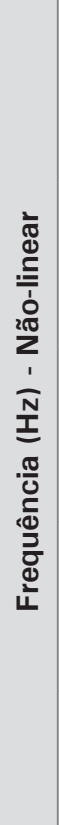 } & ㅇํ & ' & 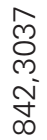 & 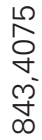 & 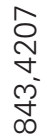 & 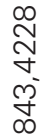 & 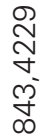 \\
\hline & ㅇ 을 & ' & 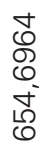 & $\begin{array}{l}\stackrel{N}{N} \\
\stackrel{N}{N} \\
\text { L } \\
0\end{array}$ & 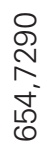 & $\begin{array}{l}\text { D } \\
\stackrel{N}{N} \\
\text { L্ } \\
0\end{array}$ & 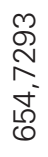 \\
\hline & $\stackrel{\circ}{\circ} \stackrel{\circ}{\frac{0}{2}}$ & ' & 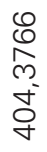 & 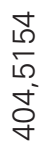 & 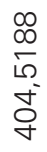 & 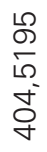 & 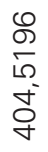 \\
\hline & $\stackrel{\circ}{\sim} \stackrel{\circ}{\circ}$ & 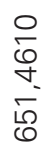 & 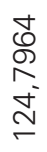 & 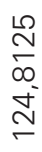 & 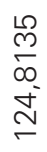 & 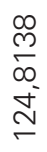 & 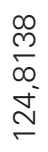 \\
\hline & $\stackrel{\circ}{\circ} \stackrel{\circ}{\frac{0}{8}}$ & 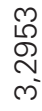 & $\begin{array}{l}\text { N } \\
\text { m} \\
\text { m. }\end{array}$ & $\begin{array}{l}\stackrel{0}{0} \\
\stackrel{N}{m} \\
m \\
m\end{array}$ & $\begin{array}{l}\bar{\infty} \\
\text { N } \\
m \\
m\end{array}$ & $\begin{array}{l}\bar{\infty} \\
\stackrel{n}{N} \\
m \\
m\end{array}$ & $\begin{array}{l}\bar{\infty} \\
\stackrel{n}{N} \\
m \\
m^{-}\end{array}$ \\
\hline \multirow{5}{*}{ 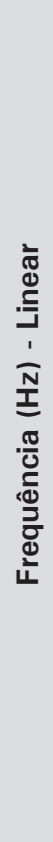 } & ㅇํㄹ & ' & $\begin{array}{l}\frac{1}{N} \\
6 \\
0 \\
\text { ஸ் } \\
\infty\end{array}$ & 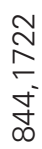 & \begin{tabular}{l}
$\bar{L}$ \\
$\infty$ \\
$\leftarrow$ \\
\multirow{5}{5}{} \\
$\infty$
\end{tabular} & $\begin{array}{l}\underset{N}{\infty} \\
\stackrel{-}{+} \\
\underset{\infty}{+}\end{array}$ & $\begin{array}{l}\bar{\kappa} \\
\infty \\
\stackrel{j}{+} \\
\infty\end{array}$ \\
\hline & $\stackrel{\circ}{\circ} \stackrel{\circ}{\frac{0}{2}}$ & ' & 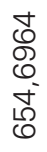 & $\begin{array}{l}\stackrel{N}{N} \\
\stackrel{N}{N} \\
\stackrel{5}{0}\end{array}$ & 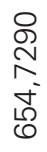 & 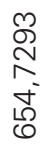 & 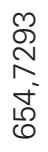 \\
\hline & ㅇ 을 & ' & 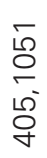 & 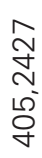 & 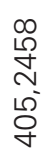 & 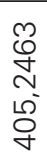 & 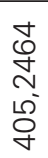 \\
\hline & $\stackrel{\circ}{\sim} \stackrel{\circ}{\circ}$ & 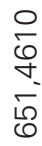 & 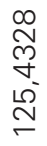 & 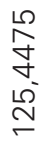 & 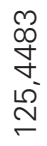 & 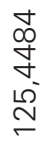 & 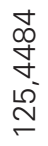 \\
\hline & $\circ \stackrel{\circ}{\circ}$ & $\begin{array}{l}\stackrel{N}{~} \\
\text { J } \\
\text { ले }\end{array}$ & 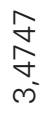 & 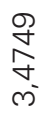 & 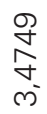 & 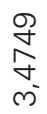 & 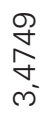 \\
\hline \multicolumn{2}{|c|}{ そ 岀 } & - & $\stackrel{ }{\circ}$ & 우 & 음 & 윰 & 응 \\
\hline \multicolumn{2}{|c|}{$-\overline{\boldsymbol{E}}$} & \multicolumn{6}{|c|}{$\begin{array}{l}\text { p } \\
\tilde{o}^{\circ}\end{array}$} \\
\hline
\end{tabular}




\begin{tabular}{|c|c|c|c|c|c|c|c|}
\hline \multirow{5}{*}{ 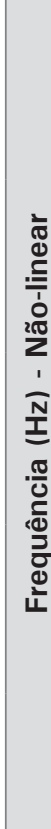 } & ㅇํํ & & 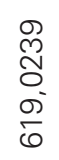 & $\begin{array}{l}\text { Dె } \\
\text { N } \\
\infty \\
\text { D } \\
\bar{\sigma}\end{array}$ & $\begin{array}{l}\text { N } \\
\text { ळ } \\
\sigma^{\prime} \\
\bar{\sigma}\end{array}$ & \begin{tabular}{l}
$\infty$ \\
\multirow{N}{*}{} \\
$\infty$ \\
$\sigma$ \\
$\sigma$ \\
$\sigma$
\end{tabular} & $\begin{array}{l}\infty \\
\mathcal{N}^{2} \\
\infty \\
\sigma \\
\bar{\sigma}\end{array}$ \\
\hline & ㅇ 윰 & & $\begin{array}{l}\text { Lิ } \\
8 \\
0 \\
10 \\
0\end{array}$ & $\begin{array}{l}\stackrel{+}{\infty} \\
\stackrel{\sim}{\sim} \\
\stackrel{0}{0} \\
\mathbb{0}\end{array}$ & $\frac{m}{8}$ & 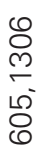 & $\begin{array}{l}\stackrel{0}{ } \\
\text { mे } \\
\stackrel{0}{0} \\
\mathbb{0}\end{array}$ \\
\hline & 용 율 & & $\begin{array}{l}\text { ญै } \\
\text { Oे } \\
\text { N- } \\
\text { N }\end{array}$ & 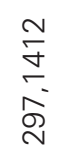 & $\frac{\stackrel{P}{\&}}{\stackrel{\text { N }}{\text { N }}}$ & $\begin{array}{l}\stackrel{O}{J} \\
\stackrel{5}{N} \\
\stackrel{N}{N}\end{array}$ & 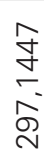 \\
\hline & $\stackrel{\circ}{\circ} \stackrel{\circ}{\circ}$ & 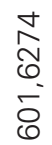 & $\begin{array}{l}0 \\
\text { o } \\
\omega \\
\tilde{\sigma} \\
\bar{\sigma}\end{array}$ & $\begin{array}{l}\stackrel{\llcorner}{0} \\
\stackrel{0}{\circ} \\
\bar{\sigma} \\
\bar{\sigma}\end{array}$ & $\begin{array}{l}\stackrel{J}{\circ} \\
\stackrel{\circ}{\circ} \\
\bar{\sigma}\end{array}$ & 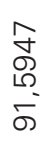 & 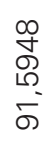 \\
\hline & 융 & 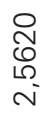 & $\begin{array}{l}\text { लै } \\
\stackrel{\circ}{\circ} \\
\text { N }\end{array}$ & 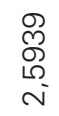 & $\begin{array}{l}\text { ㅇ } \\
\stackrel{\circ}{\circ} \\
\text { N }\end{array}$ & $\begin{array}{l}\text { o } \\
\text { ô } \\
\stackrel{\rho}{\circ} \\
\text { N }\end{array}$ & $\begin{array}{l}\text { 옹 } \\
\text { ه } \\
\text { i }\end{array}$ \\
\hline \multirow{5}{*}{ 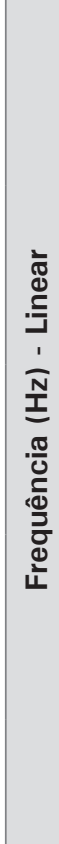 } & 용 융 & & $\begin{array}{l}\frac{1}{\sigma} \\
\frac{1}{\sigma} \\
\bar{\sigma}\end{array}$ & 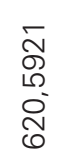 & 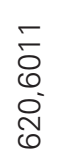 & 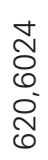 & 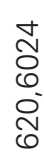 \\
\hline & $\stackrel{\circ}{\circ} \stackrel{\circ}{\circ}$ & & 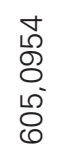 & 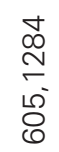 & 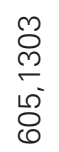 & $\begin{array}{l}8 \\
0 \\
0 \\
\delta^{\circ} \\
0\end{array}$ & $\begin{array}{l}0 \\
8 \\
\\
\\
0 \\
0\end{array}$ \\
\hline & 을 융 & & 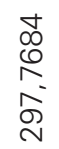 & $\begin{array}{l}\stackrel{ }{N} \\
\infty \\
\text { ஸे } \\
\stackrel{N}{N}\end{array}$ & 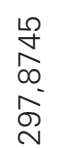 & 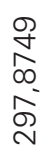 & 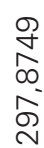 \\
\hline & $\stackrel{\circ}{\sim} \stackrel{\circ}{\circ}$ & \begin{tabular}{l}
\multirow{+}{*}{} \\
0 \\
$\vdots$ \\
0 \\
0
\end{tabular} & $\begin{array}{l}\text { Nิ } \\
\text { N } \\
\text { o }\end{array}$ & $\begin{array}{l}\stackrel{J}{\sim} \\
\underset{\sim}{N} \\
\sigma\end{array}$ & 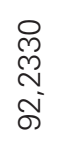 & 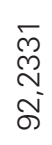 & $\begin{array}{l}\bar{ल} \\
\stackrel{N}{N} \\
\tilde{N}\end{array}$ \\
\hline & 윰 & 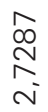 & $\begin{array}{l}\text { O } \\
\stackrel{5}{\circ} \\
\text { N }\end{array}$ & 苦 & 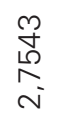 & 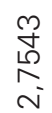 & $\begin{array}{c}\stackrel{M}{\mathcal{L}} \\
\stackrel{5}{\infty} \\
i\end{array}$ \\
\hline \multicolumn{2}{|c|}{ 吕 } & - & 으 & 우 & 8 & 迠 & \& \\
\hline \multicolumn{2}{|c|}{\lrcorner$\overline{\underline{\xi}}$} & \multicolumn{6}{|c|}{$\stackrel{\llcorner}{m}$} \\
\hline
\end{tabular}




\begin{tabular}{|c|c|c|c|c|c|c|c|}
\hline \multirow{5}{*}{ 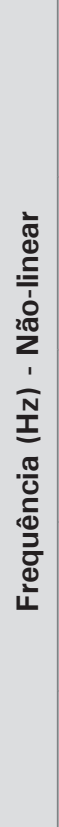 } & ㅇํ & ' & 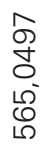 & $\begin{array}{l}\text { ग } \\
\infty \\
0 \\
0 \\
10 \\
0 \\
0\end{array}$ & $\begin{array}{l}\infty \\
0 \\
\infty \\
0 \\
1 \\
0 \\
0 \\
10\end{array}$ & $\begin{array}{l}N \\
\infty \\
0 \\
0 \\
0 \\
0 \\
0\end{array}$ & $\begin{array}{l}N \\
\infty \\
0 \\
0 \\
0 \\
0 \\
0\end{array}$ \\
\hline & 을 & ' & 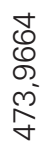 & 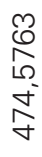 & 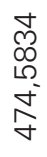 & 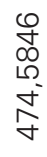 & 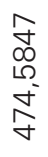 \\
\hline & ํ) 을 & 1 & 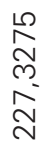 & 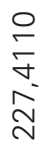 & 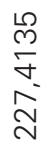 & 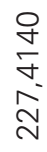 & 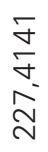 \\
\hline & $\stackrel{\circ}{\sim} \stackrel{\circ}{\circ}$ & 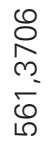 & $\begin{array}{l}0 \\
\infty \\
0 \\
0 \\
0 \\
0\end{array}$ & 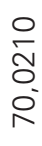 & 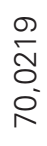 & 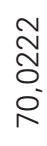 & 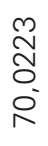 \\
\hline & $\stackrel{\circ}{\circ} \stackrel{\circ}{\circ}$ & 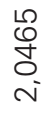 & 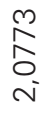 & $\begin{array}{l}\bar{\infty} \\
\text { مे } \\
\text { N }\end{array}$ & 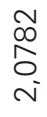 & 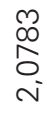 & 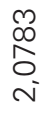 \\
\hline \multirow{5}{*}{ 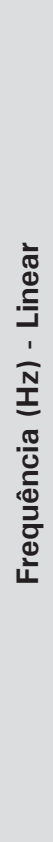 } & ㅇํ & ' & $\begin{array}{l}\infty \\
\text { ग } \\
0 \\
10 \\
0 \\
0 \\
\llcorner\end{array}$ & $\begin{array}{l}\text { ア } \\
\infty \\
0 \\
0 \\
0 \\
0 \\
0\end{array}$ & $\begin{array}{l}0 \\
0 \\
0 \\
0 \\
0 \\
0 \\
0 \\
0\end{array}$ & $\begin{array}{l}N \\
\infty \\
0 \\
0 \\
0 \\
0 \\
0\end{array}$ & $\begin{array}{l}N \\
\infty \\
0 \\
0 \\
0 \\
0 \\
0\end{array}$ \\
\hline & $\stackrel{\circ}{\circ} \stackrel{\circ}{\frac{0}{8}}$ & 1 & 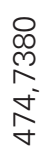 & \begin{tabular}{l}
$\bar{\infty}$ \\
\multirow{+}{*}{} \\
$\stackrel{\infty}{\infty}$ \\
$\stackrel{\sigma}{\sigma}$
\end{tabular} & 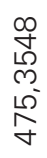 & 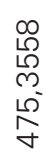 & \begin{tabular}{l}
$\infty$ \\
\llcorner \\
1 \\
$m$ \\
$\rho^{\circ}$ \\
\multirow{\gamma}{\gamma}{}
\end{tabular} \\
\hline & $\stackrel{\circ}{m} \stackrel{\circ}{\frac{0}{8}}$ & ' & $\begin{array}{l}\hat{m} \\
0 \\
0 \\
\infty \\
\stackrel{-}{N} \\
\text { }\end{array}$ & 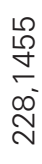 & 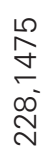 & 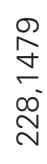 & 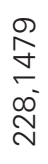 \\
\hline & $\stackrel{\circ}{\sim} \stackrel{\circ}{\circ}$ & $\begin{array}{l}0 \\
0 \\
\\
\overline{0} \\
0\end{array}$ & 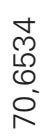 & $\begin{array}{l}\text { ग } \\
\text { 0 } \\
0 \\
0 \\
0\end{array}$ & \begin{tabular}{l}
\multirow{Z}{*}{} \\
6 \\
0 \\
0 \\
0
\end{tabular} & $\begin{array}{l}\stackrel{1}{0} \\
0 \\
0 \\
0 \\
0\end{array}$ & $\begin{array}{l}50 \\
6 \\
0 \\
0 \\
0\end{array}$ \\
\hline & $\stackrel{\circ}{\circ} \stackrel{\circ}{\circ}$ & $\begin{array}{l}\stackrel{\Omega}{N} \\
\underset{N}{N}\end{array}$ & 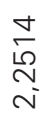 & $\begin{array}{l}\frac{0}{i} \\
\stackrel{i}{N} \\
\text { N }\end{array}$ & 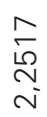 & 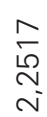 & $\begin{array}{l}\text { No } \\
\stackrel{5}{N} \\
\sim\end{array}$ \\
\hline \multicolumn{2}{|c|}{ 之 岀 } & - & $\stackrel{0}{\circ}$ & 우 & 음 & 음 & 응 \\
\hline \multicolumn{2}{|c|}{$-\overline{\boldsymbol{E}}$} & \multicolumn{6}{|c|}{$\begin{array}{l}\text { ㅁ } \\
\text { ○́ }\end{array}$} \\
\hline
\end{tabular}




\begin{tabular}{|c|c|c|c|c|c|c|c|}
\hline \multirow{5}{*}{ 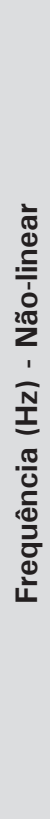 } & ㅇํㄹ & ' & 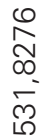 & $\begin{array}{l}0 \\
+ \\
0 \\
\infty \\
- \\
\tilde{n} \\
0\end{array}$ & 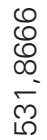 & $\begin{array}{l}0 \\
0 \\
0 \\
\infty \\
\bar{n} \\
0\end{array}$ & $\begin{array}{l}0 \\
0 \\
0 \\
\infty \\
\text { ñ } \\
0\end{array}$ \\
\hline & $\stackrel{\circ}{\circ} \stackrel{\circ}{\frac{0}{8}}$ & ' & 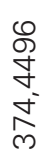 & $\begin{array}{l}\stackrel{ }{N} \\
\text { ñ } \\
\text { N } \\
\text { }\end{array}$ & \begin{tabular}{l}
$\infty$ \\
m \\
م \\
\multirow{N}{N}{}
\end{tabular} & \begin{tabular}{l} 
D \\
m \\
D \\
\multirow{N}{*}{} \\
m.
\end{tabular} & \begin{tabular}{l} 
D \\
m \\
D \\
\multirow{N}{*}{} \\
m
\end{tabular} \\
\hline & ㅇํㄹ & 1 & 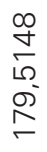 & 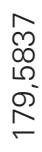 & 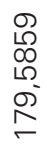 & 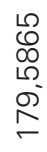 & 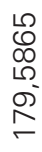 \\
\hline & $\stackrel{\circ}{\sim} \stackrel{\circ}{\stackrel{\circ}{g}}$ & 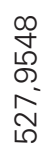 & 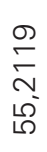 & $\begin{array}{l}\underset{N}{N} \\
\underset{N}{N} \\
\stackrel{0}{0}\end{array}$ & $\begin{array}{l}\underset{\sim}{\sim} \\
\underset{\sim}{\sim}\end{array}$ & 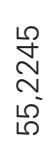 & \begin{tabular}{l}
$\stackrel{L}{+}$ \\
$\underset{1}{N}$ \\
\multirow{2}{N}{}
\end{tabular} \\
\hline & $\stackrel{\circ}{\circ} \stackrel{\circ}{\circ}$ & $\begin{array}{l}\widetilde{0} \\
\varnothing 0 \\
\mathbb{E} \\
-\end{array}$ & $\begin{array}{l}\text { N } \\
\text { ه } \\
-\end{array}$ & $\begin{array}{l}\bar{\infty} \\
\text { ه్ } \\
-\end{array}$ & $\begin{array}{l}N \\
\text { o } \\
8 \\
0 \\
-\end{array}$ & $\begin{array}{l}m \\
0 \\
8 \\
0 \\
0\end{array}$ & $\begin{array}{l}m \\
0 \\
8 \\
0 \\
0\end{array}$ \\
\hline \multirow{5}{*}{ 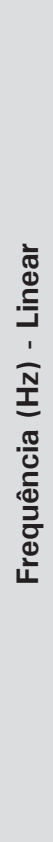 } & ㅇํำ & ' & 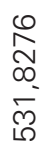 & 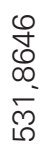 & $\begin{array}{l}0 \\
\mathbb{0} \\
\mathbb{0} \\
\infty \\
\tilde{\Gamma}\end{array}$ & $\begin{array}{l}0 \\
0 \\
0 \\
\infty \\
\bar{n} \\
\tilde{\Gamma}\end{array}$ & 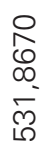 \\
\hline & $\stackrel{\circ}{\circ} \stackrel{\circ}{\circ}$ & 1 & $\begin{array}{l}\underset{\omega}{\sim} \\
\underset{N}{N} \\
\stackrel{\infty}{N}\end{array}$ & 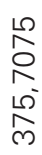 & 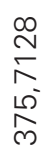 & 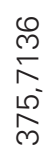 & $\begin{array}{c}\hat{m} \\
\frac{n}{n} \\
\frac{m}{m}\end{array}$ \\
\hline & ㅇํㄹ & ' & 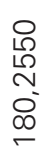 & $\begin{array}{l}\text { D } \\
\underset{N}{n} \\
\infty \\
\infty \\
\infty\end{array}$ & $\begin{array}{l}0 \\
\text { N } \\
\text { n} \\
\text { - } \\
\infty \\
-\end{array}$ & $\begin{array}{l}\text { న } \\
\text { N } \\
m \\
0 \\
\infty \\
\infty\end{array}$ & $\begin{array}{l}\text { న } \\
\text { N } \\
\text { } \\
\infty \\
\infty\end{array}$ \\
\hline & $\stackrel{\circ}{\sim} \stackrel{\circ}{\circ}$ & 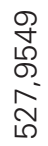 & $\begin{array}{l}\sqsubset \\
\varnothing \\
\infty \\
0 \\
0\end{array}$ & $\begin{array}{l}\mathcal{O} \\
\stackrel{0}{\infty} \\
\infty \\
10\end{array}$ & $\begin{array}{l}\text { 이 } \\
\infty \\
\infty \\
10 \\
\llcorner\end{array}$ & $\begin{array}{l}\infty \\
\stackrel{0}{0} \\
\infty \\
10 \\
0\end{array}$ & $\begin{array}{l}\infty \\
0 \\
\infty \\
\infty \\
0 \\
0\end{array}$ \\
\hline & $\stackrel{\circ}{\circ} \stackrel{\circ}{\circ}$ & $\begin{array}{l}\stackrel{\sim}{N} \\
\underset{0}{\infty} \\
\stackrel{\infty}{-}\end{array}$ & $\begin{array}{l}\stackrel{0}{+} \\
\infty \\
\infty \\
-\end{array}$ & $\begin{array}{l}\text { f } \\
\infty \\
\infty \\
-\end{array}$ & $\begin{array}{l}\infty \\
\stackrel{\infty}{+} \\
\infty \\
-\end{array}$ & \begin{tabular}{l}
$\infty$ \\
\} $\\
{\infty} \\
{\infty} \\
{-}$ & \begin{tabular}{l}
$\infty$ \\
\multirow{2}{*}{} \\
$\infty$ \\
$\infty$ \\
-
\end{tabular} \\
\hline \multicolumn{2}{|c|}{ 这 } & - & $\stackrel{ }{\circ}$ & 우 & ○ & 음 & 8 \\
\hline \multicolumn{2}{|c|}{$-\widehat{\underline{\xi}}$} & \multicolumn{6}{|c|}{\begin{tabular}{l}
$\stackrel{0}{+}$ \\
\multirow{0}{*}{}
\end{tabular}} \\
\hline
\end{tabular}
\end{tabular}




\begin{tabular}{|c|c|c|c|c|c|c|c|}
\hline \multirow{5}{*}{ 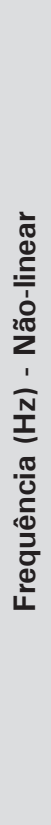 } & ㅇํ & 1 & 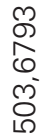 & 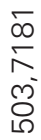 & 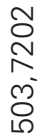 & 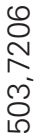 & 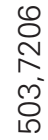 \\
\hline & $\stackrel{\circ}{\circ} \stackrel{\circ}{\frac{0}{\circ}}$ & 1 & 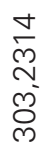 & 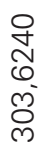 & 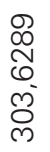 & 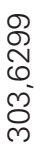 & 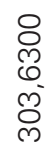 \\
\hline & $\stackrel{\circ}{\circ} \stackrel{\circ}{\frac{0}{8}}$ & 1 & 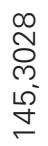 & 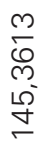 & 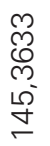 & 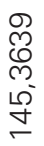 & 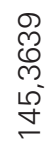 \\
\hline & $\stackrel{\circ}{\sim} \stackrel{\circ}{\circ}$ & 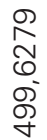 & 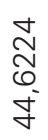 & 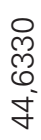 & 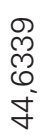 & 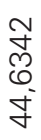 & 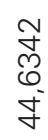 \\
\hline & $\stackrel{\circ}{\circ} \stackrel{\circ}{\frac{0}{8}}$ & 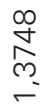 & 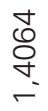 & 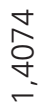 & $\begin{array}{l}\stackrel{0}{5} \\
\text { 웅 } \\
-\end{array}$ & $\begin{array}{l}\hat{\sigma} \\
\text { o } \\
-\end{array}$ & $\begin{array}{l}\text { 尺े } \\
\text { ơ }\end{array}$ \\
\hline \multirow{5}{*}{ 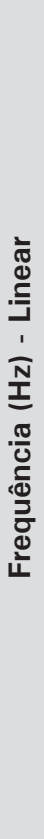 } & ㅇํㄹ 율 & 1 & 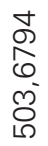 & $\begin{array}{l}\bar{\infty} \\
\bar{n} \\
\bar{\infty}\end{array}$ & 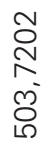 & 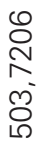 & 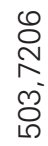 \\
\hline & $\stackrel{\circ}{\circ} \stackrel{\circ}{\frac{0}{\circ}}$ & 1 & $\begin{array}{l}0 \\
\frac{0}{\delta} \\
\text { - } \\
\text { ठ }\end{array}$ & $\begin{array}{l}m \\
\text { m } \\
\text { o } \\
\text { d } \\
\text { ల్ }\end{array}$ & \begin{tabular}{l}
$\hat{N}$ \\
O̊ \\
\multirow{2}{*}{} \\
ঠे
\end{tabular} & 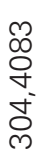 & 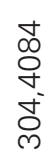 \\
\hline & $\stackrel{\circ}{\stackrel{\circ}{\circ} \stackrel{\circ}{\circ}}$ & ' & 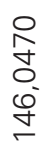 & 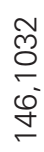 & 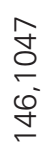 & $\begin{array}{l}0 \\
\stackrel{1}{0} \\
\stackrel{2}{0} \\
\stackrel{0}{ \pm}\end{array}$ & 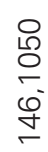 \\
\hline & $\stackrel{\circ}{\sim} \stackrel{\circ}{\frac{0}{8}}$ & 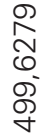 & 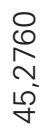 & 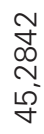 & 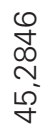 & $\begin{array}{l}\text { ণ } \\
\stackrel{\infty}{\sim} \\
\stackrel{\sim}{\sigma}\end{array}$ & 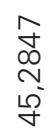 \\
\hline & $\stackrel{\circ}{\circ} \stackrel{\circ}{\circ}$ & 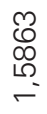 & 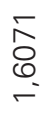 & 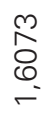 & 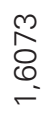 & 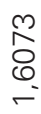 & 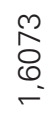 \\
\hline \multicolumn{2}{|c|}{ ～ 2 出 } & - & 음 & 우 & 응 & 음 & ᄋ \\
\hline \multicolumn{2}{|c|}{$-\overline{\mathrm{E}}$} & \multicolumn{6}{|c|}{$\begin{array}{l}0 \\
\text { L } \\
0\end{array}$} \\
\hline
\end{tabular}




\begin{tabular}{|c|c|c|c|c|c|c|c|}
\hline \multirow{5}{*}{ 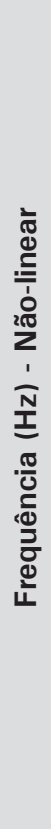 } & ㅇํㅇ & ' & 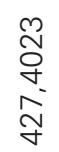 & 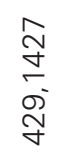 & 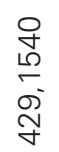 & 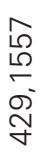 & 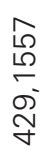 \\
\hline & 용 & ' & 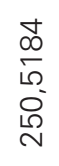 & 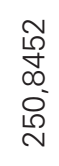 & 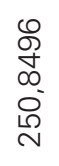 & 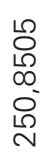 & 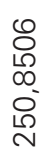 \\
\hline & 욜 율 & ' & $\begin{array}{l}\stackrel{m}{\sim} \\
\infty \\
\text { o } \\
\text { o } \\
\rightleftharpoons\end{array}$ & 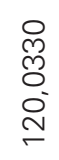 & 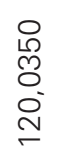 & 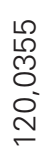 & 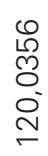 \\
\hline & $\stackrel{\circ}{\circ} \stackrel{\circ}{\circ}$ & 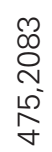 & $\begin{array}{l}\widetilde{N} \\
\infty \\
\\
0^{\circ}\end{array}$ & 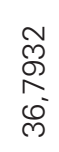 & $\begin{array}{l}\bar{\sigma} \\
\text { D } \\
\varphi^{-}\end{array}$ & 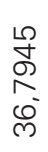 & 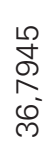 \\
\hline & $\stackrel{\circ}{\circ} \stackrel{ }{\circ}$ & 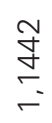 & 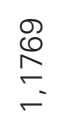 & $\begin{array}{l}\stackrel{\infty}{\infty} \\
\stackrel{+}{\rightleftharpoons} \\
\leftarrow\end{array}$ & $\begin{array}{l}\stackrel{0}{\infty} \\
\stackrel{-}{\digamma} \\
=\end{array}$ & 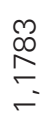 & $\begin{array}{l}\stackrel{\infty}{\infty} \\
\stackrel{\infty}{夭} \\
=\end{array}$ \\
\hline \multirow{5}{*}{ 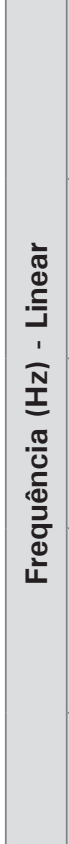 } & ㅇํ & , & 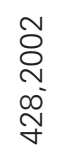 & 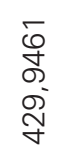 & 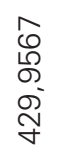 & 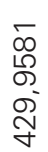 & 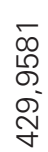 \\
\hline & ㅇ & ' & 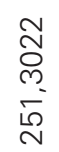 & 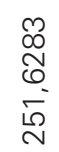 & $\begin{array}{l}\bar{\sim} \\
\bar{\sigma} \\
\stackrel{\sim}{N}\end{array}$ & 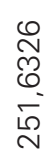 & 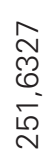 \\
\hline & 욜 융 & ' & 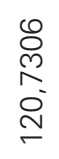 & $\begin{array}{l}\infty \\
\infty \\
\stackrel{0}{N} \\
\stackrel{-}{\circ} \\
\stackrel{-}{\sim}\end{array}$ & $\begin{array}{l}\bar{o} \\
\infty \\
\stackrel{0}{\circ} \\
\stackrel{v}{\sim}\end{array}$ & 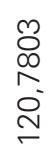 & 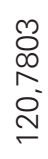 \\
\hline & $\stackrel{\circ}{\sim} \stackrel{\circ}{\circ}$ & 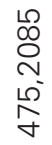 & & \begin{tabular}{l}
$\infty$ \\
$\infty$ \\
\multirow{2}{*}{} \\
$\stackrel{-}{-}$
\end{tabular} & $\begin{array}{l}\text { S } \\
\stackrel{\text { J }}{\text { N }}\end{array}$ & $\begin{array}{l}\text { Õ } \\
\text { J } \\
\text { 心 }\end{array}$ & 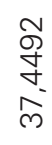 \\
\hline & 윰 & $\underset{\stackrel{0}{\infty}}{\stackrel{0}{\infty}}$ & ষ্ণ & 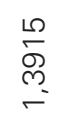 & 吕 & & $\stackrel{\circ}{\sigma}$ \\
\hline \multicolumn{2}{|c|}{ 은 } & - & 으 & 우 & 음 & ৪ & 음 \\
\hline \multicolumn{2}{|c|}{$-\overline{\underline{\xi}}$} & \multicolumn{6}{|c|}{$\begin{array}{l}\stackrel{L}{L} \\
\stackrel{\circ}{0} \\
0\end{array}$} \\
\hline
\end{tabular}




\begin{tabular}{|c|c|c|c|c|c|c|c|}
\hline \multirow{5}{*}{ 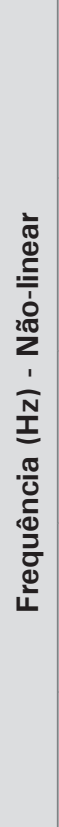 } & ㅇํ & ' & 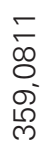 & 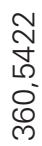 & $\begin{array}{l}\infty \\
\vdots \\
5 \\
0 \\
0 \\
0 \\
\text { ల }\end{array}$ & 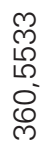 & 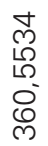 \\
\hline & $\stackrel{\circ}{\circ}$ 응 & ' & 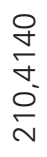 & 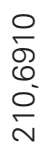 & 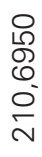 & 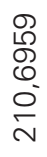 & 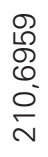 \\
\hline & ํ) 음 & ' & 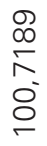 & 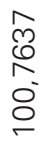 & 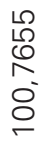 & $\begin{array}{l}\overline{6} \\
0 \\
0 \\
8 \\
\end{array}$ & \begin{tabular}{l}
$\overline{6}$ \\
0 \\
8 \\
8 \\
\hdashline
\end{tabular} \\
\hline & $\stackrel{\circ}{\sim} \stackrel{\circ}{\circ}$ & \begin{tabular}{l}
0 \\
\multirow{6}{*}{} \\
$\infty$ \\
N$^{-}$ \\
\multirow{\gamma}{\sigma}{}
\end{tabular} & $\begin{array}{l}\frac{1}{N} \\
\frac{1}{\infty} \\
\infty \\
\infty \\
\infty\end{array}$ & $\begin{array}{l}\bar{N} \\
\infty \\
\infty \\
\vdots \\
0\end{array}$ & 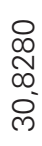 & 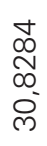 & 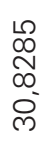 \\
\hline & $\stackrel{\circ}{\circ} \stackrel{\circ}{\circ}$ & $\begin{array}{l}0 \\
6 \\
\llcorner \\
\Omega \\
0\end{array}$ & $\begin{array}{l}\infty \\
\text { ᄋ } \\
\text { வ } \\
\circ\end{array}$ & $\begin{array}{l}\bar{N} \\
\text { న్ } \\
\text { s. }\end{array}$ & $\begin{array}{l}\text { ন } \\
\text { న } \\
\text { s. }\end{array}$ & 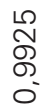 & 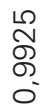 \\
\hline \multirow{5}{*}{ 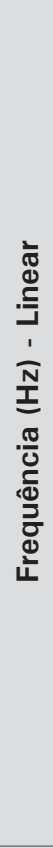 } & ㅇํ & ' & $\begin{array}{l}\bar{m} \\
\infty \\
\infty \\
\sigma_{0} \\
\stackrel{\infty}{m}\end{array}$ & 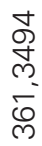 & 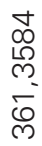 & 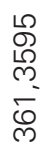 & 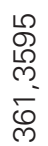 \\
\hline & $\stackrel{\circ}{\circ} \stackrel{\circ}{\frac{8}{8}}$ & ' & $\begin{array}{l}\frac{\sigma}{\circ} \\
\stackrel{\sim}{\sigma} \\
\frac{\sim}{v}\end{array}$ & \begin{tabular}{l}
$\circ$ \\
$\infty$ \\
\multirow{\sigma}{*}{} \\
$\check{\sigma}$ \\
$\bar{\sigma}$
\end{tabular} & $\begin{array}{l}\frac{m}{\sigma} \\
\dot{\infty} \\
\bar{\sigma}\end{array}$ & $\begin{array}{l}\frac{\infty}{\infty} \\
\stackrel{\infty}{+} \\
\bar{\sigma}\end{array}$ & $\begin{array}{l}\frac{\infty}{\infty} \\
\stackrel{+}{\sigma} \\
\bar{\sigma}\end{array}$ \\
\hline & $\stackrel{\circ}{\circ} \stackrel{\circ}{\frac{0}{8}}$ & ' & \begin{tabular}{l}
$\frac{m}{5}$ \\
\multirow{\sigma}{\sigma}{} \\
$\frac{\sigma}{\sigma}$
\end{tabular} & $\begin{array}{l}m \\
m \\
5 \\
5 \\
0\end{array}$ & $\begin{array}{l}\frac{10}{8} \\
\frac{5}{5} \\
5\end{array}$ & 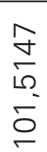 & $\begin{array}{l}\text { f } \\
\frac{5}{5} \\
\vdots\end{array}$ \\
\hline & $\stackrel{\circ}{\sim} \stackrel{\circ}{\circ}$ & 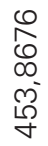 & 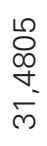 & \begin{tabular}{l}
$\overline{7}$ \\
$\infty$ \\
\multirow{\infty}{\infty}{}
\end{tabular} & 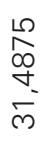 & 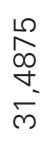 & 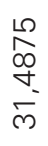 \\
\hline & $\stackrel{\circ}{\circ} \stackrel{\circ}{\circ}$ & $\begin{array}{l}\infty \\
\stackrel{8}{\circ} \\
\stackrel{-}{r}\end{array}$ & 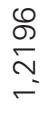 & $\begin{array}{l}\stackrel{\infty}{\sigma} \\
\stackrel{-}{\leftarrow}\end{array}$ & 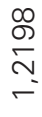 & $\begin{array}{l}\stackrel{\infty}{\sigma} \\
\stackrel{\sim}{\leftarrow}\end{array}$ & 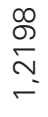 \\
\hline & 出 & - & $\stackrel{ }{\circ}$ & 우 & 음 & 윰 & 음 \\
\hline \multicolumn{2}{|c|}{$-\overline{\mathbf{E}}$} & \multicolumn{6}{|c|}{$\begin{array}{l}0 \\
\stackrel{0}{0} \\
0\end{array}$} \\
\hline
\end{tabular}




\begin{tabular}{|c|c|c|c|c|c|c|c|}
\hline \multirow{5}{*}{ 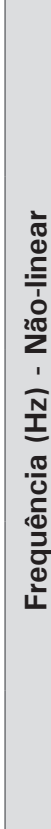 } & 요 & . & 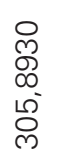 & $\begin{array}{l}\text { o } \\
\text { m } \\
\stackrel{-}{-} \\
\text { సे }\end{array}$ & 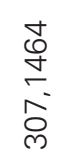 & 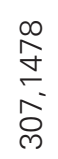 & 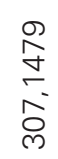 \\
\hline & $\stackrel{\circ}{\circ} \stackrel{\circ}{\circ}$ & ' & 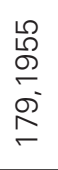 & 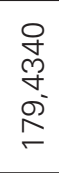 & 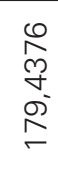 & 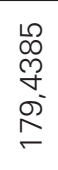 & 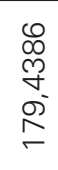 \\
\hline & 용 율 & ' & $\begin{array}{l}\stackrel{\widehat{N}}{N} \\
\underset{\infty}{\infty}\end{array}$ & 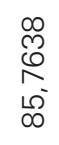 & $\begin{array}{l}0 \\
\stackrel{0}{0} \\
0 \\
\stackrel{0}{\circ} \\
\infty\end{array}$ & $\begin{array}{l}\mathbb{0} \\
\stackrel{0}{0} \\
\stackrel{0}{\circ} \\
\infty\end{array}$ & $\begin{array}{l}\mathbb{0} \\
\stackrel{0}{0} \\
\stackrel{5}{0} \\
\infty\end{array}$ \\
\hline & 율 & 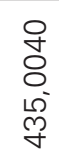 & $\begin{array}{l}\stackrel{0}{N} \\
\stackrel{+}{\infty} \\
\stackrel{N}{N}\end{array}$ & $\begin{array}{l}\frac{m}{\infty} \\
\frac{0}{0} \\
\stackrel{N}{N}\end{array}$ & 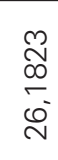 & $\begin{array}{l}\widehat{N} \\
\infty \\
\bar{\sigma} \\
\stackrel{N}{N}\end{array}$ & 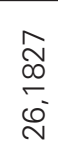 \\
\hline & $\stackrel{\circ}{-} \stackrel{\circ}{\circ}$ & $\begin{array}{l}8 \\
\circ \\
\infty \\
0^{\circ}\end{array}$ & $\begin{array}{l}\mathscr{C} \\
\mathbb{N}_{0} \\
\infty \\
0\end{array}$ & $\begin{array}{l}\infty \\
\stackrel{\infty}{N} \\
\infty \\
0^{-}\end{array}$ & $\begin{array}{l}\bar{\infty} \\
\tilde{m} \\
\infty \\
0 \\
0^{-}\end{array}$ & $\begin{array}{l}\mathscr{M} \\
\infty \\
0 \\
\infty \\
0 \\
0\end{array}$ & $\begin{array}{l}\mathscr{N} \\
\infty \\
\infty \\
\infty \\
0\end{array}$ \\
\hline \multirow{5}{*}{ 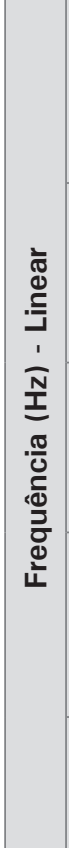 } & ㅇํ & ' & 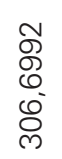 & 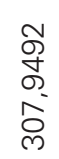 & 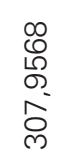 & $\begin{array}{l}\infty \\
\stackrel{\infty}{\rho} \\
\stackrel{\rho}{0} \\
\stackrel{0}{0}\end{array}$ & $\begin{array}{l}\infty \\
\stackrel{2}{\Omega} \\
\text { م } \\
\text { م }\end{array}$ \\
\hline & 용 & ' & 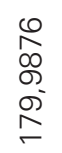 & 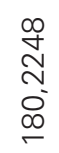 & 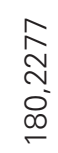 & $\begin{array}{l}\underset{0}{N} \\
\underset{N}{N} \\
\stackrel{\infty}{\circ}\end{array}$ & 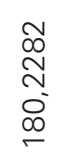 \\
\hline & 용 율 & ' & $\begin{array}{l}\infty \\
0 \\
\infty \\
0 \\
0 \\
\infty\end{array}$ & $\begin{array}{l}\infty \\
\stackrel{2}{5} \\
0 \\
0 \\
\infty\end{array}$ & $\begin{array}{l}\$ \\
\infty \\
5 \\
0 \\
0 \\
\infty\end{array}$ & $\begin{array}{l}\infty \\
\infty \\
亡 0 \\
0 \\
\infty\end{array}$ & $\begin{array}{l}\varnothing \\
\infty \\
亡 \\
0 \\
\infty\end{array}$ \\
\hline & $\stackrel{\circ}{\circ} \stackrel{\circ}{\circ}$ & 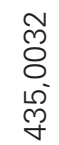 & 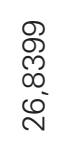 & $\begin{array}{l}8 \\
0 \\
0 \\
0 \\
0 \\
0\end{array}$ & 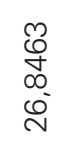 & $\begin{array}{l}0 \\
0 \\
0 \\
0 \\
0 \\
0\end{array}$ & 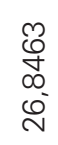 \\
\hline & $\stackrel{\circ}{\circ} \stackrel{\circ}{\circ}$ & 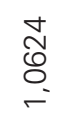 & $\begin{array}{l}\text { ठ } \\
\& \\
0 \\
\stackrel{-}{-}\end{array}$ & \begin{tabular}{l}
$\stackrel{0}{\circ}$ \\
$\& 0$ \\
$O$ \\
\hdashline
\end{tabular} & $\begin{array}{l}\stackrel{2}{0} \\
\stackrel{0}{0} \\
\stackrel{-}{-}\end{array}$ & $\begin{array}{l}\stackrel{0}{0} \\
\stackrel{0}{0} \\
\stackrel{-}{-}\end{array}$ & $\begin{array}{l}\stackrel{2}{0} \\
\infty \\
0 \\
-\end{array}$ \\
\hline \multicolumn{2}{|c|}{ 은 } & - & $\stackrel{\circ}{\circ}$ & 우 & 음 & 웅 & 8 \\
\hline \multicolumn{2}{|c|}{$-\bar{\xi}$} & \multicolumn{6}{|c|}{$\begin{array}{l}L \\
0 \\
0 \\
0\end{array}$} \\
\hline
\end{tabular}




\begin{tabular}{|c|c|c|c|c|c|c|c|}
\hline \multirow{5}{*}{ 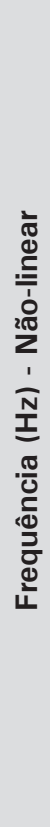 } & 요 & ' & 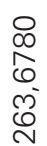 & 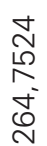 & 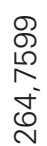 & 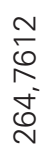 & $\begin{array}{l}\frac{m}{6} \\
\frac{1}{\sigma} \\
\stackrel{d}{N}\end{array}$ \\
\hline & $\stackrel{\circ}{\circ} \stackrel{\circ}{\circ}$ & 1 & 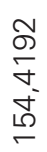 & 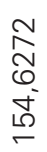 & 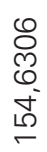 & 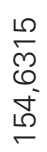 & 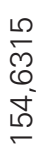 \\
\hline & $\stackrel{\circ}{\circ} \stackrel{\circ}{\circ}$ & ' & 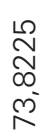 & $\begin{array}{l}\text { న } \\
\infty \\
\infty \\
\infty \\
N\end{array}$ & $\begin{array}{l}\text { 'o } \\
\infty \\
\infty \\
\text { N }\end{array}$ & $\begin{array}{l}m \\
\overline{0} \\
\infty \\
\text { m }\end{array}$ & $\begin{array}{l}\frac{\checkmark}{6} \\
\infty \\
\infty \\
N\end{array}$ \\
\hline & $\stackrel{\circ}{\sim} \stackrel{\circ}{\circ}$ & $\begin{array}{l}0 \\
\mathbb{Q} \\
\mathbb{8} \\
\infty \\
\infty \\
\frac{\infty}{\sigma}\end{array}$ & \begin{tabular}{l}
0 \\
N \\
$\infty$ \\
\multirow{\sigma}{*}{} \\
N
\end{tabular} & 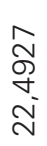 & $\begin{array}{l}\hat{n} \\
\text { ণ } \\
\text { N }\end{array}$ & 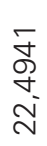 & 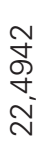 \\
\hline & $\circ \stackrel{\circ}{\circ}$ & $\begin{array}{l}0 \\
1 \\
0 \\
0 \\
0 \\
0\end{array}$ & $\begin{array}{l}0 \\
\text { 용 } \\
\text { م. } \\
0\end{array}$ & $\begin{array}{l}\infty \\
0 \\
0 \\
0 \\
0 \\
0\end{array}$ & $\begin{array}{l}\frac{N}{N} \\
\frac{0}{0} \\
0\end{array}$ & $\begin{array}{l}\frac{3}{N} \\
\frac{0}{0} \\
0\end{array}$ & $\begin{array}{l}\frac{2}{1} \\
\frac{1}{0} \\
0\end{array}$ \\
\hline \multirow{5}{*}{ 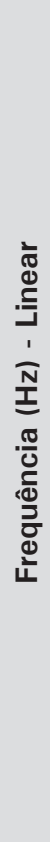 } & 요 & 1 & 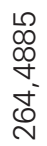 & 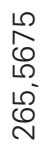 & 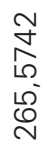 & 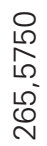 & 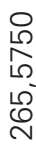 \\
\hline & $\stackrel{\circ}{\circ} \stackrel{\circ}{\circ}$ & ' & 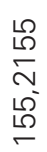 & 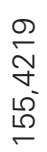 & 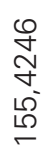 & 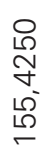 & 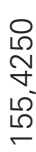 \\
\hline & $\stackrel{\circ}{\circ} \stackrel{\circ}{\circ}$ & ' & 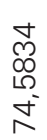 & 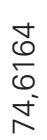 & 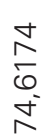 & 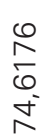 & 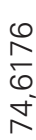 \\
\hline & $\stackrel{\circ}{\sim} \stackrel{\circ}{\circ}$ & 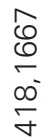 & 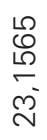 & 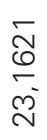 & $\frac{\stackrel{+}{\sigma}}{\stackrel{\varpi}{N}}$ & 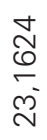 & 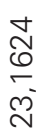 \\
\hline & 을 & $\begin{array}{l}m \\
\text { OO } \\
\text { o } \\
\text { O' }\end{array}$ & $\begin{array}{l}0 \\
1 \\
6 \\
0 \\
0\end{array}$ & $\begin{array}{l}\hat{L} \\
\mathscr{6} \\
0 \\
0\end{array}$ & $\begin{array}{l}\hat{L} \\
\mathscr{0} \\
\Omega \\
0\end{array}$ & $\begin{array}{l}\hat{L} \\
\stackrel{6}{0} \\
0 \\
0\end{array}$ & $\begin{array}{l}\hat{\rho} \\
\mathscr{6} \\
0 \\
0\end{array}$ \\
\hline \multicolumn{2}{|c|}{ 吕 出 } & - & $\stackrel{\circ}{\circ}$ & 워 & ○ & 음 & 음 \\
\hline \multicolumn{2}{|c|}{$-\widehat{\underline{E}}$} & \multicolumn{6}{|c|}{$\frac{0}{0^{\circ}}$} \\
\hline
\end{tabular}




\begin{tabular}{|c|c|c|c|c|c|c|c|}
\hline \multirow{5}{*}{ 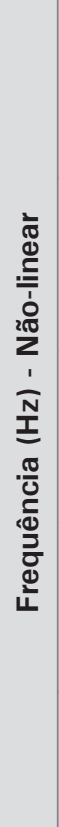 } & ㅇํ & 1 & 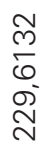 & 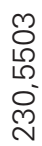 & 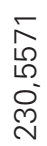 & 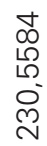 & 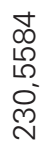 \\
\hline & $\stackrel{\circ}{\circ} \stackrel{\circ}{\circ}$ & 1 & 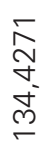 & 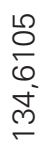 & $\begin{array}{l}\hat{n} \\
\bar{\sigma} \\
\text { m }\end{array}$ & $\begin{array}{l}0 \\
+ \\
\\
\text { Ð } \\
\text { ल }\end{array}$ & 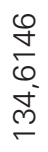 \\
\hline & ำ 을 & ' & 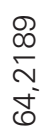 & \begin{tabular}{l}
$\stackrel{+}{N}$ \\
$\stackrel{\text { D }}{N}$ \\
\multirow{\sigma}{*}{}
\end{tabular} & 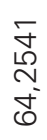 & 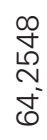 & 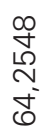 \\
\hline & $\stackrel{\circ}{\sim} \stackrel{\circ}{\frac{0}{\mathrm{~g}}}$ & 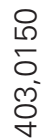 & 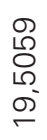 & $\begin{array}{l}\stackrel{\infty}{+} \\
\frac{5}{5} \\
\stackrel{0}{\square}\end{array}$ & 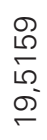 & 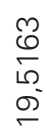 & 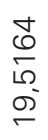 \\
\hline & $\stackrel{\circ}{\circ} \stackrel{\circ}{\frac{8}{8}}$ & \begin{tabular}{l} 
R \\
\multirow{2}{*}{} \\
0 \\
0
\end{tabular} & 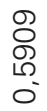 & $\begin{array}{l}\text { ? } \\
\text { న్ } \\
\text { م. } \\
\text { o }\end{array}$ & 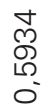 & $\begin{array}{l}0 \\
\text { लొ } \\
\text { مొ } \\
0\end{array}$ & $\begin{array}{l}0 \\
\text { लె } \\
\stackrel{1}{0} \\
0\end{array}$ \\
\hline \multirow{5}{*}{ 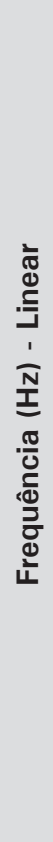 } & ㅇํ & ' & \begin{tabular}{l}
$\infty$ \\
\multirow{2}{N}{} \\
\multirow{2}{*}{} \\
$\stackrel{\text { }}{N}$
\end{tabular} & 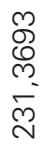 & 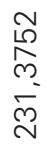 & $\begin{array}{l}0 \\
\text { m } \\
\text { m } \\
\text { m }\end{array}$ & 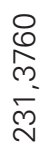 \\
\hline & $\stackrel{\circ}{\circ} \stackrel{\circ}{\frac{0}{\circ}}$ & ' & $\begin{array}{l}\stackrel{0}{N} \\
\text { Nิ} \\
\stackrel{\omega}{\sim}\end{array}$ & 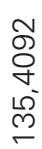 & 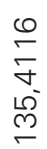 & 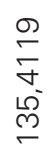 & 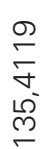 \\
\hline & $\stackrel{\circ}{\circ} \stackrel{\circ}{\frac{0}{}}$ & ' & 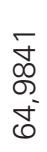 & $\begin{array}{l}\text { क } \\
\text { Ð } \\
0 \\
0 \\
0\end{array}$ & $\begin{array}{l}\underset{+}{+} \\
\vdots \\
0 \\
0\end{array}$ & $\begin{array}{l}0 \\
0 \\
0 \\
0 \\
0\end{array}$ & $\begin{array}{l}\circ \\
\qquad 0 \\
\circ \\
0 \\
0\end{array}$ \\
\hline & $\stackrel{\circ}{\sim} \stackrel{\circ}{\circ}$ & 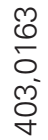 & 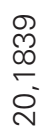 & $\begin{array}{l}\bar{\sigma} \\
\infty \\
\text { 。 }\end{array}$ & 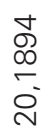 & 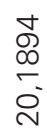 & $\begin{array}{l}\text { ठ } \\
\infty \\
\check{ } \\
\text { ঠ }\end{array}$ \\
\hline & $\stackrel{\circ}{\circ} \stackrel{\circ}{\circ}$ & $\begin{array}{l}\text { Oొ } \\
\stackrel{1}{\infty} \\
\infty \\
0^{\circ}\end{array}$ & $\begin{array}{l}0 \\
8 \\
0 \\
\infty \\
0\end{array}$ & $\begin{array}{l}\text { هి } \\
0 \\
\infty \\
0\end{array}$ & $\begin{array}{l}\infty \\
8 \\
0 \\
\infty \\
0\end{array}$ & $\begin{array}{l}\infty \\
\text { ه } \\
0 \\
0 \\
0\end{array}$ & $\begin{array}{l}\infty \\
8 \\
0 \\
\infty \\
0 \\
0\end{array}$ \\
\hline \multicolumn{2}{|c|}{ 之 出 } & - & $\stackrel{ }{\circ}$ & 우 & 음 & 응 & 음 \\
\hline \multicolumn{2}{|c|}{$-\overline{\mathbf{E}}$} & \multicolumn{6}{|c|}{$\frac{L^{\circ}}{0_{0}^{\circ}}$} \\
\hline
\end{tabular}




\begin{tabular}{|c|c|c|c|c|c|c|c|}
\hline \multirow{5}{*}{ 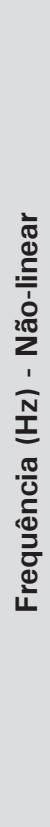 } & ㅇํำ & ' & 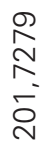 & 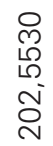 & 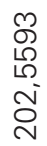 & 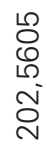 & 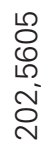 \\
\hline & $\stackrel{\circ}{\circ} \stackrel{\circ}{\frac{0}{8}}$ & ' & 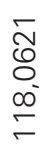 & 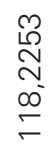 & $\begin{array}{l}\stackrel{\varpi}{\infty} \\
\underset{N}{\sim} \\
\infty \\
\infty \\
\approx\end{array}$ & $\begin{array}{l}\text { D } \\
\underset{N}{ } \\
\infty \\
\approx \\
\approx\end{array}$ & 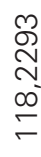 \\
\hline & ㅇ & ' & $\begin{array}{l}\overline{1} \\
\text { n } \\
6 \\
6\end{array}$ & 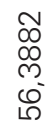 & $\begin{array}{l}\text { న } \\
\infty \\
\text { m } \\
0 \\
0\end{array}$ & $\begin{array}{l}0 \\
\text { ○ } \\
\text { m } \\
0^{\circ}\end{array}$ & 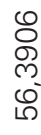 \\
\hline & $\stackrel{\circ}{\sim} \stackrel{\circ}{\mathrm{g}}$ & $\begin{array}{l}m \\
\infty \\
\infty \\
\text { N } \\
\rho^{2} \\
\infty\end{array}$ & $\begin{array}{l}9 \\
6 \\
0 \\
\circ \\
\end{array}$ & 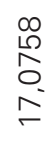 & 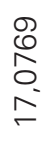 & 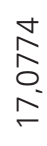 & 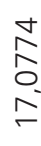 \\
\hline & $\stackrel{\circ}{\circ} \stackrel{\circ}{8}$ & 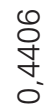 & $\begin{array}{l}\bar{\sigma} \\
\infty \\
+ \\
\vdots \\
0\end{array}$ & \begin{tabular}{l}
0 \\
$\frac{\sigma}{+}$ \\
\multirow{0}{0}{}
\end{tabular} & 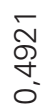 & 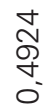 & 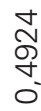 \\
\hline \multirow{5}{*}{ 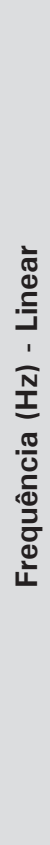 } & ㅇํㄹ & ' & 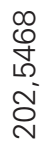 & 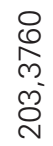 & $\begin{array}{l}\text { m } \\
\text { o } \\
m \\
\text { m } \\
\text { N }\end{array}$ & 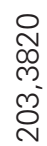 & 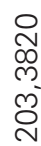 \\
\hline & $\stackrel{\circ}{\circ} \stackrel{\circ}{\frac{0}{8}}$ & ' & $\begin{array}{l}\infty \\
0 \\
0 \\
\infty \\
\infty \\
\mp \\
\leftarrow\end{array}$ & 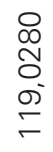 & 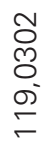 & 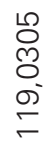 & 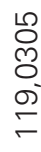 \\
\hline & 을 을 & ' & $\begin{array}{l}\hat{0} \\
\stackrel{N}{\sigma} \\
\hat{\sigma}\end{array}$ & $\begin{array}{l}\hat{n} \\
\stackrel{0}{\circ} \\
\hat{n}\end{array}$ & 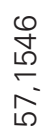 & 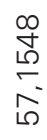 & مَّ \\
\hline & $\stackrel{\circ}{\sim} \stackrel{\circ}{8}$ & 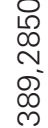 & 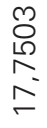 & 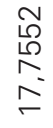 & 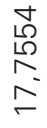 & $\begin{array}{l}\stackrel{L}{\circ} \\
\stackrel{0}{N} \\
\stackrel{-}{-}\end{array}$ & 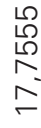 \\
\hline & $\circ \stackrel{\circ}{\circ}$ & $\frac{\stackrel{L}{N}}{\stackrel{N}{*}}$ & 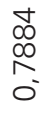 & $\begin{array}{l}0 \\
\infty \\
\infty \\
1 \\
\vdots \\
0\end{array}$ & $\begin{array}{l}0 \\
\infty \\
\infty \\
1 \\
0 \\
0\end{array}$ & $\begin{array}{l}0 \\
0 \\
\infty \\
0 \\
0 \\
0\end{array}$ & 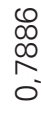 \\
\hline \multicolumn{2}{|c|}{ 之 出 } & - & $\stackrel{ }{\circ}$ & 우 & ○ & 응 & 음 \\
\hline \multicolumn{2}{|c|}{$-\overline{\mathbf{E}}$} & \multicolumn{6}{|c|}{$\begin{array}{l}\circ \\
\infty \\
0\end{array}$} \\
\hline
\end{tabular}




\begin{tabular}{|c|c|c|c|c|c|c|c|}
\hline \multirow{5}{*}{ 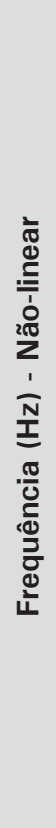 } & 요 & ' & $\begin{array}{l}\frac{\bar{m}}{\bar{c}} \\
\infty \\
\frac{\infty}{\sigma}\end{array}$ & 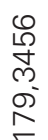 & $\begin{array}{l}m \\
\frac{m}{n} \\
m \\
\stackrel{2}{n}\end{array}$ & 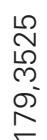 & 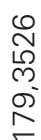 \\
\hline & $\stackrel{\circ}{\circ}$ 을 & ' & 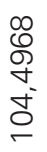 & 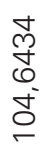 & 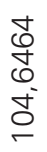 & \begin{tabular}{l} 
N \\
ठ \\
\multirow{0}{0}{} \\
0
\end{tabular} & \begin{tabular}{l}
$m$ \\
\multirow{2}{f}{} \\
0 \\
\multirow{0}{0}{}
\end{tabular} \\
\hline & 을 을 & 1 & 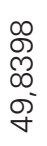 & $\begin{array}{l}\infty \\
\infty \\
0 \\
\infty \\
\infty \\
\text { g }\end{array}$ & $\begin{array}{l}\qquad \\
\stackrel{0}{0} \\
\infty \\
\text { g }\end{array}$ & 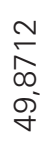 & $\begin{array}{l}m \\
\frac{\pi}{\infty} \\
\infty \\
\infty \\
\sigma\end{array}$ \\
\hline & $\stackrel{\circ}{\sim} \stackrel{\circ}{\circ}$ & $\begin{array}{l}\frac{0}{6} \\
\frac{6}{N} \\
\frac{6}{\infty}\end{array}$ & 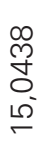 & 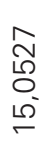 & $\begin{array}{l}\infty \\
\prod_{0} \\
0 \\
\stackrel{\infty}{\leftarrow}\end{array}$ & 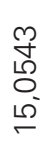 & \begin{tabular}{l}
8 \\
\multirow{2}{0}{} \\
0 \\
10
\end{tabular} \\
\hline & $\circ \stackrel{\circ}{-} \stackrel{\circ}{\circ}$ & $\begin{array}{l}m \\
\infty \\
m \\
m \\
0\end{array}$ & 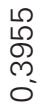 & $\begin{array}{l}\infty \\
\infty \\
\text { D } \\
\text { ח. } \\
0\end{array}$ & $\begin{array}{l}\bar{\sigma} \\
\text { ले } \\
\text { o. }\end{array}$ & $\begin{array}{l}\text { Jా } \\
\text { ని } \\
\text { రీ }\end{array}$ & $\begin{array}{l}\text { J } \\
\text { ले } \\
\text { ". }\end{array}$ \\
\hline \multirow{5}{*}{ 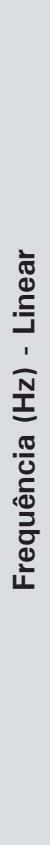 } & 을 & ' & 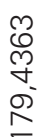 & $\begin{array}{l}\stackrel{L}{N} \\
\stackrel{0}{\circ} \\
\infty\end{array}$ & $\frac{m}{\stackrel{n}{N}}$ & 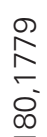 & $\begin{array}{l}\infty \\
\infty \\
\frac{\infty}{\sigma} \\
\infty\end{array}$ \\
\hline & $\stackrel{\circ}{\circ} \stackrel{\circ}{\frac{0}{\circ}}$ & ' & 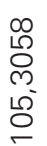 & \begin{tabular}{l}
5 \\
$\circ$ \\
\multirow{2}{0}{} \\
0 \\
0 \\
0
\end{tabular} & 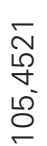 & 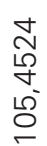 & 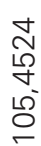 \\
\hline & ํ $\stackrel{\circ}{\circ}$ & 1 & $\begin{array}{l}\infty \\
m \\
\overline{0} \\
\vdots \\
\square\end{array}$ & 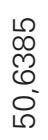 & $\begin{array}{l}\text { ठ } \\
\text { లె } \\
0 \\
\circ \\
\llcorner\end{array}$ & 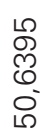 & $\begin{array}{l}\text { ग } \\
\text { लొ } \\
0 \\
0\end{array}$ \\
\hline & $\stackrel{\circ}{\sim} \stackrel{\circ}{\circ}$ & 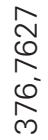 & $\begin{array}{l}\hat{N} \\
\stackrel{N}{n} \\
\stackrel{0}{n}\end{array}$ & $\frac{m}{\stackrel{m}{N}}$ & $\frac{n}{\infty}$ & $\frac{n}{\stackrel{n}{N}}$ & 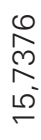 \\
\hline & 을 응 & $\frac{\hat{n}}{\sigma_{0}}$ & $\frac{8}{\frac{8}{\pi}}$ & $\frac{\tilde{\sigma}}{\frac{\pi}{0}}$ & $\frac{\tilde{\sigma}}{\frac{\pi}{0}}$ & $\frac{\tilde{\sigma}}{\frac{\pi}{0}}$ & $\frac{\pi}{\frac{\pi}{\pi}}$ \\
\hline \multicolumn{2}{|c|}{ そ 는 } & - & 으 & 아 & 응 & 음 & 8 \\
\hline \multicolumn{2}{|c|}{$-\bar{\xi}$} & \multicolumn{6}{|c|}{$\begin{array}{l}\stackrel{1}{\infty} \\
\infty \\
0\end{array}$} \\
\hline
\end{tabular}




\begin{tabular}{|c|c|c|c|c|c|c|c|}
\hline \multirow{5}{*}{ 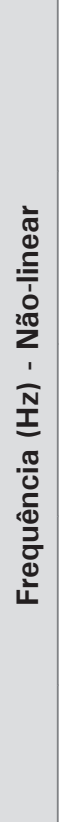 } & 요 & ' & 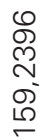 & $\begin{array}{l}\text { J } \\
\infty \\
\infty \\
\text { న } \\
{[}\end{array}$ & 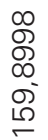 & $\begin{array}{l}\circ \\
\text { 으 } \\
\text { வ } \\
\text { م } \\
\square\end{array}$ & $\begin{array}{l}\bar{\sigma} \\
\text { ᄋ } \\
\text { వ } \\
\text { م }\end{array}$ \\
\hline & $\stackrel{\circ}{\circ} \stackrel{\circ}{\circ}$ & ' & $\frac{\Gamma}{\stackrel{\nwarrow}{\sim}}$ & $\begin{array}{l}\hat{\sigma} \\
\stackrel{\leftrightarrow}{N} \\
\text { ñ }\end{array}$ & 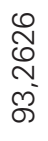 & $\begin{array}{l}\stackrel{L}{ } \\
\text { @ } \\
\text { N } \\
\text { ñ }\end{array}$ & 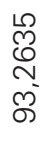 \\
\hline & ㅇํ & ' & 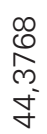 & $\begin{array}{l}\bar{J} \\
\text { Oे } \\
\text { J }\end{array}$ & 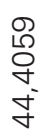 & 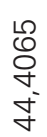 & 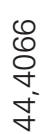 \\
\hline & $\stackrel{\circ}{\sim} \stackrel{\circ}{\circ}$ & 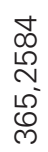 & 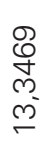 & 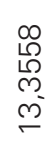 & 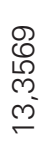 & $\begin{array}{l}\stackrel{\omega}{N} \\
\stackrel{n}{m} \\
\text { m. }\end{array}$ & $\begin{array}{l}\stackrel{\omega}{N} \\
\stackrel{n}{n} \\
n\end{array}$ \\
\hline & 용 & $\begin{array}{l}\stackrel{\sim}{N} \\
\stackrel{N}{N} \\
\text { }\end{array}$ & $\begin{array}{l}m \\
\text { مొ } \\
\text { m } \\
0\end{array}$ & $\begin{array}{l}\text { ने } \\
\text { లి } \\
\text { ల' }\end{array}$ & $\begin{array}{l}\text { न } \\
\text { Oे } \\
\text { ल. } \\
0\end{array}$ & $\begin{array}{l}m \\
\frac{0}{m} \\
0 \\
0\end{array}$ & $\begin{array}{l}\text { ठ } \\
\frac{m}{m} \\
0\end{array}$ \\
\hline \multirow{5}{*}{ 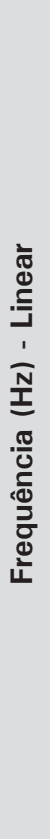 } & ㅇํ & ' & \begin{tabular}{l}
0 \\
\multirow{0}{0}{} \\
0 \\
0 \\
0
\end{tabular} & $\begin{array}{l}\text { L } \\
\stackrel{N}{N} \\
0 \\
0 \\
0\end{array}$ & 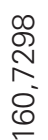 & $\begin{array}{l}m \\
\text { m } \\
\text { D } \\
0\end{array}$ & $\begin{array}{l}\text { ¿ } \\
\text { న } \\
0 \\
0 \\
0\end{array}$ \\
\hline & $\stackrel{\circ}{\circ} \stackrel{\circ}{\circ}$ & ' & $\begin{array}{l}\text { ঠ } \\
\text { ঠे } \\
\text { ஸ் }\end{array}$ & 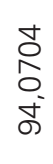 & $\begin{array}{l}\stackrel{\infty}{N} \\
\text { ○ } \\
\text { ঠ }\end{array}$ & 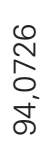 & $\begin{array}{l}\stackrel{0}{N} \\
\text { ○े } \\
\text { ঠ }\end{array}$ \\
\hline & 요 $\stackrel{\circ}{\frac{0}{0}}$ & ' & 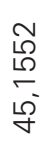 & $\begin{array}{l}\infty \\
\stackrel{\infty}{\sigma} \\
\frac{0}{\sigma}\end{array}$ & 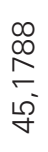 & 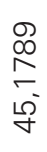 & 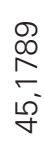 \\
\hline & $\stackrel{\circ}{\sim} \stackrel{\circ}{\circ}$ & 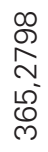 & 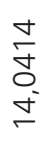 & 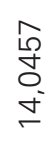 & 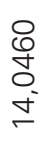 & 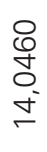 & 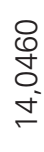 \\
\hline & $\stackrel{\circ}{\circ} \stackrel{\circ}{\circ}$ & \begin{tabular}{l}
$\stackrel{M}{+}$ \\
\multirow{J}{*}{} \\
0
\end{tabular} & 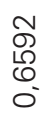 & $\begin{array}{l}\text { Oొ } \\
\stackrel{1}{0} \\
0 \\
0\end{array}$ & 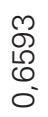 & $\begin{array}{l}\text { 円 } \\
\text { L } \\
0 \\
0\end{array}$ & $\begin{array}{l}\text { న } \\
\text { ه } \\
0 \\
0\end{array}$ \\
\hline \multicolumn{2}{|c|}{ そ 岀 } & - & $\stackrel{ }{\circ}$ & ণ & 음 & 윰 & 음 \\
\hline \multicolumn{2}{|c|}{$-\overline{\boldsymbol{E}}$} & \multicolumn{6}{|c|}{$\begin{array}{l}\text { ㅇ. } \\
\text { - }\end{array}$} \\
\hline
\end{tabular}




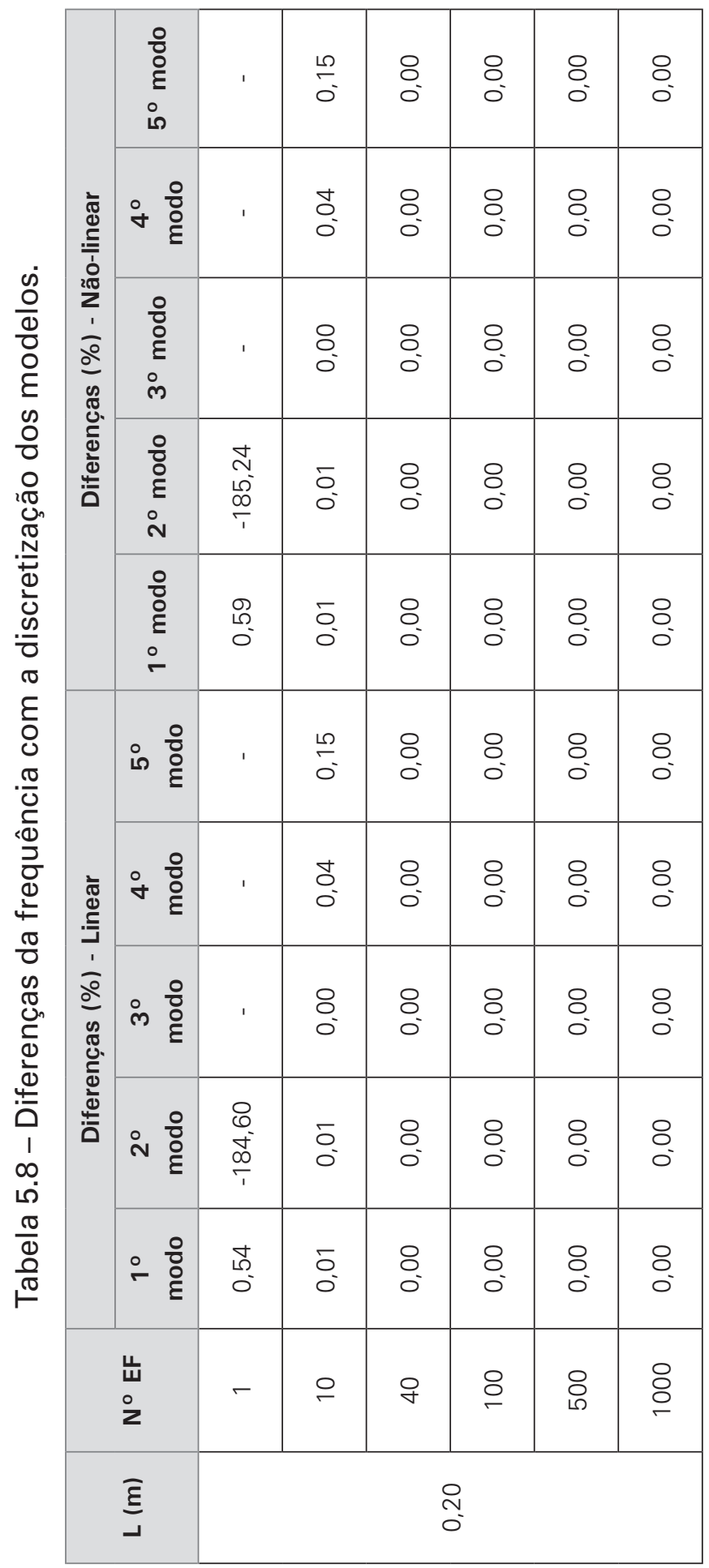




\begin{tabular}{|c|c|c|c|c|c|c|c|}
\hline \multirow{5}{*}{ 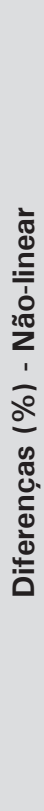 } & 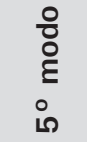 & & $\stackrel{8}{\check{0}}$ & : & : & \&. & : \\
\hline & $\stackrel{\circ}{\circ} \stackrel{\circ}{\circ}$ & & : & 8 & 8 & $\begin{array}{l}8 \\
0\end{array}$ & 8 \\
\hline & $\begin{array}{l}\circ \\
\text { 이 } \\
\text { हे } \\
\stackrel{0}{m}\end{array}$ & ' & O̊ & 웅 & : & 8 & 8. \\
\hline & $\begin{array}{l}\stackrel{\circ}{\circ} \\
\stackrel{\Xi}{\xi} \\
\stackrel{2}{N}\end{array}$ & 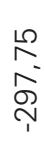 & $\overline{0}$ & ㅇ. & : & : & ㅇ. \\
\hline & $\begin{array}{l}\text { 음 } \\
\text { ğ } \\
\stackrel{\circ}{-}\end{array}$ & $\begin{array}{l}\hat{乏} \\
0^{\prime}\end{array}$ & $\overline{0}$ & 웅 & : & 8 & 8. \\
\hline \multirow{5}{*}{ 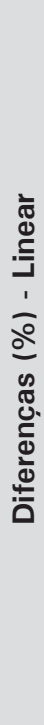 } & ㅇํํ & & $\frac{\nabla}{0}$ & $\begin{array}{l}8 \\
0\end{array}$ & $\begin{array}{l}8 \\
0\end{array}$ & $\begin{array}{l}8 \\
0 \\
0\end{array}$ & 8. \\
\hline & $\stackrel{\circ}{\circ} \stackrel{\circ}{\circ}$ & & : & 8. & 8 & 8. & : \\
\hline & $\stackrel{\circ}{\circ} \stackrel{\circ}{\circ}$ & 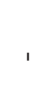 & Oֶ. & 8 & 8 & $\begin{array}{l}8 \\
0\end{array}$ & 8 \\
\hline & $\stackrel{\circ}{\sim} \stackrel{\circ}{\circ}$ & $\begin{array}{l}0 \\
\text { m } \\
0 \\
o \\
\text { N }\end{array}$ & $\overline{0}$ & $\begin{array}{l}8 \\
0\end{array}$ & 8 & 8 & $\begin{array}{l}8 \\
0 \\
0\end{array}$ \\
\hline & 융 & $\begin{array}{l}\hat{\theta} \\
0\end{array}$ & $\overline{0}^{\circ}$ & $\begin{array}{l}8 \\
0\end{array}$ & : & : & $\begin{array}{l}8 \\
0 \\
0\end{array}$ \\
\hline & $\begin{array}{l}\text { 岀 } \\
\text { o } \\
z\end{array}$ & $r$ & $\stackrel{\circ}{\circ}$ & 우 & 으 & ৪ & B. \\
\hline & $\underline{\underline{\xi}}$ & & & & & & \\
\hline
\end{tabular}




\begin{tabular}{|c|c|c|c|c|c|c|c|}
\hline \multirow{5}{*}{ 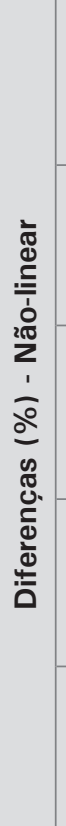 } & $\begin{array}{l}\circ \\
\stackrel{\circ}{\circ} \\
\stackrel{2}{\varepsilon} \\
\text { டे }\end{array}$ & & $\stackrel{m}{\circ}$ & : & : & 8. & $\begin{array}{l}8 \\
0\end{array}$ \\
\hline & $\stackrel{\circ}{\circ} \stackrel{\circ}{\circ}$ & ' & $\begin{array}{l}\bar{\delta} \\
0\end{array}$ & 8. & 8. & 8 & 8. \\
\hline & $\begin{array}{l}\stackrel{\circ}{\circ} \\
\stackrel{0}{\xi} \\
\stackrel{\circ}{m}\end{array}$ & ' & $\begin{array}{l}\text { O } \\
0 \\
0\end{array}$ & $\begin{array}{l}8 \\
0\end{array}$ & 8 & 8 & 8 \\
\hline & 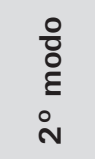 & 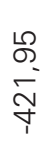 & $\begin{array}{l}\bar{o} \\
0\end{array}$ & : & ○ & : & $\begin{array}{l}8 \\
0\end{array}$ \\
\hline & $\begin{array}{l}\stackrel{0}{\circ} \\
\stackrel{8}{\xi} \\
\circ \\
-\end{array}$ & $\begin{array}{l}\text { I. } \\
\text { - }\end{array}$ & $\begin{array}{l}\text { Oे } \\
\text { O. }\end{array}$ & $\begin{array}{l}8 \\
0\end{array}$ & O & 8 & 8 \\
\hline \multirow{5}{*}{ 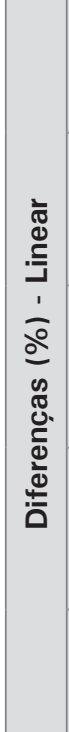 } & 요 $\stackrel{\circ}{\circ}$ & ' & $\stackrel{m}{\circ}$ & O & 8. & 8 & 8 \\
\hline & $\stackrel{\circ}{\circ} \stackrel{\circ}{\circ}$ & ' & $\begin{array}{l}\overline{0} \\
0 \\
0\end{array}$ & O & O & O. & 8. \\
\hline & $\stackrel{\circ}{\circ} \stackrel{\circ}{\circ}$ & . & O̊ & 8. & 8. & 8 & $\begin{array}{l}8 \\
0\end{array}$ \\
\hline & $\stackrel{\circ}{\circ} \stackrel{\circ}{\circ}$ & $\begin{array}{l}\bar{m} \\
\bar{\sigma} \\
\bar{y}\end{array}$ & $\begin{array}{l}\tilde{O} \\
0\end{array}$ & 8. & 8 & $\begin{array}{l}8 \\
0\end{array}$ & $\begin{array}{l}8 \\
0\end{array}$ \\
\hline & $\stackrel{\circ}{-} \stackrel{\circ}{\circ}$ & $\begin{array}{l}\infty \\
\infty \\
0\end{array}$ & $\bar{O}$ & \& & \&. & : & $\begin{array}{l}8 \\
0 \\
0\end{array}$ \\
\hline & 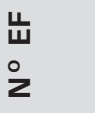 & - & $\stackrel{\circ}{\sim}$ & 아 & 으 & ৪ & 으 \\
\hline & छ్ & & & & & & \\
\hline
\end{tabular}




\begin{tabular}{|c|c|c|c|c|c|c|c|}
\hline \multirow{5}{*}{ 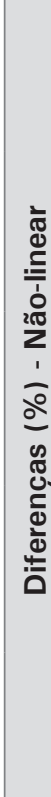 } & $\begin{array}{l}\circ \\
\stackrel{\circ}{\circ} \\
\grave{\Xi} \\
\circ \\
\text { ட) }\end{array}$ & ' & $\frac{m}{\sigma}$ & : & : & : & : \\
\hline & $\stackrel{\circ}{\circ} \stackrel{\circ}{\circ}$ & ' & $\begin{array}{l}\overline{0} \\
0\end{array}$ & 8 & 8. & 8 & 8 \\
\hline & 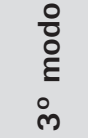 & ' & $\begin{array}{l}\text { Oे } \\
0\end{array}$ & 8 & : & 8 & 8 \\
\hline & $\begin{array}{l}\stackrel{\circ}{\circ} \\
\stackrel{0}{\xi} \\
\stackrel{\circ}{N}\end{array}$ & $\begin{array}{l}1 \\
\infty \\
0 \\
0 \\
0 \\
0\end{array}$ & $\begin{array}{l}\tilde{N} \\
0 \\
0\end{array}$ & : & : & : & : \\
\hline & 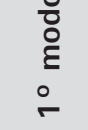 & $\stackrel{\overbrace{}}{\stackrel{N}{\leftarrow}}$ & $\begin{array}{l}\text { Oे } \\
\text { o. }\end{array}$ & $\begin{array}{l}\overline{0} \\
0\end{array}$ & 8. & 8 & 8 \\
\hline \multirow{5}{*}{ 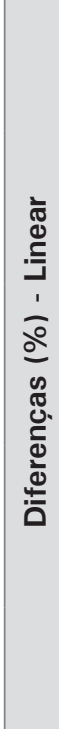 } & 요 & ' & $\stackrel{m}{\circ}$ & 8. & : & 8 & $\begin{array}{l}8 \\
0 \\
0\end{array}$ \\
\hline & ㅇ 융 & ' & $\begin{array}{l}\bar{\sigma} \\
0 \\
0\end{array}$ & 8 & 8. & 8 & 8 \\
\hline & $\stackrel{\circ}{\circ} \stackrel{\circ}{\circ}$ & ' & $\begin{array}{l}\text { O } \\
0 \\
0\end{array}$ & 8 & : & $\begin{array}{l}8 \\
0\end{array}$ & $\begin{array}{l}8 \\
0\end{array}$ \\
\hline & $\stackrel{\circ}{\circ} \stackrel{\circ}{\circ}$ & 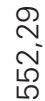 & $\begin{array}{l}\tilde{\sigma} \\
0\end{array}$ & 8 & 8 & 8 & 8. \\
\hline & $\circ \stackrel{\circ}{\circ}$ & $\begin{array}{l}\text { @) } \\
0 \\
0\end{array}$ & $\begin{array}{l}\overline{0} \\
0\end{array}$ & : & : & : & : \\
\hline & $\begin{array}{l}\frac{1}{4} \\
\text { o } \\
2\end{array}$ & $\tau$ & $\stackrel{\circ}{\circ}$ & 우 & 8 & 윰 & $\stackrel{8}{\circ}$ \\
\hline & $\bar{\xi}$ & & & & & & \\
\hline
\end{tabular}




\begin{tabular}{|c|c|c|c|c|c|c|c|}
\hline \multirow{5}{*}{ 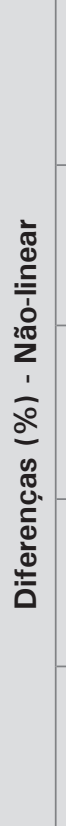 } & 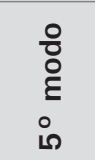 & & $\bar{O}$ & : & : & 8. & $\begin{array}{l}8 \\
0\end{array}$ \\
\hline & $\stackrel{\circ}{\circ} \stackrel{\circ}{\circ}$ & , & $\frac{m}{5}$ & 8. & 8. & 8 & 8. \\
\hline & $\begin{array}{l}\stackrel{\circ}{\circ} \\
\stackrel{0}{\xi} \\
\stackrel{0}{m}\end{array}$ & ' & $\begin{array}{l}\text { O } \\
0 \\
0\end{array}$ & $\begin{array}{l}8 \\
0\end{array}$ & 8 & 8 & 8 \\
\hline & 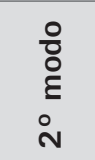 & $\begin{array}{l}\text { R } \\
\text { - } \\
\frac{1}{1}\end{array}$ & Õ. & : & ○ & : & $\begin{array}{l}8 \\
0\end{array}$ \\
\hline & $\begin{array}{l}\stackrel{0}{\circ} \\
\stackrel{8}{\xi} \\
\circ \\
-\end{array}$ & 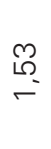 & $\stackrel{2}{\circ}$ & $\bar{o}$ & 8 & 8 & 8 \\
\hline \multirow{5}{*}{ 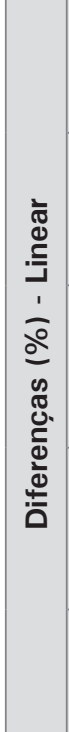 } & 요 $\stackrel{\circ}{\circ}$ & ' & $\bar{o}$ & O & 8. & 8 & 8 \\
\hline & $\stackrel{\circ}{\circ} \stackrel{\circ}{\circ}$ & ' & $\stackrel{m}{\circ}$ & O & O & O. & 8. \\
\hline & 용 율 & . & $\begin{array}{l}\text { O } \\
O \\
0\end{array}$ & 8. & 8. & 8 & $\begin{array}{l}8 \\
0\end{array}$ \\
\hline & $\stackrel{\circ}{\circ} \stackrel{\circ}{\circ}$ & 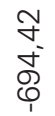 & Õ & 8. & 8 & $\begin{array}{l}8 \\
0\end{array}$ & $\begin{array}{l}8 \\
0\end{array}$ \\
\hline & $\stackrel{\circ}{-} \stackrel{\circ}{\circ}$ & $\stackrel{8}{\stackrel{-}{-}}$ & $\bar{O}$ & \& & \&. & : & $\begin{array}{l}8 \\
0 \\
0\end{array}$ \\
\hline & 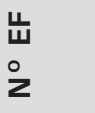 & - & 우 & 아 & 으 & ৪ & 으 \\
\hline & छ్ & & & & & & \\
\hline
\end{tabular}




\begin{tabular}{|c|c|c|c|c|c|c|c|}
\hline \multirow{5}{*}{ 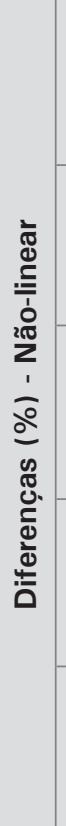 } & $\begin{array}{l}\circ \\
\stackrel{\circ}{\circ} \\
\stackrel{2}{\varepsilon} \\
\text { ட }\end{array}$ & & $\bar{O}$ & O: & : & : & $\begin{array}{l}8 \\
0\end{array}$ \\
\hline & $\stackrel{\circ}{\circ} \stackrel{\circ}{\circ}$ & , & $\frac{m}{5}$ & 8. & 8. & 8 & 8. \\
\hline & $\begin{array}{l}\stackrel{\circ}{\circ} \\
\stackrel{0}{\xi} \\
\stackrel{0}{m}\end{array}$ & ' & $\begin{array}{l}\text { O } \\
0 \\
0\end{array}$ & $\begin{array}{l}8 \\
0\end{array}$ & 8 & 8 & 8 \\
\hline & $\begin{array}{l}\stackrel{\circ}{\circ} \\
\text { हे } \\
\stackrel{\text { N }}{ }\end{array}$ & $\begin{array}{l}\widetilde{0} \\
0 \\
0^{\prime} \\
\infty\end{array}$ & 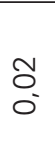 & : & ○ & : & $\begin{array}{l}8 \\
0\end{array}$ \\
\hline & $\begin{array}{l}\stackrel{0}{\circ} \\
\stackrel{8}{\xi} \\
\circ \\
-\end{array}$ & $\begin{array}{l}\infty \\
\stackrel{\infty}{-} \\
\leftarrow\end{array}$ & $\begin{array}{l}0 \\
0 \\
0\end{array}$ & $\bar{o}$ & 8 & 8 & 8 \\
\hline \multirow{5}{*}{ 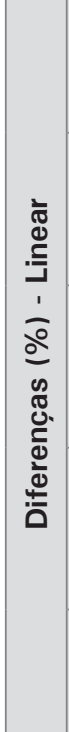 } & 요 $\stackrel{\circ}{\circ}$ & ' & $\bar{o}$ & O & 8. & 8 & 8 \\
\hline & $\stackrel{\circ}{\circ} \stackrel{\circ}{\circ}$ & ' & $\stackrel{m}{\circ}$ & O & O & O. & 8. \\
\hline & $\stackrel{\circ}{\circ} \stackrel{\circ}{\circ}$ & ' & $\begin{array}{l}\text { O } \\
O \\
0\end{array}$ & 8. & 8. & 8 & 8. \\
\hline & $\stackrel{\circ}{\circ} \stackrel{\circ}{\circ}$ & 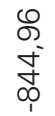 & Õ & 8. & 8 & $\begin{array}{l}8 \\
0\end{array}$ & $\begin{array}{l}8 \\
0\end{array}$ \\
\hline & $\stackrel{\circ}{-} \stackrel{\circ}{\circ}$ & $\stackrel{\infty}{=}$ & $\bar{O}$ & \& & \&. & : & $\begin{array}{l}8 \\
0 \\
0\end{array}$ \\
\hline & 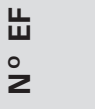 & - & 우 & 아 & 으 & ৪ & 으 \\
\hline & छ్ & & & & & & \\
\hline
\end{tabular}




\begin{tabular}{|c|c|c|c|c|c|c|c|}
\hline \multirow{5}{*}{ 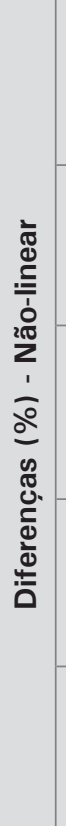 } & 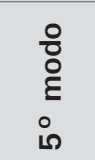 & & $\bar{O}$ & : & : & : & $\begin{array}{l}8 \\
0\end{array}$ \\
\hline & $\stackrel{\circ}{\circ} \stackrel{\circ}{\circ}$ & , & $\frac{m}{5}$ & 8. & 8. & 8 & 8. \\
\hline & $\begin{array}{l}\stackrel{\circ}{\circ} \\
\stackrel{0}{\xi} \\
\stackrel{0}{m}\end{array}$ & ' & $\begin{array}{l}\text { O } \\
0 \\
0\end{array}$ & $\begin{array}{l}8 \\
0\end{array}$ & 8 & 8 & 8 \\
\hline & $\begin{array}{l}\circ \\
\stackrel{0}{\circ} \\
\grave{\Xi} \\
\stackrel{2}{N}\end{array}$ & $\begin{array}{l}\infty \\
\text { m } \\
\sigma^{2} \\
\stackrel{0}{\sigma}\end{array}$ & $\begin{array}{l}3 \\
0 \\
0\end{array}$ & : & ○ & : & $\begin{array}{l}8 \\
0\end{array}$ \\
\hline & $\begin{array}{l}\stackrel{0}{\circ} \\
\stackrel{8}{\xi} \\
\circ \\
-\end{array}$ & 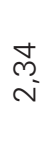 & $\begin{array}{l}8 \\
0 \\
0\end{array}$ & $\begin{array}{l}\text { Oे } \\
\text { O }\end{array}$ & $\bar{o}$ & 8 & 8 \\
\hline \multirow{5}{*}{ 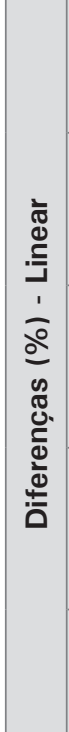 } & 요 $\stackrel{\circ}{\circ}$ & ' & $\bar{o}$ & O & 8. & 8 & 8 \\
\hline & $\stackrel{\circ}{\circ} \stackrel{\circ}{\circ}$ & ' & $\stackrel{m}{\circ}$ & O & O & O. & 8. \\
\hline & $\stackrel{\circ}{\circ} \stackrel{\circ}{\circ}$ & . & $\begin{array}{l}\text { O } \\
O \\
0\end{array}$ & 8. & 8. & 8 & $\begin{array}{l}8 \\
0\end{array}$ \\
\hline & $\stackrel{\circ}{\circ} \stackrel{\circ}{\circ}$ & $\begin{array}{l}\bar{m} \\
\tilde{j} \\
\tilde{\delta}^{-} \\
\overline{1}\end{array}$ & Õ & 8. & 8 & $\begin{array}{l}8 \\
0\end{array}$ & $\begin{array}{l}8 \\
0\end{array}$ \\
\hline & $\stackrel{\circ}{-} \stackrel{\circ}{\circ}$ & $\stackrel{m}{\stackrel{m}{-}}$ & $\bar{O}$ & \& & \&. & : & $\begin{array}{l}8 \\
0 \\
0\end{array}$ \\
\hline & 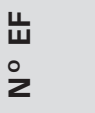 & - & 우 & 아 & 으 & ৪ & 으 \\
\hline & छ్ & & & & & & \\
\hline
\end{tabular}




\begin{tabular}{|c|c|c|c|c|c|c|c|}
\hline \multirow{5}{*}{ 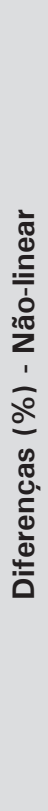 } & 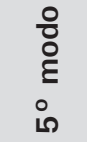 & & ঠ্ঠি & : & : & : & : \\
\hline & $\stackrel{\circ}{\circ} \stackrel{\circ}{\circ}$ & & $\frac{m}{0}$ & 8 & 8 & $\begin{array}{l}8 \\
0^{\circ}\end{array}$ & $\begin{array}{l}8 \\
0 \\
0\end{array}$ \\
\hline & $\begin{array}{l}\stackrel{0}{\circ} \\
\stackrel{\circ}{\xi} \\
\circ \\
\stackrel{m}{0}\end{array}$ & 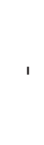 & $\begin{array}{l}\text { ¿ } \\
0\end{array}$ & 웅 & : & 8. & 8. \\
\hline & $\begin{array}{l}\stackrel{\circ}{\circ} \\
\stackrel{\Xi}{\xi} \\
\stackrel{2}{N}\end{array}$ & $\begin{array}{l}\text { గ్ } \\
\bar{\sigma} \\
\frac{1}{7}\end{array}$ & $\begin{array}{l}\text { Oे } \\
0\end{array}$ & ㅇ. & : & : & ㅇ. \\
\hline & $\begin{array}{l}\text { 윰 } \\
\stackrel{2}{\varepsilon} \\
\circ \\
\end{array}$ & 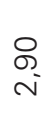 & $\frac{m}{\sigma}$ & O̊ & $\overline{0}$ & $\begin{array}{l}8 \\
0\end{array}$ & 웅 \\
\hline \multirow{5}{*}{ 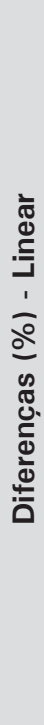 } & ㅇํํ & & $\underset{0}{\tilde{f}}$ & $\begin{array}{l}8 \\
0\end{array}$ & $\begin{array}{l}8 \\
0\end{array}$ & 8 & 8. \\
\hline & $\stackrel{\circ}{\circ} \stackrel{\circ}{\circ}$ & & $\frac{m}{0}$ & 8. & 8 & 8 & 8 \\
\hline & $\stackrel{\circ}{\circ} \stackrel{\circ}{\circ}$ & , & $\begin{array}{l}\text { D } \\
0\end{array}$ & 8 & 8 & $\begin{array}{l}8 \\
0\end{array}$ & $\begin{array}{l}8 \\
0 \\
0\end{array}$ \\
\hline & $\stackrel{\circ}{\sim} \stackrel{\circ}{\circ}$ & 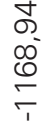 & $\begin{array}{l}\widetilde{0} \\
\text { Oे } \\
0\end{array}$ & $\begin{array}{l}8 \\
0\end{array}$ & 8 & 8 & $\begin{array}{l}8 \\
0 \\
0\end{array}$ \\
\hline & 융 & $\stackrel{\mathscr{P}}{=}$ & $\overline{0}^{\circ}$ & $\begin{array}{l}8 \\
0\end{array}$ & : & $\begin{array}{l}8 \\
0\end{array}$ & $\begin{array}{l}8 \\
0 \\
0\end{array}$ \\
\hline & $\begin{array}{l}\text { 岀 } \\
\text { o } \\
z\end{array}$ & $r$ & $\stackrel{\circ}{\circ}$ & 우 & 으 & 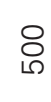 & 음 \\
\hline & $\underline{\underline{\xi}}$ & & & & & & \\
\hline
\end{tabular}




\begin{tabular}{|c|c|c|c|c|c|c|c|}
\hline & $\begin{array}{l}\frac{0}{0} \\
\text { ㅇ } \\
\text { Ė } \\
\text { 오 }\end{array}$ & 1 & テ̃ & $\begin{array}{l}\circ \\
\circ \\
0\end{array}$ & $\begin{array}{l}8 \\
\circ \\
0\end{array}$ & $\begin{array}{l}\circ \\
\circ \\
\circ\end{array}$ & $\begin{array}{l}\circ \\
\circ\end{array}$ \\
\hline ֻ & $\stackrel{\circ}{\circ} \stackrel{\circ}{\frac{0}{0}}$ & I & $\frac{m}{5}$ & $\begin{array}{l}8 \\
0\end{array}$ & $\begin{array}{l}8 \\
0 \\
0\end{array}$ & $\begin{array}{l}8 \\
0 \\
0\end{array}$ & $\begin{array}{l}8 \\
0\end{array}$ \\
\hline$\frac{1}{\frac{1}{2}}$ & $\begin{array}{l}\frac{0}{0} \\
\stackrel{0}{\circ} \\
\text { E } \\
\text { m }\end{array}$ & ' & $\begin{array}{l}\text { L } \\
0 \\
0\end{array}$ & $\begin{array}{l}8 \\
0 \\
0\end{array}$ & $\begin{array}{l}8 \\
0 \\
0\end{array}$ & $\begin{array}{l}8 \\
0 \\
0\end{array}$ & $\begin{array}{l}8 \\
0\end{array}$ \\
\hline 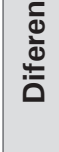 & $\begin{array}{l}\stackrel{\circ}{\circ} \\
\stackrel{\circ}{E} \\
\stackrel{\circ}{N}\end{array}$ & 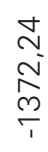 & $\begin{array}{l}\text { ठ } \\
0 \\
0\end{array}$ & $\begin{array}{l}8 \\
0 \\
0\end{array}$ & $\begin{array}{l}\circ \\
\circ \\
0\end{array}$ & $\begin{array}{l}\circ \\
\text { ㅇ. }\end{array}$ & $\begin{array}{l}8 \\
0\end{array}$ \\
\hline & $\begin{array}{l}\stackrel{ }{0} \\
\stackrel{\circ}{E} \\
\stackrel{-}{\circ}\end{array}$ & $\begin{array}{l}\overline{6} \\
\text { m }\end{array}$ & $\begin{array}{l}1 \\
\vdots\end{array}$ & $\begin{array}{l}\text { J } \\
0 \\
0\end{array}$ & $\begin{array}{l}5 \\
0\end{array}$ & $\begin{array}{l}8 \\
\circ \\
0\end{array}$ & $\begin{array}{l}8 \\
0\end{array}$ \\
\hline & 을 응 & ' & $\begin{array}{l}\bar{\sigma} \\
\text { ó }\end{array}$ & $\begin{array}{l}8 \\
0\end{array}$ & $\begin{array}{l}8 \\
0\end{array}$ & $\begin{array}{l}8 \\
0 \\
0\end{array}$ & $\begin{array}{l}8 \\
0 \\
0\end{array}$ \\
\hline ষ্ত & $\stackrel{\circ}{\circ} \stackrel{\circ}{\circ}$ & ' & $\frac{m}{5}$ & $\begin{array}{l}8 \\
0 \\
0\end{array}$ & $\begin{array}{l}8 \\
0 \\
0\end{array}$ & $\begin{array}{l}8 \\
0 \\
0\end{array}$ & $\begin{array}{l}8 \\
0\end{array}$ \\
\hline$\frac{5}{2}$ & 용 응 & ' & $\begin{array}{l}\text { ¿ } \\
\text { ○' }\end{array}$ & $\begin{array}{l}8 \\
0 \\
0\end{array}$ & 8. & $\begin{array}{l}8 \\
0 \\
0\end{array}$ & $\begin{array}{l}8 \\
0 \\
0\end{array}$ \\
\hline 这 & $\stackrel{\circ}{\sim} \stackrel{\circ}{\circ}$ & 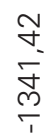 & $\begin{array}{l}\text { ปิ } \\
\text { ○. }\end{array}$ & $\begin{array}{l}8 \\
0 \\
0\end{array}$ & $\begin{array}{l}8 \\
0 \\
0\end{array}$ & $\begin{array}{l}8 \\
0 \\
0\end{array}$ & $\begin{array}{l}8 \\
\circ\end{array}$ \\
\hline & $\stackrel{\circ}{\circ} \stackrel{\circ}{\circ}$ & $\stackrel{\stackrel{0}{\circ}}{\leftarrow}$ & $\begin{array}{l}\text { J̃ } \\
\text { ó }\end{array}$ & $\begin{array}{l}8 \\
0 \\
0\end{array}$ & $\begin{array}{l}\circ \\
\circ \\
0\end{array}$ & $\begin{array}{l}8 \\
0 \\
0\end{array}$ & $\begin{array}{l}8 \\
\circ \\
\circ\end{array}$ \\
\hline & $\begin{array}{l}\text { 出 } \\
\text { ○ } \\
Z\end{array}$ & - & 으 & ㅇ & 음 & ○ & 음 \\
\hline & छ & \multicolumn{6}{|c|}{$\begin{array}{l}8 \\
0 \\
0\end{array}$} \\
\hline
\end{tabular}




\begin{tabular}{|c|c|c|c|c|c|c|c|}
\hline \multirow{5}{*}{ 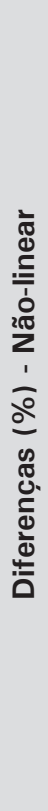 } & 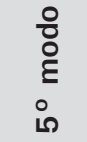 & & ঠ্ঠি & : & : & : & : \\
\hline & $\stackrel{\circ}{\circ} \stackrel{\circ}{\circ}$ & & $\frac{8}{\sigma}$ & 8 & 8 & $\begin{array}{l}8 \\
0^{\circ}\end{array}$ & $\begin{array}{l}8 \\
0 \\
0\end{array}$ \\
\hline & $\begin{array}{l}\circ \\
\text { 이 } \\
\text { हे } \\
\stackrel{0}{m}\end{array}$ & 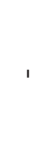 & $\begin{array}{l}\stackrel{8}{0} \\
0\end{array}$ & 웅 & : & 8. & 8. \\
\hline & $\begin{array}{l}\stackrel{\circ}{\circ} \\
\stackrel{\Xi}{\xi} \\
\stackrel{2}{N}\end{array}$ & $\begin{array}{l}\text { I } \\
\overline{0} \\
\frac{1}{1}\end{array}$ & $\begin{array}{l}\text { ¿ } \\
\text { O. }\end{array}$ & ס̊ & : & : & ㅇ. \\
\hline & $\begin{array}{l}\stackrel{0}{\circ} \\
\stackrel{0}{\varepsilon} \\
\stackrel{\circ}{\ulcorner}\end{array}$ & $\begin{array}{l}\stackrel{\leftrightarrow}{\stackrel{\rho}{\sim}} \\
\sim\end{array}$ & $\underset{J}{\stackrel{J}{J}}$ & $\begin{array}{l}\mathscr{0} \\
0 \\
0\end{array}$ & O̊ & $\begin{array}{l}8 \\
0\end{array}$ & 웅 \\
\hline \multirow{5}{*}{ 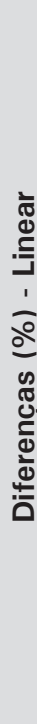 } & 요 & & $\underset{0}{\tilde{f}}$ & $\begin{array}{l}8 \\
0\end{array}$ & $\begin{array}{l}8 \\
0\end{array}$ & 8 & 8. \\
\hline & $\stackrel{\circ}{\circ} \stackrel{\circ}{\circ}$ & & $\frac{m}{0}$ & 8. & 8 & 8 & 8 \\
\hline & $\stackrel{\circ}{\circ} \stackrel{\circ}{\circ}$ & , & $\begin{array}{l}\text { D } \\
0\end{array}$ & 8 & $\begin{array}{l}8 \\
0\end{array}$ & $\begin{array}{l}8 \\
0\end{array}$ & $\begin{array}{l}8 \\
0 \\
0\end{array}$ \\
\hline & $\stackrel{\circ}{\sim} \stackrel{\circ}{\circ}$ & $\begin{array}{l}\text { ले } \\
\text { ○ } \\
\text { స్ }\end{array}$ & $\begin{array}{l}\widetilde{0} \\
\text { Oे } \\
0\end{array}$ & $\begin{array}{l}8 \\
0\end{array}$ & 8 & 8 & $\begin{array}{l}8 \\
0 \\
0\end{array}$ \\
\hline & 융 & $\begin{array}{l}\infty \\
\stackrel{\leftrightarrow}{\Theta} \\
-\end{array}$ & O̊ & $\begin{array}{l}8 \\
0\end{array}$ & : & $\begin{array}{l}8 \\
0\end{array}$ & $\begin{array}{l}8 \\
0 \\
0\end{array}$ \\
\hline & $\begin{array}{l}\text { 岀 } \\
\text { o } \\
z\end{array}$ & $r$ & $\stackrel{\circ}{\circ}$ & 우 & 으 & 유 & 음 \\
\hline & $\underline{\underline{\xi}}$ & & & & & & \\
\hline
\end{tabular}




\begin{tabular}{|c|c|c|c|c|c|c|c|}
\hline \multirow{5}{*}{ 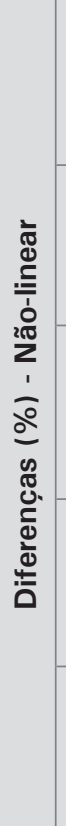 } & $\begin{array}{l}\circ \\
\stackrel{\circ}{\circ} \\
\stackrel{2}{\varepsilon} \\
\text { டे }\end{array}$ & & $\begin{array}{l}\tilde{J} \\
\tilde{\sigma}\end{array}$ & : & : & 8. & $\begin{array}{l}8 \\
0\end{array}$ \\
\hline & $\stackrel{\circ}{\circ} \stackrel{\circ}{\circ}$ & , & $\stackrel{\nabla}{ \pm}$ & 8. & 8. & 8 & 8. \\
\hline & $\begin{array}{l}\stackrel{\circ}{\circ} \\
\stackrel{0}{\xi} \\
\stackrel{\circ}{m}\end{array}$ & ' & $\stackrel{\text { L̊ }}{\circ}$ & $\begin{array}{l}8 \\
0\end{array}$ & 8 & 8 & 8 \\
\hline & 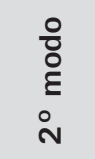 & $\begin{array}{l}8 \\
\circ \\
\circ \\
\stackrel{\circ}{N} \\
\frac{1}{1}\end{array}$ & $\stackrel{\text { L̊ }}{\circ}$ & ס. & \&. & : & $\begin{array}{l}8 \\
0\end{array}$ \\
\hline & $\begin{array}{l}\stackrel{0}{\circ} \\
\stackrel{8}{\xi} \\
\circ \\
-\end{array}$ & $\begin{array}{l}\infty \\
\infty \\
\infty \\
\sigma^{\circ}\end{array}$ & $\begin{array}{l}m \\
\text { m. } \\
0\end{array}$ & $\begin{array}{l}0 \\
\text { O } \\
\text { O }\end{array}$ & $\begin{array}{l}\text { Oo } \\
0\end{array}$ & 8 & 8 \\
\hline \multirow{5}{*}{ 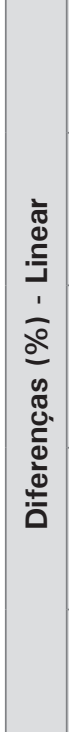 } & 요 $\stackrel{\circ}{\circ}$ & ' & $\begin{array}{l}\tilde{J} \\
0\end{array}$ & O & 8. & 8 & 8 \\
\hline & $\stackrel{\circ}{\circ} \stackrel{\circ}{\circ}$ & ' & $\stackrel{m}{\circ}$ & O & O & O. & 8. \\
\hline & $\stackrel{\circ}{\circ} \stackrel{\circ}{\circ}$ & . & $\stackrel{\text { L̊ }}{\circ}$ & 8. & 8. & 8 & $\begin{array}{l}8 \\
0\end{array}$ \\
\hline & $\stackrel{\circ}{\sim} \stackrel{\circ}{\circ}$ & $\begin{array}{l}\hat{n} \\
\text { s. } \\
\stackrel{0}{0} \\
\frac{1}{1}\end{array}$ & $\mathscr{O}_{0}^{\infty}$ & 8. & 8 & $\begin{array}{l}8 \\
0\end{array}$ & $\begin{array}{l}8 \\
0\end{array}$ \\
\hline & $\stackrel{\circ}{-} \stackrel{\circ}{\circ}$ & $\begin{array}{l}\infty \\
\stackrel{\infty}{-} \\
-\end{array}$ & Õ & \& & \&. & : & $\begin{array}{l}8 \\
0 \\
0\end{array}$ \\
\hline & 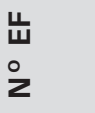 & - & $\stackrel{\circ}{\sim}$ & 아 & 으 & ৪ & 으 \\
\hline & छ్ & & & & & & \\
\hline
\end{tabular}




\begin{tabular}{|c|c|c|c|c|c|c|c|}
\hline \multirow{5}{*}{ 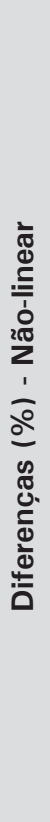 } & $\begin{array}{l}\text { 응 } \\
\text { ㅇ } \\
\text { Ė } \\
\text { ㅇ }\end{array}$ & 1 & テ & $\begin{array}{l}8 \\
\text { ○ }\end{array}$ & $\begin{array}{l}8 \\
\text { ○ }\end{array}$ & $\begin{array}{l}8 \\
\text { ○ }\end{array}$ & $\begin{array}{l}8 \\
\text { ○. }\end{array}$ \\
\hline & $\stackrel{\circ}{\circ} \stackrel{\circ}{\frac{0}{}}$ & ' & $\frac{5}{5}$ & $\begin{array}{l}8 \\
0 \\
0\end{array}$ & $\begin{array}{l}8 \\
0 \\
0\end{array}$ & $\begin{array}{l}8 \\
0 \\
0\end{array}$ & $\begin{array}{l}8 \\
0 \\
0\end{array}$ \\
\hline & $\begin{array}{l}\text { 응 } \\
\text { ㅇ } \\
\text { Ė } \\
\text { m }\end{array}$ & ' & $\begin{array}{l}0 \\
8 \\
0\end{array}$ & $\begin{array}{l}8 \\
0 \\
0\end{array}$ & $\begin{array}{l}8 \\
0 \\
0\end{array}$ & $\begin{array}{l}8 \\
0 \\
0\end{array}$ & $\begin{array}{l}8 \\
0 \\
0\end{array}$ \\
\hline & $\begin{array}{l}\stackrel{ }{0} \\
\stackrel{\circ}{\varrho} \\
\text { E } \\
\stackrel{\circ}{N}\end{array}$ & $\begin{array}{l}5 \\
10 \\
0 \\
0 \\
\end{array}$ & $\begin{array}{l}\text { L } \\
\text { 웅 }\end{array}$ & ర్ & $\begin{array}{l}8 \\
\circ \\
0\end{array}$ & $\begin{array}{l}8 \\
\circ \\
0\end{array}$ & $\begin{array}{l}8 \\
\text { ○. }\end{array}$ \\
\hline & $\begin{array}{l}\frac{0}{0} \\
\text { 을 } \\
\stackrel{\circ}{-}\end{array}$ & $\frac{0}{N}$ & $\begin{array}{l}0 \\
\stackrel{0}{+} \\
0\end{array}$ & $\frac{0}{0}$ & $\begin{array}{l}\text { J } \\
0 \\
0\end{array}$ & $\begin{array}{l}8 \\
0 \\
0\end{array}$ & $\begin{array}{l}8 \\
0 \\
0\end{array}$ \\
\hline \multirow{5}{*}{ 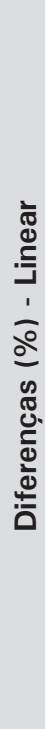 } & 요 & . & $\begin{array}{l}\bar{t} \\
0\end{array}$ & 8. & $\begin{array}{l}8 \\
\text { ○ }\end{array}$ & $\begin{array}{l}8 \\
0 \\
0\end{array}$ & $\begin{array}{l}8 \\
\text { ○ }\end{array}$ \\
\hline & $\stackrel{\circ}{+} \stackrel{\circ}{\frac{0}{\circ}}$ & ' & $\frac{1}{5}$ & $\begin{array}{l}8 \\
0 \\
0\end{array}$ & $\begin{array}{l}8 \\
0 \\
0\end{array}$ & $\begin{array}{l}8 \\
0 \\
0\end{array}$ & $\begin{array}{l}8 \\
0\end{array}$ \\
\hline & ำ 을 & ' & $\begin{array}{l}\text { L } \\
0 \\
0\end{array}$ & ○ & $\begin{array}{l}8 \\
\text { ○. }\end{array}$ & $\begin{array}{l}8 \\
0 \\
0\end{array}$ & $\begin{array}{l}8 \\
0\end{array}$ \\
\hline & $\stackrel{\circ}{\sim} \stackrel{\circ}{\circ}$ & $\begin{array}{l}\text { No } \\
0 \\
\infty \\
\infty\end{array}$ & $\begin{array}{l}\text { Oे } \\
0 \\
0\end{array}$ & $\begin{array}{l}8 \\
0\end{array}$ & $\begin{array}{l}8 \\
0 \\
0\end{array}$ & $\begin{array}{l}8 \\
0 \\
0\end{array}$ & $\begin{array}{l}8 \\
0\end{array}$ \\
\hline & $\stackrel{\circ}{\circ} \frac{\circ}{\circ}$ & ฮ్ & $\begin{array}{l}\text { Ō } \\
\text { O. }\end{array}$ & $\begin{array}{l}8 \\
\text { ○. }\end{array}$ & $\begin{array}{l}\circ \\
\text { ○. }\end{array}$ & $\begin{array}{l}8 \\
\text { ○ }\end{array}$ & $\begin{array}{l}8 \\
\text { ○ }\end{array}$ \\
\hline & $\begin{array}{l}\text { U } \\
\text { 岁 } \\
\mathbf{Z}\end{array}$ & - & $\stackrel{\circ}{\circ}$ & 아 & ○ & 유 & ৪ \\
\hline & $\underline{\underline{\xi}}$ & & & & & & \\
\hline
\end{tabular}




\begin{tabular}{|c|c|c|c|c|c|c|c|}
\hline \multirow{5}{*}{ 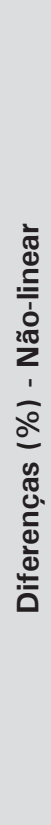 } & $\begin{array}{l}\circ \\
\stackrel{\circ}{\circ} \\
\stackrel{0}{0} \\
\circ \\
\text { in }\end{array}$ & & $\begin{array}{l}\check{\sigma} \\
\dot{0}\end{array}$ & ㅇ. & : & : & : \\
\hline & $\stackrel{\circ}{\circ} \stackrel{\circ}{\circ}$ & ( & $\underset{\square}{ \pm}$ & 8 & 8 & 8 & 8 \\
\hline & $\begin{array}{l}\text { 유 } \\
\text { ㅌ } \\
\text { ○ }\end{array}$ & & $\begin{array}{l}\mathscr{8} \\
0\end{array}$ & 8 & 8 & 8 & 8 \\
\hline & 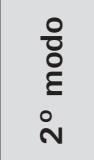 & $\begin{array}{l}\stackrel{\llcorner}{\llcorner} \\
\stackrel{\Omega}{N} \\
\stackrel{\top}{\top}\end{array}$ & $\begin{array}{l}\mathscr{8} \\
0 \\
0\end{array}$ & $\overline{0}$ & : & : & : \\
\hline & $\begin{array}{l}\text { 응 } \\
\stackrel{2}{\xi} \\
\circ \\
-\end{array}$ & $\begin{array}{l}\overline{1} \\
0 \\
\circ\end{array}$ & $\begin{array}{l}\mathbb{O}^{\prime} \\
0\end{array}$ & $\frac{12}{\circ}$ & $\stackrel{8}{\circ}$ & $\overline{0}$ & 8 \\
\hline \multirow{5}{*}{ 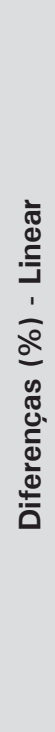 } & ㅇํํ & , & ঠ் & 8 & 8 & 8 & $\begin{array}{l}8 \\
0\end{array}$ \\
\hline & $\stackrel{\circ}{\circ} \stackrel{\circ}{\circ}$ & ' & $\stackrel{\nabla}{\leftarrow}$ & 8 & 8 & $\begin{array}{l}8 \\
0\end{array}$ & $\begin{array}{l}8 \\
0\end{array}$ \\
\hline & 용 율 & , & 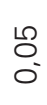 & 8 & 8 & 8 & 8 \\
\hline & $\stackrel{\circ}{\circ} \stackrel{\circ}{\circ}$ & $\begin{array}{l}\stackrel{\infty}{+} \\
\text { ণ } \\
\text { O্ }\end{array}$ & O̊. & 8. & 8 & 8 & $\begin{array}{l}8 \\
0\end{array}$ \\
\hline & $\stackrel{\circ}{\circ} \stackrel{\circ}{\circ}$ & $\stackrel{+}{\text { i }}$ & $\begin{array}{l}\widetilde{O} \\
\text { O. } \\
0\end{array}$ & 응 & : & : & : \\
\hline & $\begin{array}{l}\text { 出 } \\
\text { ○ }\end{array}$ & $r$ & $\stackrel{\circ}{\circ}$ & 우 & 음 & 80 & 음 \\
\hline & $\underline{\bar{\xi}}$ & & & & & & \\
\hline
\end{tabular}




\begin{tabular}{|c|c|c|c|c|c|c|c|}
\hline \multirow{5}{*}{ 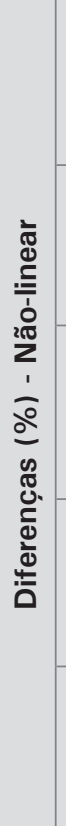 } & $\begin{array}{l}\circ \\
\stackrel{\circ}{\circ} \\
\stackrel{2}{\varepsilon} \\
\text { டे }\end{array}$ & & $\begin{array}{l}\tilde{J} \\
\tilde{\sigma}\end{array}$ & : & : & 8. & $\begin{array}{l}8 \\
0\end{array}$ \\
\hline & $\stackrel{\circ}{\circ} \stackrel{\circ}{\circ}$ & , & $\stackrel{\nabla}{ \pm}$ & 8. & 8. & 8 & 8. \\
\hline & $\begin{array}{l}\stackrel{\circ}{\circ} \\
\stackrel{0}{\xi} \\
\stackrel{\circ}{m}\end{array}$ & ' & $\begin{array}{l}8 \\
\stackrel{0}{0}\end{array}$ & $\begin{array}{l}8 \\
0\end{array}$ & 8 & 8 & 8 \\
\hline & 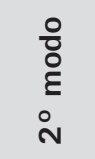 & $\begin{array}{l}\text { Ô } \\
\text { i } \\
\stackrel{O}{+} \\
\text { it }\end{array}$ & $\begin{array}{l}\text { o } \\
\text { o }\end{array}$ & ס. & ○ & : & $\begin{array}{l}8 \\
0\end{array}$ \\
\hline & $\begin{array}{l}\stackrel{0}{\circ} \\
\stackrel{8}{\xi} \\
\circ \\
-\end{array}$ & 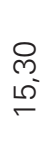 & $\begin{array}{l}\text { ' } \\
0 \\
0\end{array}$ & 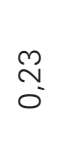 & $\begin{array}{l}8 \\
0 \\
0\end{array}$ & $\overline{0}$ & 8 \\
\hline \multirow{5}{*}{ 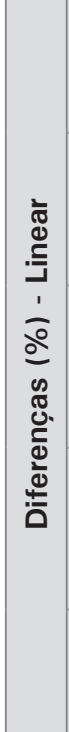 } & 요 $\stackrel{\circ}{\circ}$ & ' & $\begin{array}{l}\tilde{J} \\
0\end{array}$ & O & 8. & 8 & 8 \\
\hline & $\stackrel{\circ}{\circ} \stackrel{\circ}{\circ}$ & ' & $\stackrel{+}{\circ}$ & O & O & O. & 8. \\
\hline & $\stackrel{\circ}{\circ} \stackrel{\circ}{\circ}$ & . & $\stackrel{\text { L̊ }}{\circ}$ & 8. & 8. & 8 & $\begin{array}{l}8 \\
0\end{array}$ \\
\hline & $\stackrel{\circ}{\sim} \stackrel{\circ}{\circ}$ & 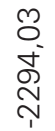 & $\mathscr{O}_{0}^{\infty}$ & 8. & 8 & $\begin{array}{l}8 \\
0\end{array}$ & $\begin{array}{l}8 \\
0\end{array}$ \\
\hline & $\stackrel{\circ}{-} \stackrel{\circ}{\circ}$ & $\stackrel{0}{c}$ & Õ & \& & \&. & : & $\begin{array}{l}8 \\
0 \\
0\end{array}$ \\
\hline & 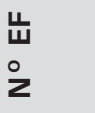 & - & $\stackrel{\circ}{\sim}$ & 아 & 으 & ৪ & 으 \\
\hline & छ్ & & & & & & \\
\hline
\end{tabular}




\begin{tabular}{|c|c|c|c|c|c|c|c|}
\hline \multirow{5}{*}{ 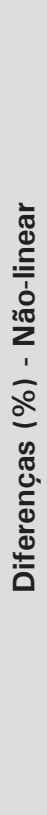 } & 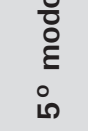 & ' & $\begin{array}{l}\overleftarrow{\sigma} \\
\text { ¿ }\end{array}$ & ¿ & : & : & $\begin{array}{l}8 \\
0 \\
0\end{array}$ \\
\hline & $\stackrel{\circ}{\circ} \stackrel{\circ}{\circ}$ & ' & $\frac{\llcorner}{\sigma}$ & 8 & : & 8. & $\begin{array}{l}8 \\
0\end{array}$ \\
\hline & $\begin{array}{l}\stackrel{\circ}{\circ} \\
\stackrel{0}{\xi} \\
\stackrel{\circ}{m}\end{array}$ & ' & $\begin{array}{l}0 \\
0 \\
0\end{array}$ & $\begin{array}{l}\overline{0} \\
0 \\
0\end{array}$ & $\begin{array}{l}8 \\
0\end{array}$ & 8 & 8. \\
\hline & $\begin{array}{l}\stackrel{\circ}{\circ} \\
\stackrel{0}{E} \\
\stackrel{\circ}{N}\end{array}$ & 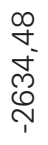 & $\begin{array}{l}\infty \\
\stackrel{-}{0} \\
0\end{array}$ & ס̊ & : & : & \&. \\
\hline & $\begin{array}{l}\stackrel{\circ}{\circ} \\
\stackrel{0}{\varepsilon} \\
\circ \\
-\end{array}$ & $\begin{array}{l}\frac{0}{2} \\
\stackrel{5}{2}\end{array}$ & $\stackrel{\mathbb{U}}{=}$ & $\begin{array}{l}\infty \\
m \\
\vdots \\
0\end{array}$ & $\frac{\nabla}{\sigma}$ & $\begin{array}{l}\text { O } \\
\text { Oे }\end{array}$ & 8 \\
\hline \multirow{5}{*}{ 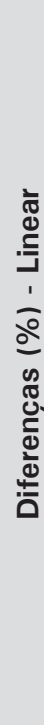 } & 요 $\stackrel{\circ}{\circ}$ & , & $\begin{array}{l}\check{\sigma} \\
\text { ¿ }\end{array}$ & 8 & 8 & 8. & $\begin{array}{l}8 \\
0 \\
0\end{array}$ \\
\hline & $\stackrel{\circ}{\circ} \stackrel{\circ}{\circ}$ & ' & $\frac{8}{\sigma}$ & $\begin{array}{l}8 \\
0\end{array}$ & O & 8. & $\begin{array}{l}8 \\
0\end{array}$ \\
\hline & 효 $\stackrel{\circ}{\circ}$ & ' & $\begin{array}{l}\mathscr{0} \\
0 \\
0\end{array}$ & 8 & O: & O & 웅 \\
\hline & $\stackrel{\circ}{\sim} \stackrel{\circ}{\circ}$ & 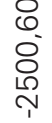 & $\begin{array}{l}\text { Oू } \\
0 \\
0\end{array}$ & 8 & 8 & 8. & 8. \\
\hline & 윰 & 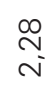 & $\begin{array}{l}\tilde{N} \\
0 \\
0\end{array}$ & : & : & : & : \\
\hline & $\begin{array}{l}\frac{1}{4} \\
\stackrel{0}{2} \\
z\end{array}$ & - & $\stackrel{\circ}{\circ}$ & ㅇ & $\stackrel{\circ}{\circ}$ & 요 & ঃ \\
\hline & $\bar{\xi}$ & & & & & & \\
\hline
\end{tabular}


Para o primeiro modo, a diferença entre a frequência do modelo mais simplesmente discretizado e o modelo mais densamente discretizado aumenta continuamente, alcançando 2,28\% quando a frequência é obtida de forma linear e $25,16 \%$ quando é calculada com a não-lineraidade geométrica. É importante realizar a discretização com mais de um elemento para o cálculo da resposta da estrutura sob ação de vento, que pretendam incluir o segundo modo de vibração ou superiores, pois o segundo modo de vibração, para modelos discretizados com apenas um elemento, é um modo axial de vibração.

Quando se trata de análises não-lineares as diferenças entre as frequências do primeiro modo de vibração de modelos de discretização mais pobre para os de discretização mais rica vão se ampliando com a esbeltez.

\subsubsection{Análise dos ensaios para o esforço de tração}

Os resultados obtidos no ensaio de tração estão dispostos a seguir com os correspondentes da solução proposta. As respostas do ensaio de tração revelaram o comportamento apresentado no gráfico da Figura 5.14, no qual se verifica, novamente, uma boa aproximação com a solução proposta. 
Tabela 5.9 - Esforço de tração: resultados experimentais e Proposto.

\begin{tabular}{|c|c|c|c|c|}
\hline \multicolumn{5}{|c|}{ Esforço de tração } \\
\hline \multirow{2}{*}{$\begin{array}{l}\text { Comprimento } \\
\text { (m) }\end{array}$} & \multicolumn{2}{|c|}{ Frequências $(\mathrm{Hz})$} & \multicolumn{2}{|c|}{ Diferenças } \\
\hline & $\begin{array}{c}\text { Resultados } \\
\text { experimentais }\end{array}$ & $\begin{array}{l}\text { Solução } \\
\text { proposta }\end{array}$ & $\mathrm{Hz}$ & $\%$ \\
\hline 0,20 & 6,5430 & 6,5660 & $-0,023$ & 0,35 \\
\hline 0,25 & 4,6997 & 4,7400 & $-0,040$ & 0,85 \\
\hline 0,30 & 3,5706 & 3,6452 & $-0,075$ & 2,05 \\
\hline 0,35 & 2,8687 & 2,9298 & $-0,061$ & 2,09 \\
\hline 0,40 & 2,3804 & 2,4330 & $-0,053$ & 2,16 \\
\hline 0,45 & 1,9836 & 2,0721 & $-0,088$ & 4,27 \\
\hline 0,50 & 1,7330 & 1,8004 & $-0,067$ & 3,74 \\
\hline 0,55 & 1,5240 & 1,5902 & $-0,066$ & 4,16 \\
\hline 0,60 & 1,3430 & 1,4237 & $-0,081$ & 5,67 \\
\hline 0,65 & 1,2210 & 1,2892 & $-0,068$ & 5,29 \\
\hline 0,70 & 1,1230 & 1,1789 & $-0,056$ & 4,74 \\
\hline 0,75 & 1,0250 & 1,0870 & $-0,062$ & 5,71 \\
\hline 0,80 & 0,9770 & 1,0096 & $-0,033$ & 3,23 \\
\hline 0,85 & 0,9520 & 0,9437 & 0,008 & 0,88 \\
\hline 0,90 & 0,8790 & 0,8869 & $-0,008$ & 0,90 \\
\hline
\end{tabular}


Graficamente tem-se:

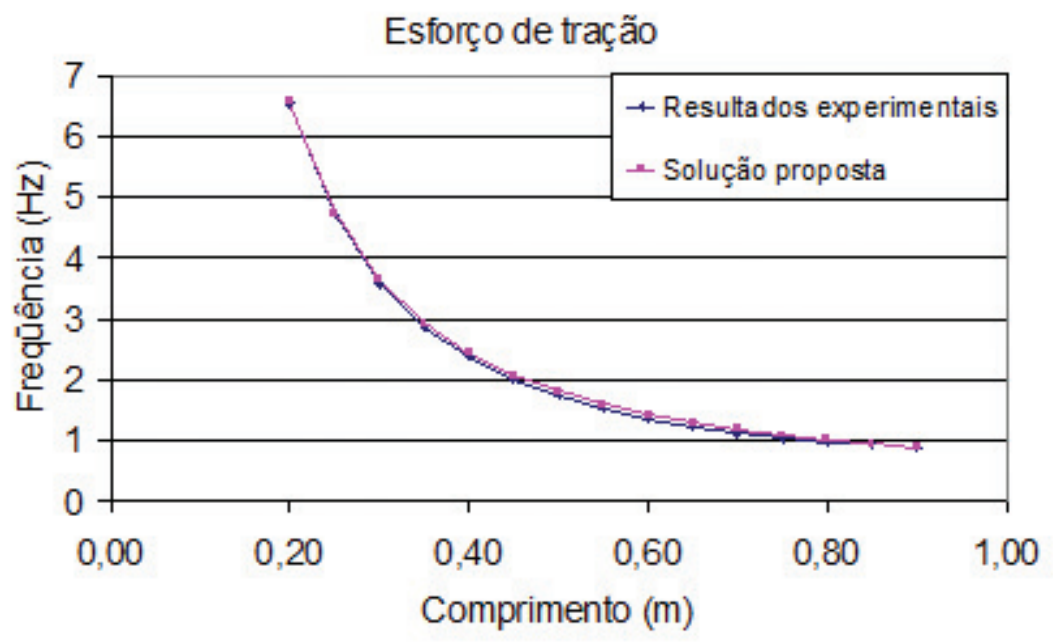

Figura 5.14 - Resultados experimentais de tração e Proposto.

A média das diferenças entre os valores experimentais e a formulação desenvolvida pelo método proposto foi de 0,052 Hz. Em valores percentuais isso representa 3,07\%, considerando todo o conjunto de resultados. Portanto, pelos resultados experimentais obtidos para o esforço de tração, é possível concluir pela propriedade da solução analítica, proposta neste trabalho, para o cálculo da frequência de sistemas não-lineares geométricos. Na análise numérica pelo Método dos Elementos Finitos, quando a força normal é de tração, a situação se repete. A Tabela 5.10 apresenta os resultados da análise não-linear pelo MEF. 
Tabela 5.10 - Resultados da análise não-linear pelo MEF para o esforço de tração.

\begin{tabular}{|c|c|}
\hline \multicolumn{2}{|c|}{ Análise não-linear - Frequências $(\mathrm{Hz})$} \\
\hline Comprimento (m) & Tração \\
\hline 0,20 & 6,5146 \\
\hline 0,25 & 4,7022 \\
\hline 0,30 & 3,6155 \\
\hline 0,35 & 2,9053 \\
\hline 0,40 & 2,4121 \\
\hline 0,45 & 2,0536 \\
\hline 0,50 & 1,7839 \\
\hline 0,55 & 1,5751 \\
\hline 0,60 & 1,4096 \\
\hline 0,65 & 1,2760 \\
\hline 0,70 & 1,1664 \\
\hline 0,75 & 1,0751 \\
\hline 0,80 & 0,9981 \\
\hline 0,85 & 0,9325 \\
\hline 0,90 & 0,8760 \\
\hline
\end{tabular}


As curvas que representam a análise não-linear por Elementos Finitos, a da solução proposta e os resultados experimentais praticamente se sobrepõem, com o pode ser observado no gráfico da Figura 5.15.

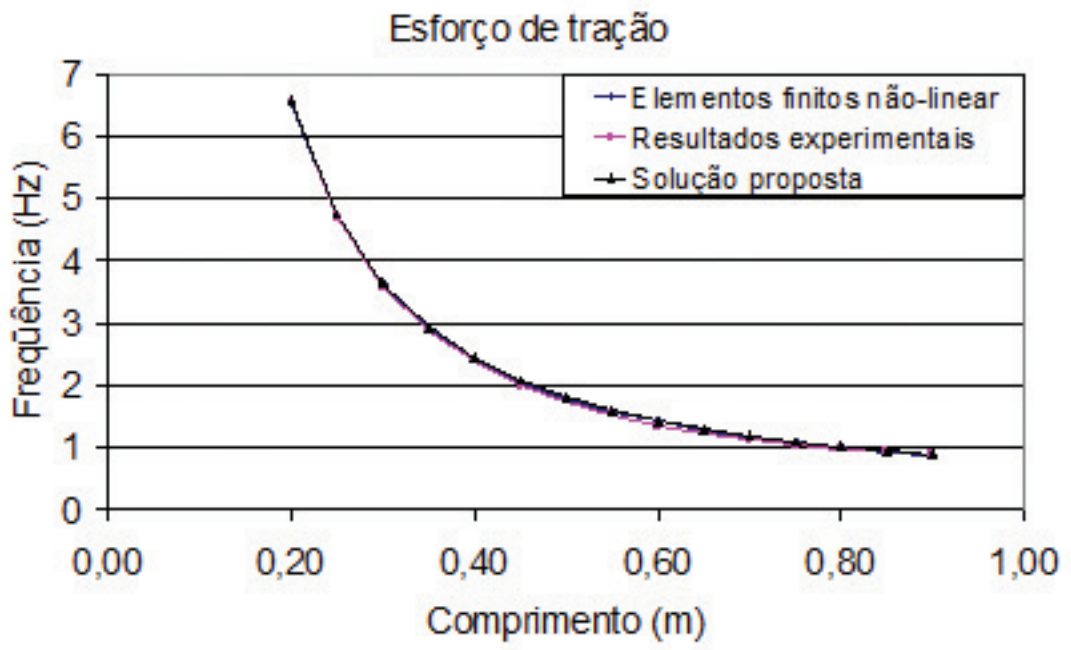

Figura 5.15 - Tração não-linear: Elementos finitos, experimental e proposto.

Quanto às diferenças da análise não-linear, presentes na Tabela 5.11, o panorama permanece semelhante ao obtido para o esforço de compressão, com percentuais elevados entre os resultados lineares e não-lineares, pequenos percentuais entre os não-lineares e a solução proposta e praticamente inexistindo entre os resultados não-lineares e os resultados dos ensaios. 
Tabela 5.11 - Tração - Diferenças percentuais da análise nãolinear pelo MEF.

\begin{tabular}{|c|c|c|c|}
\hline $\begin{array}{c}\text { Comprimento } \\
\text { (m) }\end{array}$ & $\begin{array}{c}\text { Com linear pelo } \\
\text { MEF }\end{array}$ & $\begin{array}{c}\text { Com } \\
\text { experimental }\end{array}$ & $\begin{array}{c}\text { Com } \\
\text { proposto }\end{array}$ \\
\hline 0,20 & 1,789 & 1,446 & $-1,096$ \\
\hline 0,25 & 2,777 & 1,606 & $-0,752$ \\
\hline 0,30 & 3,973 & 1,775 & 0,291 \\
\hline 0,35 & 5,373 & 1,951 & 0,149 \\
\hline 0,40 & 6,962 & 2,139 & 0,033 \\
\hline 0,45 & 8,735 & 2,336 & 1,982 \\
\hline 0,50 & 10,681 & 2,544 & 1,229 \\
\hline 0,55 & 12,794 & 2,759 & 1,432 \\
\hline 0,60 & 15,061 & 2,984 & 2,747 \\
\hline 0,65 & 17,475 & 3,217 & 2,117 \\
\hline 0,70 & 20,026 & 3,457 & 1,294 \\
\hline 0,75 & 22,704 & 3,705 & 2,035 \\
\hline 0,80 & 25,503 & 3,958 & $-0,812$ \\
\hline 0,85 & 28,414 & 4,218 & $-5,391$ \\
\hline 0,90 & 31,429 & 4,482 & $-3,830$ \\
\hline
\end{tabular}




\subsubsection{Análise dos ensaios para a ausência do esforço axial}

Os resultados obtidos nos ensaios horizontais, i.e., sem a influência da carga axial, estão dispostos na Tabela 5.12, ao lado dos correspondentes resultados da solução analítica proposta.

A diferença média percentual para todo o grupo de resultados é de $7,30 \%$ e a diferença absoluta média entre os dois resultados é de 0,008 Hz.

Tabela 5.12 - Sem esforço axial: resultados experimentais e proposto.

\begin{tabular}{|c|c|c|c|c|}
\hline \multicolumn{5}{|c|}{ Sem esforço axial } \\
\hline \multirow{2}{*}{$\begin{array}{c}\text { Comprimento } \\
\text { (m) }\end{array}$} & \multicolumn{2}{|c|}{ Frequências (Hz) } & \multicolumn{2}{|c|}{ Diferenças } \\
\hline & $\begin{array}{c}\text { Resultados } \\
\text { experimentais }\end{array}$ & $\begin{array}{l}\text { Solução } \\
\text { proposta }\end{array}$ & $\mathrm{Hz}$ & $\%$ \\
\hline 0,20 & 6,3230 & 6,4479 & $-0,125$ & 1,94 \\
\hline 0,25 & 4,3700 & 4,6084 & $-0,238$ & 5,17 \\
\hline 0,30 & 3,4180 & 3,5017 & $-0,084$ & 2,39 \\
\hline 0,35 & 2,7100 & 2,7756 & $-0,066$ & 2,36 \\
\hline 0,40 & 2,2220 & 2,2691 & $-0,047$ & 2,08 \\
\hline 0,45 & 1,8550 & 1,8995 & $-0,044$ & 2,34 \\
\hline 0,50 & 1,6110 & 1,6199 & $-0,009$ & 0,55 \\
\hline 0,55 & 1,4160 & 1,4025 & 0,013 & 0,96 \\
\hline 0,60 & 1,2450 & 1,2295 & 0,015 & 1,26 \\
\hline
\end{tabular}




\begin{tabular}{|c|c|c|c|c|}
\hline \multicolumn{5}{|c|}{ Sem esforço axial } \\
\hline \multirow{2}{*}{$\begin{array}{c}\text { Comprimento } \\
\text { (m) }\end{array}$} & \multicolumn{2}{|c|}{ Frequências $(\mathrm{Hz})$} & \multicolumn{2}{|c|}{ Diferenças } \\
\hline & $\begin{array}{c}\text { Resultados } \\
\text { experimentais }\end{array}$ & $\begin{array}{l}\text { Solução } \\
\text { proposta }\end{array}$ & $\mathrm{Hz}$ & $\%$ \\
\hline 0,65 & 1,1470 & 1,0892 & 0,058 & 5,31 \\
\hline 0,70 & 1,0500 & 0,9735 & 0,077 & 7,86 \\
\hline 0,75 & 0,9770 & 0,8768 & 0,100 & 11,43 \\
\hline 0,80 & 0,9520 & 0,7950 & 0,157 & 19,75 \\
\hline 0,85 & 0,8790 & 0,7250 & 0,154 & 21,23 \\
\hline 0,90 & 0,8300 & 0,6647 & 0,165 & 24,86 \\
\hline
\end{tabular}

A curva com a solução dada pela Eq. (4.19) tem a tendência de sobrepor-se à experimental, como pode ser visto no gráfico da Figura 5.16.

É importante ressaltar que, para o comprimento igual a $70 \mathrm{~cm}$ e superiores, os modelos apresentavam visível configuração deformada, o que os coloca fora da hipótese cinemática assumida, como já foi mencionado.

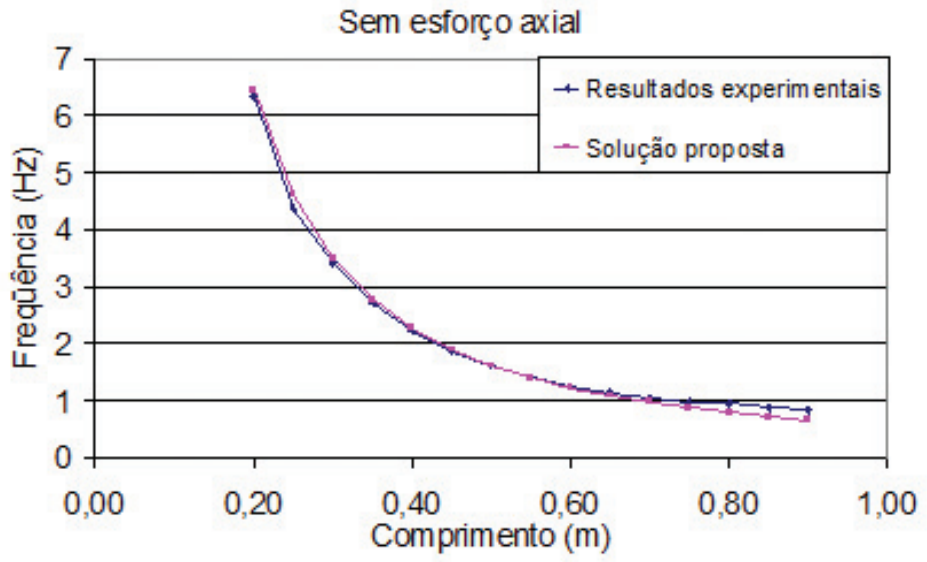

Figura 5.16 - CP horizontais: Resultados experimentais e proposto. 
As análises não-lineares pelo Método dos Elementos Finitos forneceram os resultados presentes na Tabela 5.13.

Tabela 5.13 - Resultados da análise não-linear pelo MEF sem a consideração do esforço normal.

\begin{tabular}{|c|c|}
\hline \multicolumn{2}{|c|}{ Análise não-linear - Frequências $(\mathrm{Hz})$} \\
\hline Comprimento (m) & Sem esforço normal \\
\hline 0,20 & 6,3621 \\
\hline 0,25 & 4,5450 \\
\hline 0,30 & 3,4544 \\
\hline 0,35 & 2,7416 \\
\hline 0,40 & 2,2473 \\
\hline 0,45 & 1,8896 \\
\hline 0,50 & 1,6222 \\
\hline 0,55 & 1,4174 \\
\hline 0,60 & 1,2575 \\
\hline 0,65 & 1,1308 \\
\hline 0,70 & 1,0291 \\
\hline 0,75 & 0,9466 \\
\hline 0,80 & 0,8790 \\
\hline 0,85 & 0,8231 \\
\hline 0,90 & 0,7763 \\
\hline
\end{tabular}


Os resultados não-lineares pelo MEF, os da solução proposta e os resultados dos ensaios estão praticamente sobrepostos, conforme se vê na Figura 5.17, o que revela a adequabilidade da solução analítica, também, para o cálculo da frequência de sistemas exclusivamente elástico-llineares.

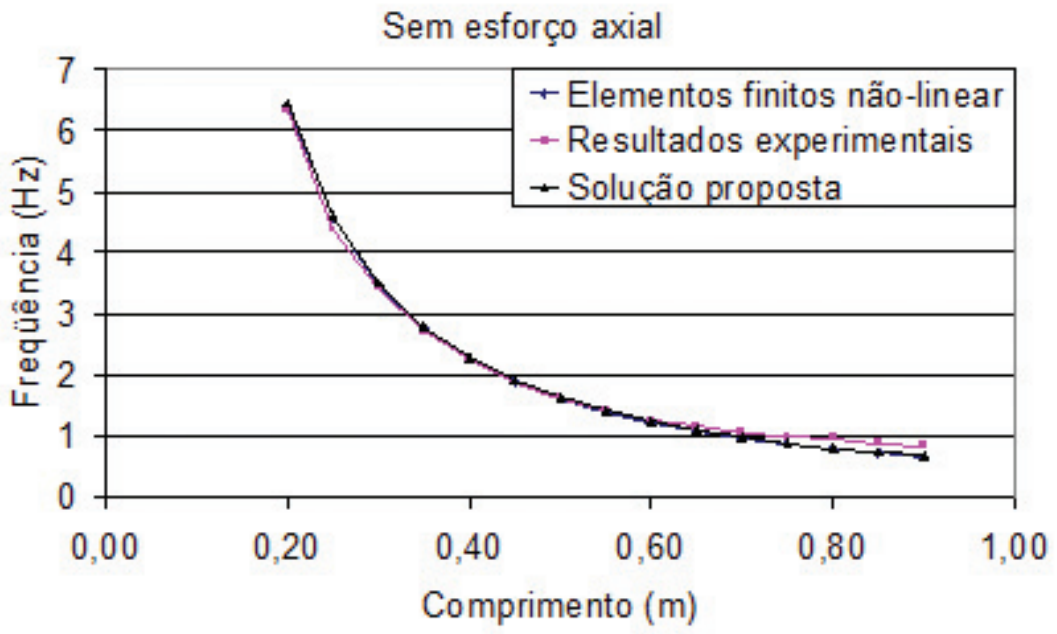

Figura 5.17 - Sem esforço axial não-linear: Elementos finitos, experimental e proposto.

As diferenças percentuais entre a análise não-linear pelo MEF e os resultados experimentais mantêm a tendência de crescimento à medida que os modelos tornam-se longos, chagando a alcançar 25,89\%, pelos motivos já expostos.

Em relação ao método proposto, a análise não-linear pelo MEF segue com resultados muito próximos aos dados pela Eq. (4.19). 
Tabela 5.14 - Sem esforço axial - Diferenças percentuais da análise não-linear pelo MEF.

\begin{tabular}{|c|c|c|c|}
\hline $\begin{array}{l}\text { Comprimento } \\
\text { (m) }\end{array}$ & $\begin{array}{c}\text { Com linear por } \\
\text { EF }\end{array}$ & $\begin{array}{c}\text { Com } \\
\text { experimental }\end{array}$ & $\begin{array}{c}\text { Com } \\
\text { proposto }\end{array}$ \\
\hline 0,20 & 0,00 & 1,19 & 0,77 \\
\hline 0,25 & 0,00 & 4,45 & 0,77 \\
\hline 0,30 & 0,00 & 1,64 & 0,77 \\
\hline 0,35 & 0,00 & 1,61 & 0,77 \\
\hline 0,40 & 0,00 & 1,32 & 0,78 \\
\hline 0,45 & 0,00 & 1,58 & 0,78 \\
\hline 0,50 & 0,00 & 0,23 & 0,78 \\
\hline 0,55 & 0,00 & 1,76 & 0,79 \\
\hline 0,60 & 0,00 & 2,06 & 0,79 \\
\hline 0,65 & 0,00 & 6,15 & 0,80 \\
\hline 0,70 & 0,00 & 8,73 & 0,80 \\
\hline 0,75 & 0,00 & 12,33 & 0,81 \\
\hline 0,80 & 0,00 & 20,72 & 0,81 \\
\hline 0,85 & 0,00 & 22,22 & 0,82 \\
\hline 0,90 & 0,00 & 25,89 & 0,82 \\
\hline
\end{tabular}


Os resultados experimentais podem então ser reunidos em um único gráfico (Figura 5.18), para que se perceba o conjunto de diferentes resultados que aparecem conforme a solicitação axial imposta aos modelos físicos.

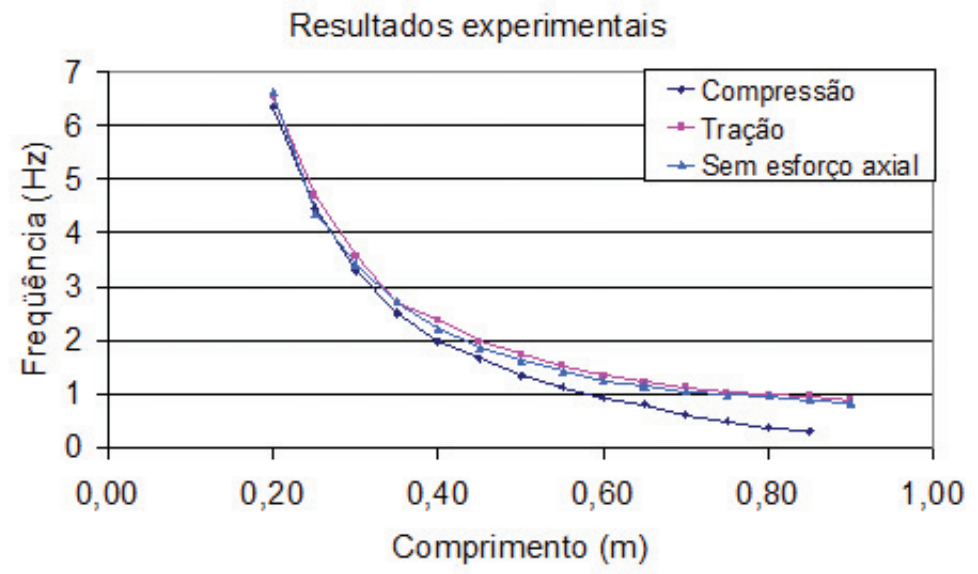

Figura 5.18 - Resultados experimentais.

O gráfico da Figura 5.19 reúne os resultados experimentais e os da solução proposta pela Eq. (4.19).

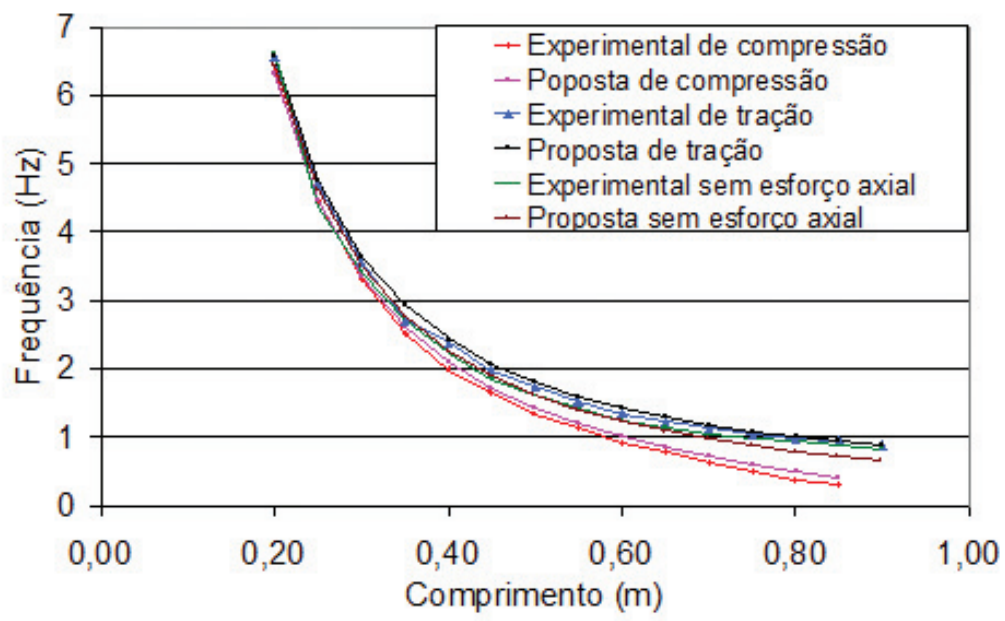

Figura 5.19 - Resultados experimentais e da solução proposta. 


\subsubsection{Análise dos ensaios exclusivamente com o peso próprio}

A solução dinâmica proposta neste trabalho, para os ensaios com a influência exclusiva do peso próprio, estão baseados na expressão (4.21), na qual fez-se a correção da massa na extremidade devida a influência do acelerômetro e sua base magnética, conforme recomendado no item 4. De forma semelhante, foi feito na modelagem pelo Método dos Elementos Finitos, com o lançamento dessa massa adicional e da força axial correspondente, atribuídas, no modelo numérico, no ponto relativo à aplicação do sensor.

A carga crítica de flambagem de barras submetidas exclusivamente ao seu próprio peso pode ser analisada pela estática ou pela dinâmica. No primeiro processo encontram-se a formulação de Euler-Greenhill e a formulação por autovalores desenvolvida pelo Método dos Elementos Finitos, conforme descrito na Eq. (3.10). No segundo processo, a solução pode ser obtida dinamicamente pelo método proposto neste trabalho ou também pela solução, não-linear, por autovalores pelo Método dos Elementos Finitos.

A Tabela 5.15 apresenta os resultados experimentais obtidos e as diferenças guardadas com as mencionadas soluções dinâmicas. A diferença entre os resultados experimentais e a análise dinâmica linear pelo MEF chega a alcançar mais de $15 \%$, enquanto que na comparação com as análises não-lineares esse valor fica em torno de 3\%. Na avaliação dinâmica se pode observar a boa aproximação das soluções não-lineares com os resultados experimentais e um afastamento desses com os resultados lineares. 


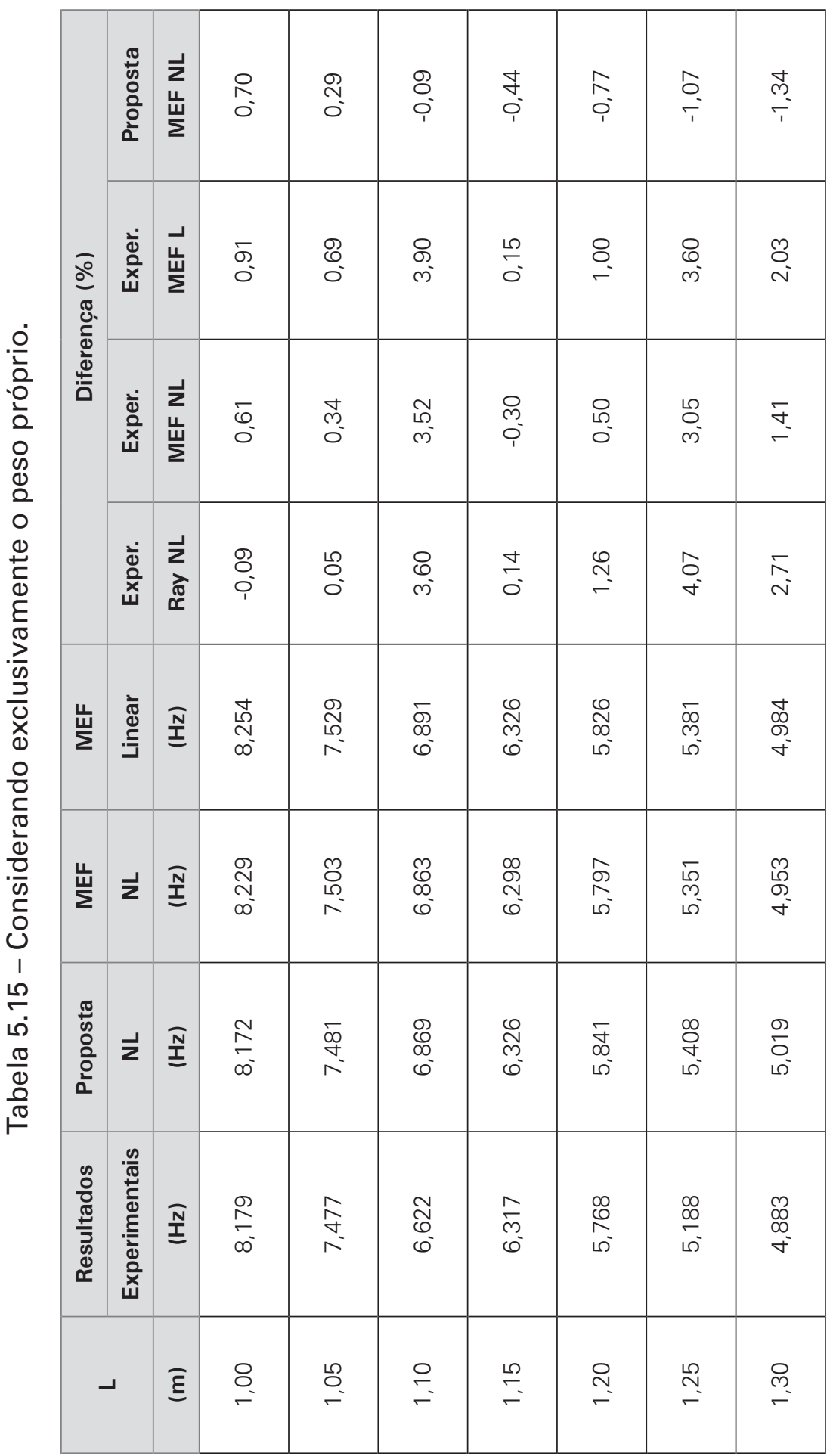




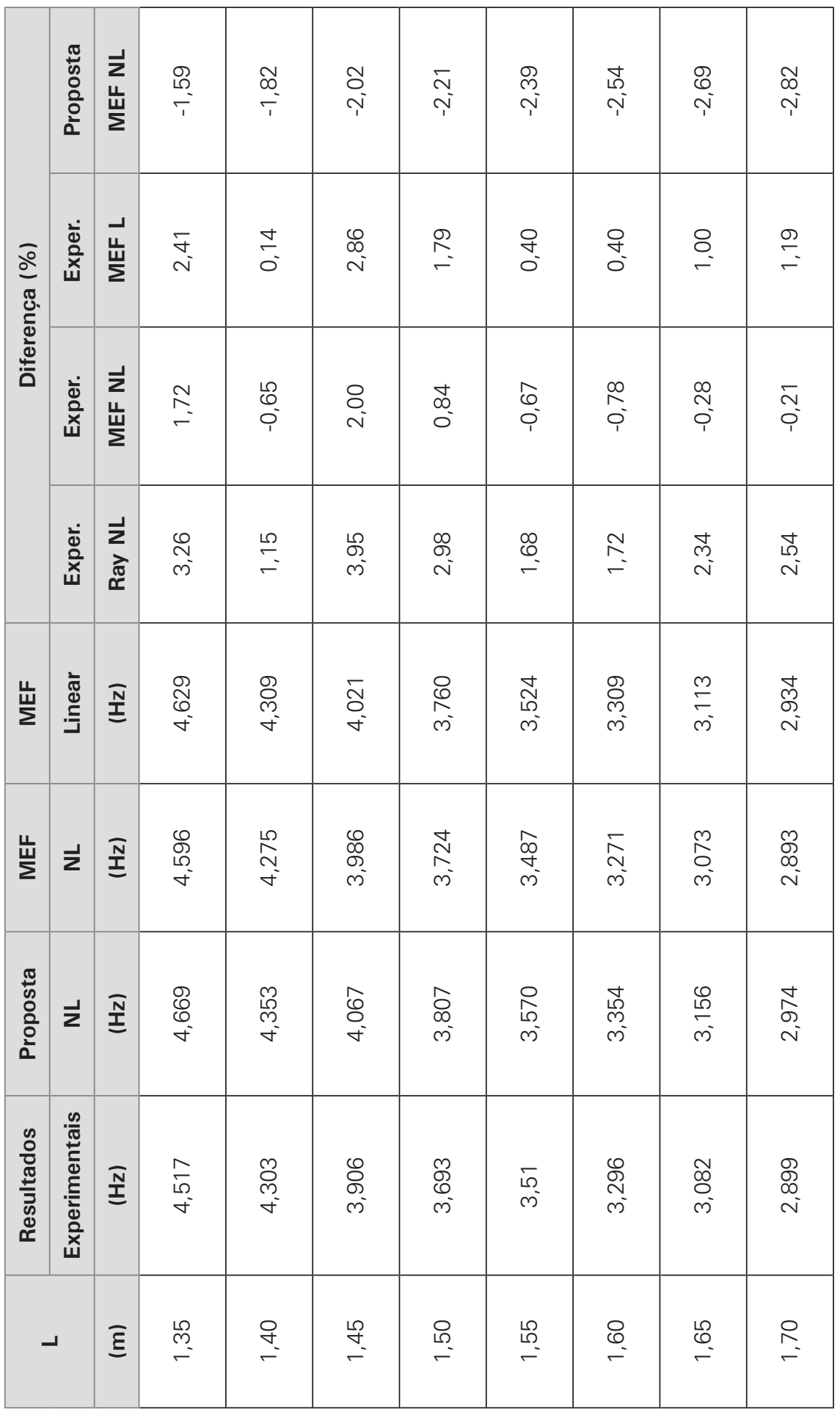




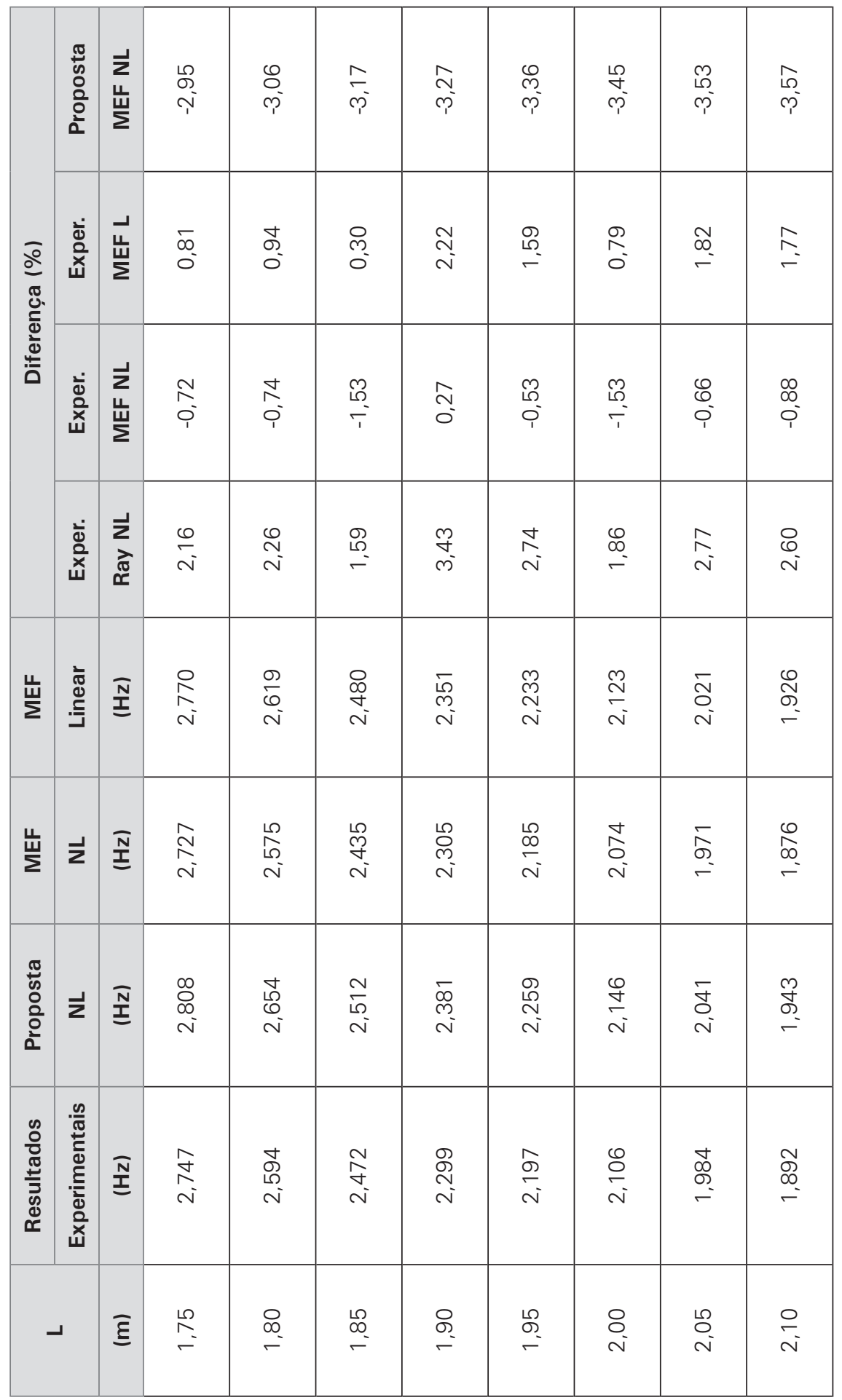




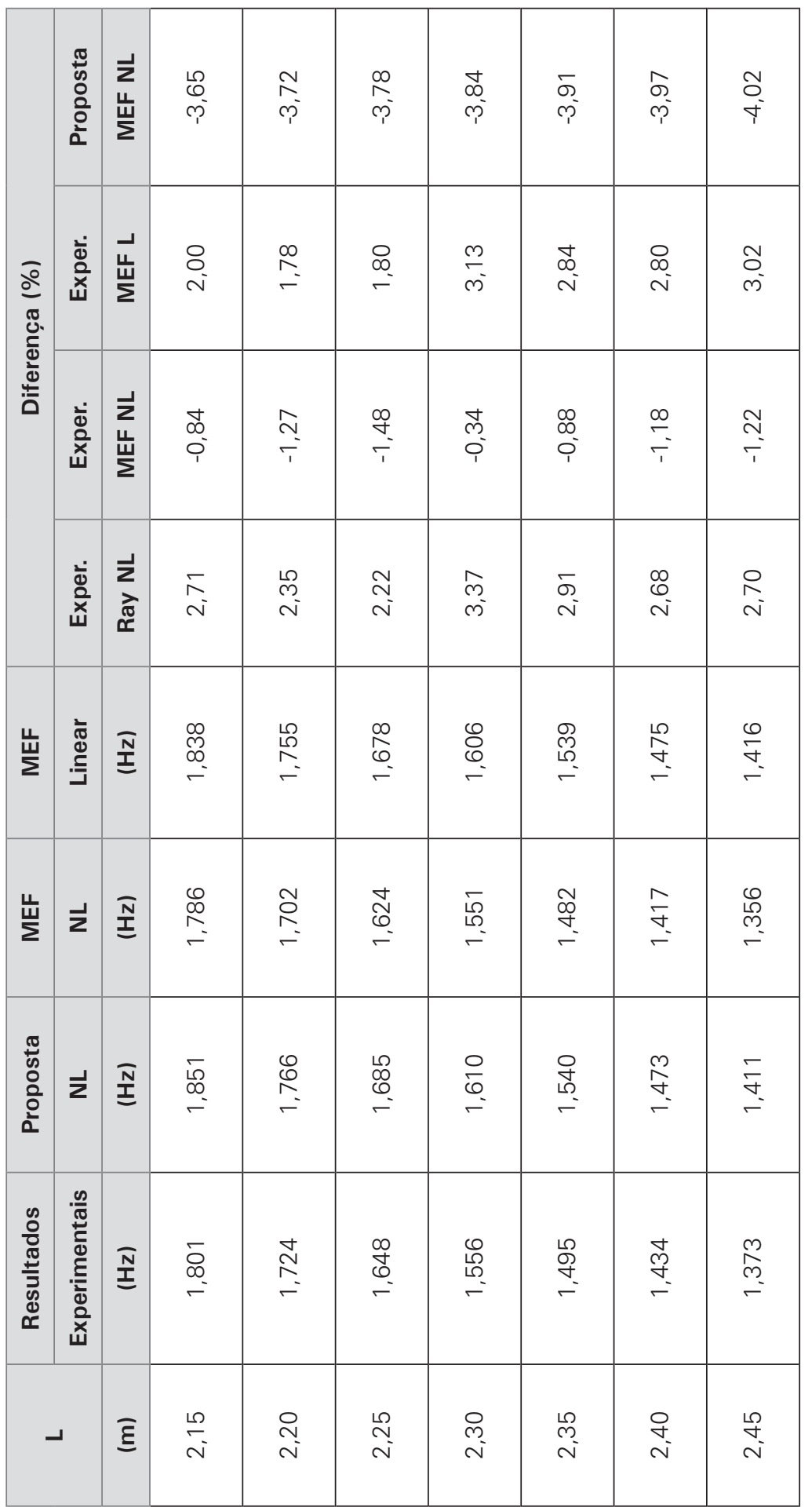




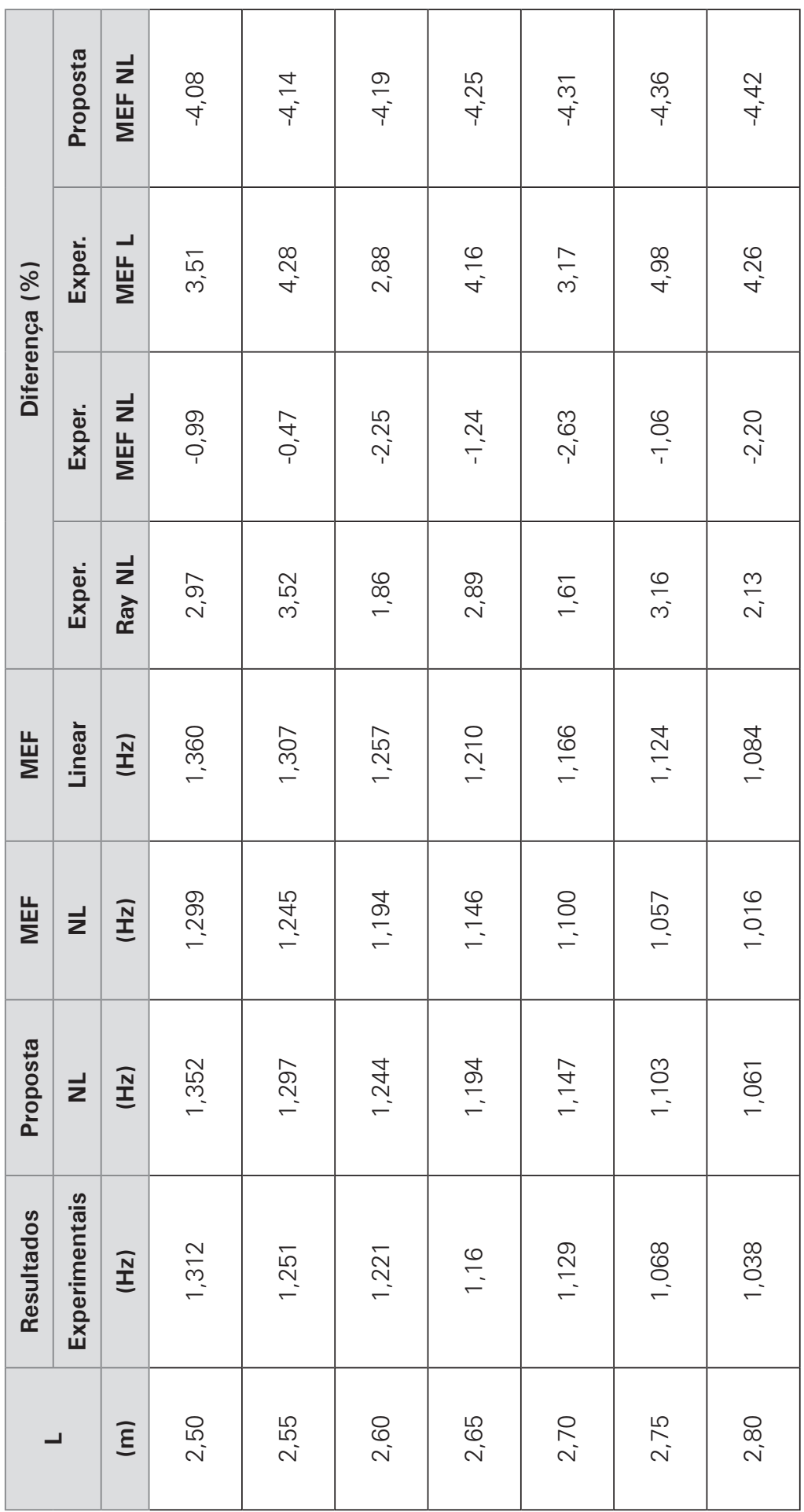




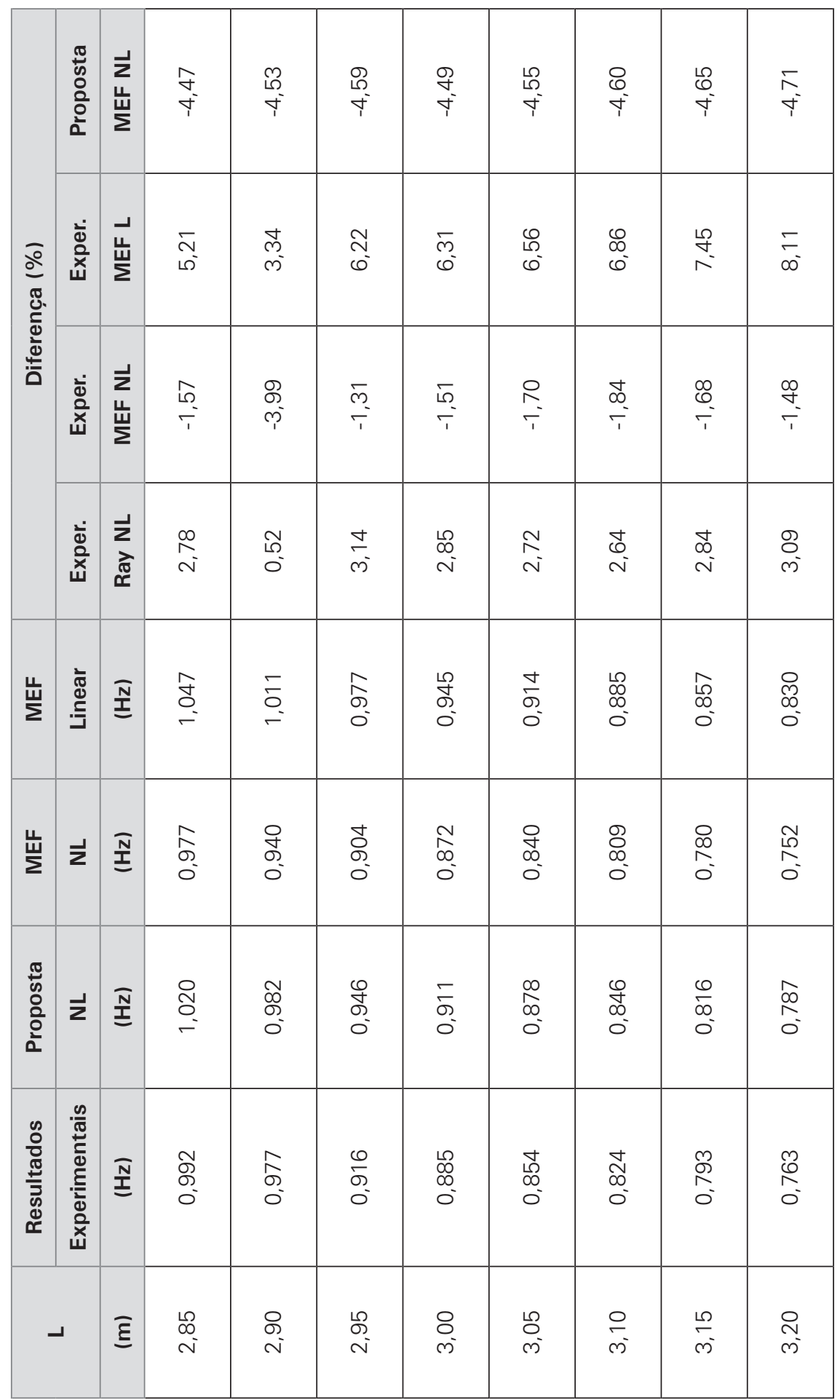




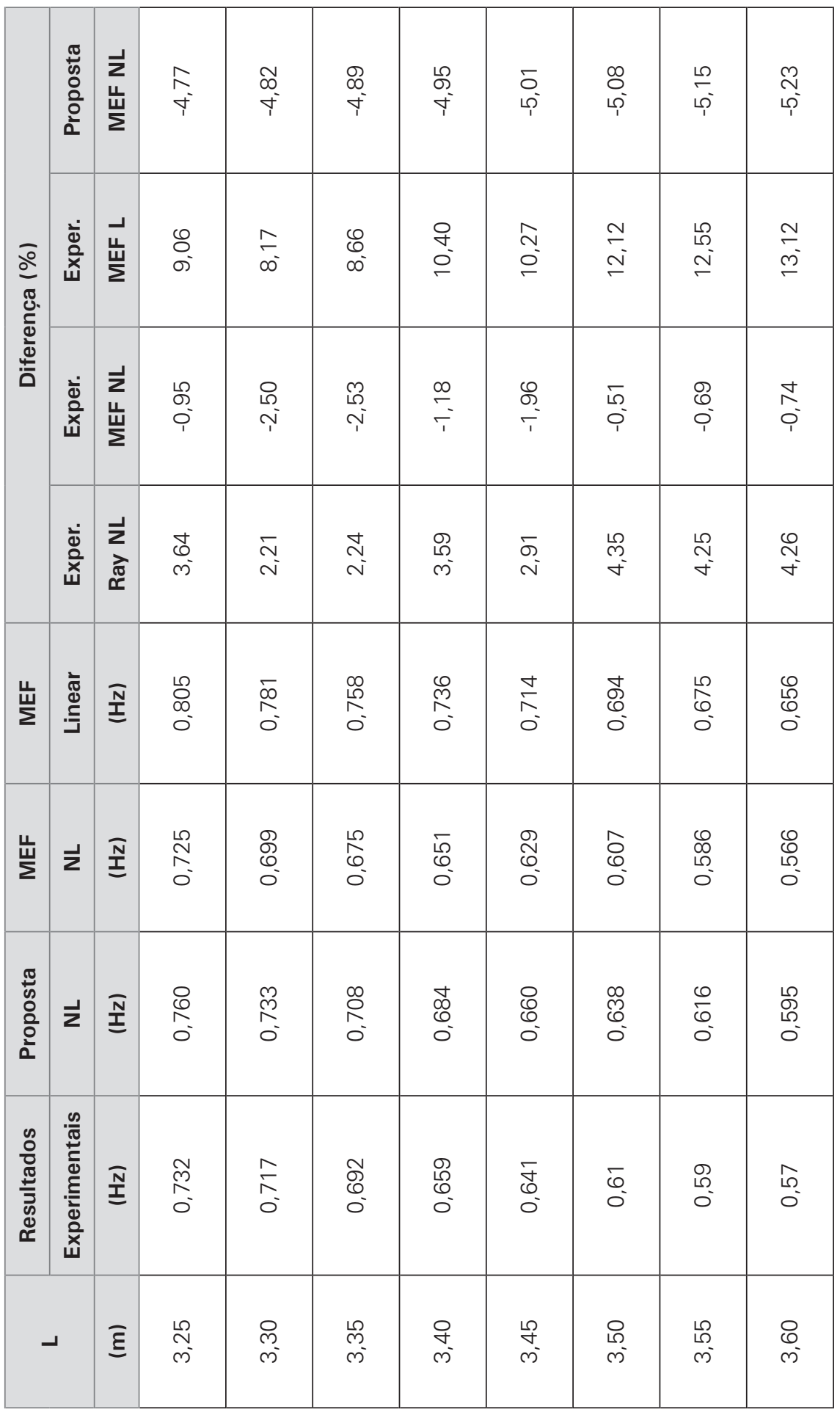




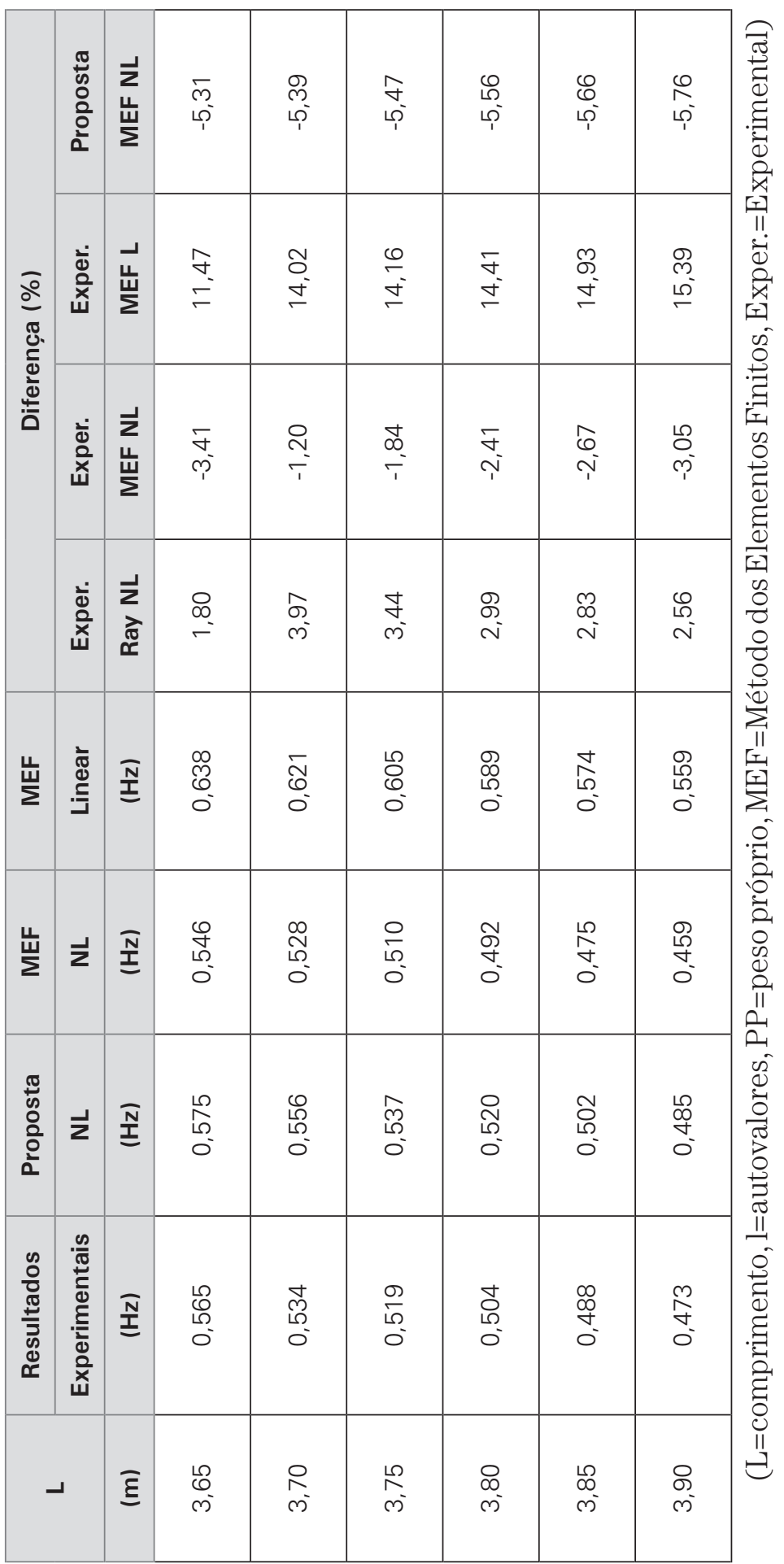


Os gráficos da Figura 5.20 trazem as curvas dos resultados dinâmicos e uma ampliação da região de comprimentos mais elevados, onde se torna mais evidente a influência da rigidez geométrica.

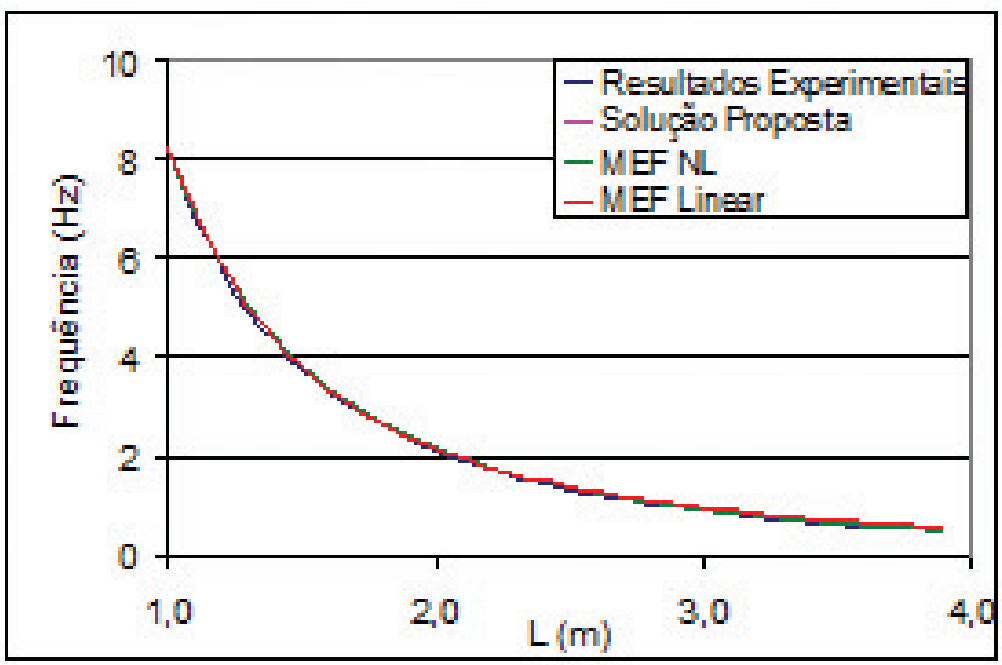

(a) todo o ensaio.

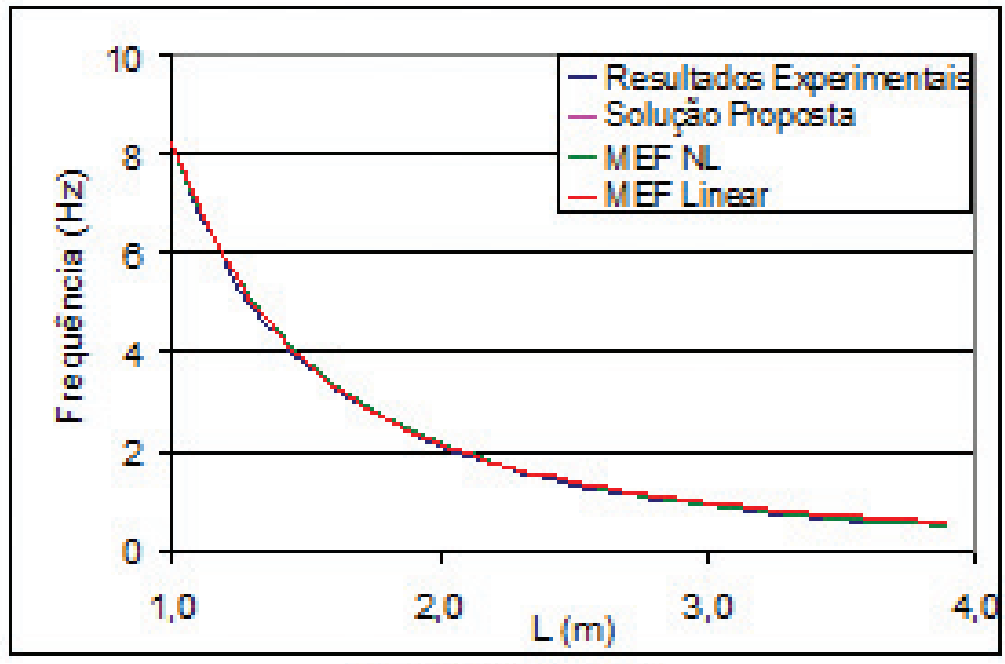

(a) todo o ensaio.

Figura 5.20 - Resultados do ensaio como peso próprio-tubo. 
Pela Figura 5.21 fica clara a tendência de que o comprimento crítico de flambagem corresponda ao mesmo valor, tanto pela análise estática de Euler-Greenhill quanto pelos resultados experimentais.

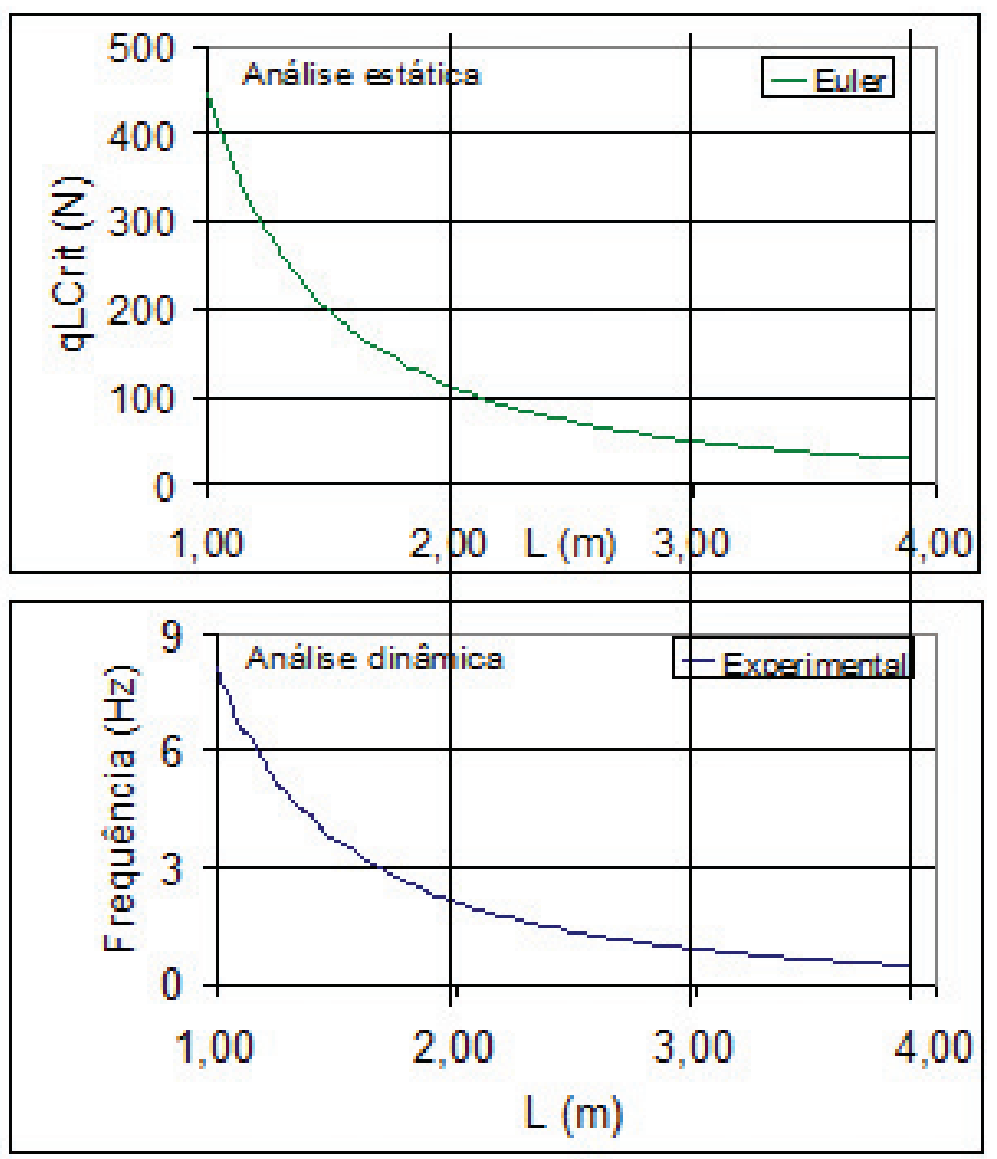

Figura 5.21 - Resultados do ensaio com o peso próprio.

As diferenças entre os resultados obtidos pela formulação de Euler-Greenhill e a de Elementos Finitos situam-se logo acima dos 2\%. A Tabela 5.16 e a Figura 5.22 apresentam os resultados dessas análises. 


\begin{tabular}{|c|c|c|c|c|c|c|c|c|c|}
\hline 这 & $0^{\circ}$ & ৪ & $\bar{\infty}$ & $\stackrel{\cong}{\approx}$ & ש్ & مْ & $\stackrel{Q}{q}$ & $\stackrel{\infty}{\stackrel{\infty}{\sim}}$ & ஓ \\
\hline$\frac{\grave{\varpi}}{\bar{\Xi}}$ & $\bar{\Sigma}$ & 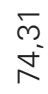 & $\stackrel{\hat{m}}{\hat{n}}$ & $\begin{array}{l}0 \\
0 \\
0 \\
0\end{array}$ & $\begin{array}{l}\text { S } \\
\infty \\
0\end{array}$ & $\begin{array}{l}\text { గ్ } \\
\text { లో }\end{array}$ & $\frac{\sigma}{\sigma}$ & $\begin{array}{l}\infty \\
\infty \\
\infty \\
\infty \\
\infty^{-}\end{array}$ & $\begin{array}{l}8 \\
0 \\
0 \\
0^{\circ}\end{array}$ \\
\hline 岀 & $\bar{\Sigma}$ & $\frac{m}{\stackrel{n}{N}}$ & $\begin{array}{l}0 \\
\mathbb{N} \\
N\end{array}$ & $\frac{\infty}{\stackrel{\infty}{\infty}}$ & $\begin{array}{l}0 \\
0 \\
0\end{array}$ & \begin{tabular}{l}
$\circ$ \\
$\stackrel{0}{0}$ \\
\multirow{0}{*}{}
\end{tabular} & 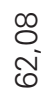 & $\begin{array}{l}\text { ○ } \\
\infty \\
\text { న } \\
\end{array}$ & $\begin{array}{l}\text { ৫ } \\
\text { ல }\end{array}$ \\
\hline z & 岀 & 으 & 음 & 유 & 유 & 음 & 음 & 음 & 음 \\
\hline$\frac{0}{a}$ & $\bar{\Xi}$ & $\underset{\sigma}{\stackrel{\leftarrow}{*}}$ & $\begin{array}{l}0 \\
\text { m. } \\
0^{\circ}\end{array}$ & \begin{tabular}{l}
$\infty$ \\
\multirow{0}{*}{}
\end{tabular} & $\begin{array}{l}0 \\
0 \\
0\end{array}$ & $\underset{0}{\stackrel{N}{N}}$ & $\begin{array}{l}\text { D } \\
\sigma^{-}\end{array}$ & $\begin{array}{l}0 \\
0 \\
6\end{array}$ & $\stackrel{\infty}{\circ}$ \\
\hline 艺 & - & $\begin{array}{l}\stackrel{+}{\leftarrow} \\
\stackrel{-}{-}\end{array}$ & $\begin{array}{l}\stackrel{m}{\sigma} \\
=\end{array}$ & $\begin{array}{l}\hat{0} \\
0 \\
-\end{array}$ & $\begin{array}{l}0 \\
\vdots \\
\circ\end{array}$ & $\begin{array}{l}\stackrel{\circ}{0} \\
\text { ") }\end{array}$ & $\begin{array}{l}\infty \\
\circ \\
0\end{array}$ & $\begin{array}{l}\text { 乃 } \\
\infty^{\circ}\end{array}$ & $\frac{⿱ 亠}{\stackrel{\circ}{\circ}}$ \\
\hline 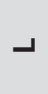 & $\overline{\underline{\xi}}$ & $\stackrel{\substack{+\sim}}{\sim}$ & $\begin{array}{l}\text { ○ } \\
\stackrel{1}{\sim}\end{array}$ & $\begin{array}{l}\stackrel{L}{\llcorner} \\
\sim \\
\sim\end{array}$ & \begin{tabular}{l}
8 \\
\multirow{1}{*}{}
\end{tabular} & $\begin{array}{l}\stackrel{L}{0} \\
\stackrel{0}{N}\end{array}$ & $\stackrel{\circ}{\stackrel{\circ}{N}}$ & 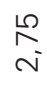 & $\begin{array}{l}\circ \\
\infty \\
\sim\end{array}$ \\
\hline 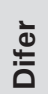 & $0^{\circ}$ & $\begin{array}{l}\infty \\
0 \\
0\end{array}$ & $\underset{-}{\stackrel{g}{*}}$ & ס & $\begin{array}{l}\underset{+}{\sim} \\
\sim\end{array}$ & $\bar{N}$ & $\bar{\sigma}$ & $\begin{array}{l}\text { m } \\
\text { m. }\end{array}$ & $\frac{0}{\text { m. }}$ \\
\hline$\frac{\frac{亠}{5}}{\text { ய }}$ & $\underline{\Sigma}$ & 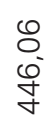 & 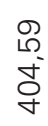 & $\begin{array}{l}10 \\
0 \\
00^{\circ} \\
0 \\
ల\end{array}$ & 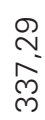 & $\begin{array}{l}\hat{N} \\
\text { Dे } \\
\text { Dे }\end{array}$ & \begin{tabular}{l}
$\infty$ \\
\multirow{+}{\infty}{} \\
$\stackrel{\infty}{\sim}$
\end{tabular} & 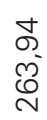 & $\begin{array}{l}\stackrel{+2}{\sim} \\
\underset{+}{+}\end{array}$ \\
\hline$\stackrel{\text { 岀 }}{\Sigma}$ & $\underline{\Xi}$ & 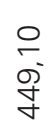 & $\begin{array}{l}\bar{\tau} \\
\bar{\sigma} \\
\bar{\sigma}\end{array}$ & $\begin{array}{l}+ \\
0 \\
0 \\
\infty\end{array}$ & 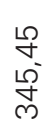 & $\begin{array}{l}\bar{\alpha} \\
\frac{\infty}{m} \\
\frac{\infty}{2}\end{array}$ & 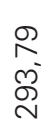 & $\begin{array}{l}\stackrel{\text { O }}{-} \\
\stackrel{N}{\sim}\end{array}$ & $\begin{array}{l}m \\
m \\
\stackrel{N}{N} \\
\sim\end{array}$ \\
\hline z & 岀 & 유 & 요 & 유 & 윰 & 요 & 윰 & 요 & 은 \\
\hline : & $\underline{\Sigma}$ & $\stackrel{m}{N}$ & $\begin{array}{l}\llcorner \\
\infty \\
\sim\end{array}$ & $\begin{array}{l}\text { o } \\
\text { v }\end{array}$ & $\frac{\circ}{\text { m. }}$ & $\begin{array}{l}\underset{N}{m} \\
\text { N }\end{array}$ & $\begin{array}{l}\text { m } \\
\text { m. }\end{array}$ & $\begin{array}{l}0 \\
\text { cे } \\
\text { n. }\end{array}$ & $\begin{array}{l}\infty \\
\stackrel{\rho}{0} \\
\text { m. }\end{array}$ \\
\hline 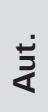 & - & 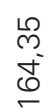 & 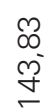 & 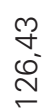 & $\begin{array}{l}\bar{\sigma} \\
\tilde{E}\end{array}$ & $\begin{array}{l}\text { ম } \\
\text { ळ' }\end{array}$ & $\begin{array}{l}10 \\
0 \\
\infty \\
\infty\end{array}$ & $\begin{array}{l}0 \\
0 \\
\infty^{-} \\
N\end{array}$ & $\begin{array}{l}N \\
0 \\
0 \\
\end{array}$ \\
\hline 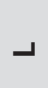 & $\bar{\xi}$ & 8 & $\stackrel{\rho}{\circ}$ & $\stackrel{0}{\check{-}}$ & $\stackrel{\llcorner 0}{\check{\tau}}$ & $\stackrel{\overbrace{}}{\stackrel{ }{-}}$ & $\stackrel{\llcorner}{\sim}$ & pి & $\stackrel{\stackrel{m}{m}}{-}$ \\
\hline
\end{tabular}




\begin{tabular}{|c|c|c|c|c|c|c|c|c|c|}
\hline 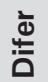 & ¿0 & $\underset{\sim}{\widetilde{V}}$ & $\stackrel{\llcorner}{\check{\tau}}$ & Oo & $\hat{\sim}$ & $\begin{array}{l}\circ \\
\stackrel{0}{N} \\
\sim\end{array}$ & $\begin{array}{l}\text { \& } \\
\text { ' }\end{array}$ & $\hat{m}$ & $\bar{m}$ \\
\hline$\frac{\text { ప }}{\overline{\mathbf{W}}}$ & $\bar{z}$ & $\begin{array}{l}\text { హ̄ } \\
\text { டீ }\end{array}$ & 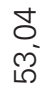 & 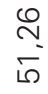 & $\begin{array}{l}0 \\
\stackrel{0}{ } \\
\sigma^{\circ}\end{array}$ & 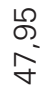 & $\begin{array}{l}\stackrel{\checkmark}{\checkmark} \\
\underset{+}{+}\end{array}$ & $\begin{array}{l}\text { ద̊ } \\
\text { \& }\end{array}$ & 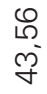 \\
\hline 岌 & $\bar{\Sigma}$ & 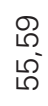 & 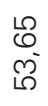 & $\begin{array}{l}\bar{\infty} \\
\bar{\Sigma}\end{array}$ & $\begin{array}{l}m \\
\infty \\
\infty \\
\infty\end{array}$ & $\frac{\llcorner}{\check{\sigma}}$ & 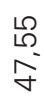 & $\begin{array}{l}\mathcal{N} \\
\text { Ō } \\
\text { Oे }\end{array}$ & $\begin{array}{l}\hat{\imath} \\
\text { f }\end{array}$ \\
\hline${ }^{\circ} \mathbf{z}$ & 出 & 으 & 은 & 으 & $\stackrel{\text { ○ }}{-}$ & 음 & ○ & 음 & ○ \\
\hline$\frac{0}{\alpha}$ & $\underline{z}$ & $\stackrel{\curvearrowright}{N}$ & $\stackrel{\text { }}{N}$ & ন & $\begin{array}{l}\mathscr{L} \\
\end{array}$ & $\begin{array}{l}8 \\
0 \\
\end{array}$ & $\underset{\infty}{\infty}$ & S & $\begin{array}{l}\stackrel{2}{\circ} \\
\infty \\
\infty\end{array}$ \\
\hline 䒕 & - & $\frac{N}{N}$ & $\stackrel{m}{M}$ & $\begin{array}{l}0 \\
\text { D } \\
6\end{array}$ & $\frac{N}{\sigma^{-}}$ & $\begin{array}{l}\stackrel{+}{+} \\
0\end{array}$ & $\begin{array}{l}\text { I } \\
0\end{array}$ & $\begin{array}{l}\delta \\
\infty \\
\sigma^{-}\end{array}$ & 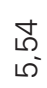 \\
\hline ـ & छ్ & $\begin{array}{l}\stackrel{1}{\infty} \\
\sim \\
\sim\end{array}$ & $\begin{array}{l}\text { ৪ } \\
\text { N }\end{array}$ & $\stackrel{\stackrel{\leftrightarrow}{\leftrightarrow}}{\sim}$ & $\begin{array}{l}\text { ৪ } \\
\text { लं }\end{array}$ & $\begin{array}{l}\stackrel{2}{O} \\
\text { ले }\end{array}$ & $\frac{O}{\text { m}^{-}}$ & $\frac{L 0}{\Gamma^{-}}$ & $\begin{array}{l}\stackrel{ }{N} \\
\text { m. }\end{array}$ \\
\hline 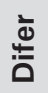 & $\stackrel{0}{0}$ & $\frac{\stackrel{N}{\check{m}}}{\bar{r}}$ & $\frac{\circ}{m^{-}}$ & 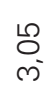 & $\begin{array}{l}\stackrel{\infty}{\sim} \\
\sim\end{array}$ & $\begin{array}{l}\text { ৪ } \\
\text { N }\end{array}$ & $\begin{array}{l}\circ \\
\sim \\
\sim\end{array}$ & $\begin{array}{l}8 \\
\mathbb{1} \\
\sim\end{array}$ & $\begin{array}{l}\infty \\
\stackrel{\circ}{\circ} \\
\sim\end{array}$ \\
\hline$\frac{\frac{\grave{d}}{5}}{\text { ய }}$ & $\bar{z}$ & $\begin{array}{l}\infty \\
\stackrel{1}{N} \\
\stackrel{N}{N}\end{array}$ & $\begin{array}{l}\stackrel{0}{\sim} \\
\stackrel{\sim}{\sim}\end{array}$ & $\begin{array}{l}\stackrel{10}{N} \\
\infty^{\circ} \\
\stackrel{\circ}{\sim}\end{array}$ & $\begin{array}{l}\hat{6} \\
\omega^{\circ} \\
\infty \\
-\end{array}$ & $\begin{array}{l}\stackrel{⿱}{\sim} \\
\underset{\Sigma}{\sim}\end{array}$ & $\begin{array}{l}\text { ¿ } \\
\text { లె } \\
\text { ర్ }\end{array}$ & $\begin{array}{l}\stackrel{\llcorner}{m} \\
\stackrel{0}{0}\end{array}$ & $\begin{array}{l}L \\
0 \\
00^{\circ} \\
\square\end{array}$ \\
\hline$\frac{\text { 岀 }}{\Sigma}$ & $\bar{z}$ & $\begin{array}{l}\text { Uి } \\
\text { Dે } \\
\text { N }\end{array}$ & $\begin{array}{l}\frac{m}{N} \\
\infty^{-} \\
\frac{\sim}{N}\end{array}$ & $\begin{array}{l}\stackrel{D}{N} \\
\underset{\sim}{\sim}\end{array}$ & 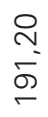 & 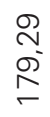 & 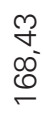 & $\begin{array}{l}\circ \\
\llcorner 0 \\
\infty \\
\llcorner 0\end{array}$ & \begin{tabular}{l}
$\overline{+}$ \\
g্ \\
\multirow{2}{*}{}
\end{tabular} \\
\hline z & 岀 & 유 & 옹 & 유 & 유 & 유 & 유 & 유 & 유 \\
\hline 음 & $\bar{z}$ & $\frac{\stackrel{P}{r}}{m^{-}}$ & $\begin{array}{l}\infty \\
\infty \\
\text { m- }\end{array}$ & $\begin{array}{l}\text { J } \\
\text { m }\end{array}$ & 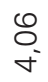 & $\stackrel{\infty}{\underset{\sim}{\sigma}}$ & $\stackrel{\text { p }}{\text { p }}$ & 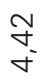 & \begin{tabular}{l}
\multirow{\leftarrow}{*}{} \\
\multirow{\leftarrow}{*}{}
\end{tabular} \\
\hline تُ & - & $\begin{array}{l}\text { \& } \\
\text { ભુ }\end{array}$ & $\begin{array}{l}\stackrel{0}{N} \\
\stackrel{N}{0}\end{array}$ & 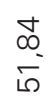 & \begin{tabular}{l}
$\infty$ \\
\multirow{\gamma}{*}{} \\
\multirow{\gamma}{*}{}
\end{tabular} & $\begin{array}{l}\hat{\infty} \\
\stackrel{\gamma}{\gamma} \\
\text { vo }\end{array}$ & $\begin{array}{l} \pm \\
\stackrel{\Xi}{-}\end{array}$ & $\begin{array}{l}m \\
\infty \\
\infty \\
m\end{array}$ & $\begin{array}{l}\infty \\
\infty \\
\sim \\
\sim \\
m\end{array}$ \\
\hline - & छ & $\stackrel{\text { o }}{\leftarrow}$ & 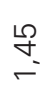 & 옴 & $\stackrel{\llcorner}{\llcorner}$ & $\stackrel{8}{0}$ & 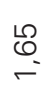 & $\stackrel{?}{\stackrel{2}{r}}$ & $\stackrel{L}{\stackrel{2}{\overbrace{}}}$ \\
\hline
\end{tabular}




\begin{tabular}{|c|c|c|c|c|c|c|c|c|c|}
\hline 㐫 & o & $\stackrel{\stackrel{\sim}{\sim}}{\sim}$ & $\begin{array}{l}\stackrel{ }{\sim} \\
\sim\end{array}$ & $\frac{+}{\sim}$ & $\begin{array}{l}\infty \\
0 \\
\sim\end{array}$ & $\begin{array}{l}\text { O } \\
\text { N }\end{array}$ & 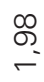 & $\stackrel{g}{\sigma}$ & $\begin{array}{l}\infty \\
\infty \\
-\end{array}$ \\
\hline$\frac{\grave{\varpi}}{\bar{\varpi}}$ & $\grave{z}$ & 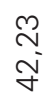 & 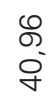 & 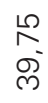 & $\begin{array}{l}\text { న } \\
\infty \\
\infty \\
\text { ల' }\end{array}$ & $\stackrel{\infty}{\stackrel{\infty}{+}}$ & $\begin{array}{l}\tau \\
\dot{\nabla} \\
\text { ల }\end{array}$ & $\begin{array}{l}\text { m } \\
\stackrel{10}{m}\end{array}$ & $\begin{array}{l}\stackrel{\sim}{f} \\
\stackrel{+}{\text { ले }}\end{array}$ \\
\hline$\frac{\text { 岀 }}{\Sigma}$ & 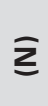 & $\stackrel{\infty}{\stackrel{\infty}{\sim}}$ & $\begin{array}{l}0 \\
\infty \\
-\end{array}$ & $\begin{array}{l}0 \\
0 \\
0 \\
\circ\end{array}$ & $\begin{array}{l}\text { m } \\
\text { న }\end{array}$ & $\begin{array}{l}\stackrel{+}{N} \\
\infty \\
\infty\end{array}$ & $\frac{m}{n}$ & $\begin{array}{l}\infty \\
0 \\
0 \\
0\end{array}$ & $\begin{array}{l}0 \\
\stackrel{0}{\circ} \\
\stackrel{1}{0}\end{array}$ \\
\hline z & 出 & $\stackrel{8}{\circ}$ & ᄋ으 & 음 & ᄋ & 음 & ৪ & ᄋ으 & ○ \\
\hline$\frac{n}{\alpha}$ & $\underline{z}$ & $\frac{1}{\infty}$ & $\underset{\infty}{\stackrel{\mathcal{N}}{\sim}}$ & $\begin{array}{l}\bar{\checkmark} \\
\infty\end{array}$ & $\stackrel{\widetilde{\Omega}}{\infty^{\circ}}$ & $\begin{array}{l}\stackrel{L}{\Theta} \\
\infty\end{array}$ & $\underset{\infty}{\stackrel{N}{N}}$ & $\begin{array}{l}\infty \\
\infty \\
\infty\end{array}$ & $\begin{array}{l}5 \\
\text { - }\end{array}$ \\
\hline تُ & - & $\underset{\sim}{\stackrel{\overbrace{}}{\sim}}$ & $\begin{array}{l}\stackrel{1}{\circ} \\
\stackrel{0}{10}\end{array}$ & \begin{tabular}{l}
$M$ \\
$\infty$ \\
\multirow{\sigma}{*}{}
\end{tabular} & 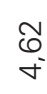 & $\begin{array}{l}\stackrel{\sim}{\sim} \\
\underset{\sim}{*}\end{array}$ & $\stackrel{m}{\underset{\sim}{*}}$ & $\begin{array}{l}\varrho \\
\stackrel{-}{\circ}\end{array}$ & $\begin{array}{l}\text { D } \\
\text { ल) }\end{array}$ \\
\hline 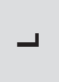 & छ & $\stackrel{\llcorner}{\stackrel{L}{N}}$ & $\begin{array}{l}\text { m } \\
\text { m. }\end{array}$ & $\begin{array}{l}\stackrel{\omega}{m} \\
m\end{array}$ & $\begin{array}{l}\text { P } \\
\text { nं }\end{array}$ & $\begin{array}{l}\stackrel{+}{+} \\
\text { ले }\end{array}$ & $\begin{array}{l}\text { ○ } \\
\text { m. }\end{array}$ & 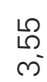 & $\begin{array}{l}8 \\
\text { 'ं }\end{array}$ \\
\hline 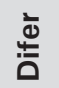 & 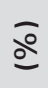 & $\begin{array}{l}0 \\
\stackrel{+}{N} \\
\sim\end{array}$ & $\stackrel{\text { m }}{\sim}$ & $\underset{N}{\approx}$ & $\frac{O}{i}$ & 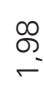 & $\stackrel{\infty}{\infty}$ & 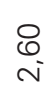 & $\underset{\sim}{\stackrel{\sigma}{\sim}}$ \\
\hline$\frac{\frac{亠}{\sigma}}{\bar{\varpi}}$ & $\overline{\mathbf{z}}$ & $\begin{array}{l}\hat{\theta} \\
\hat{m}\end{array}$ & $\begin{array}{l}m \\
m \\
\rho^{\circ} \\
m\end{array}$ & 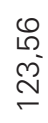 & $\begin{array}{l}\bar{n} \\
\stackrel{\Sigma}{E}\end{array}$ & $\begin{array}{l}\text { مै } \\
\text { Е }\end{array}$ & 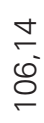 & $\begin{array}{l}\text { م) } \\
\text { ○ }\end{array}$ & $\begin{array}{l}\circ \\
\text { దீ } \\
\text { ه' }\end{array}$ \\
\hline$\stackrel{\text { 岀 }}{\Sigma}$ & 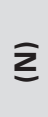 & $\begin{array}{l}0 \\
8 \\
\dot{\Xi} \\
\text { ¿ }\end{array}$ & $\begin{array}{l}\text { m } \\
\text { m} \\
m\end{array}$ & $\begin{array}{l}\bar{m} \\
\stackrel{0}{ } \\
\stackrel{N}{ }\end{array}$ & $\begin{array}{l}\curvearrowright \\
\stackrel{2}{\sigma} \\
\stackrel{\sigma}{\sigma}\end{array}$ & $\begin{array}{l}\mathbb{N} \\
\stackrel{N}{\leftarrow} \\
\leftarrow\end{array}$ & 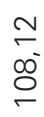 & 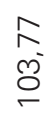 & $\begin{array}{l}\text { ᄋ } \\
\text { ه }\end{array}$ \\
\hline z & 岀 & 이 & 요 & 유 & 으 & 음 & 음 & 음 & 으 \\
\hline$\frac{0}{2}$ & $\bar{z}$ & $\begin{array}{l}\hat{\theta} \\
\text { - }\end{array}$ & $\underset{+}{\stackrel{9}{\sim}}$ & চ & $\begin{array}{l}\text { M } \\
0\end{array}$ & $\frac{\text { م) }}{\leftarrow}$ & $\underset{\sim}{\stackrel{N}{0}}$ & $\begin{array}{l}\text { m } \\
\text { L }\end{array}$ & $\bar{\Sigma}$ \\
\hline تُ & - & 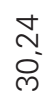 & $\stackrel{\infty}{\hat{N}}$ & $\stackrel{+}{\stackrel{+}{N}}$ & $\begin{array}{l}\infty \\
\text { N } \\
\text { N }\end{array}$ & $\begin{array}{l}8 \\
\text { ○ } \\
\text { N }\end{array}$ & 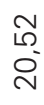 & $\stackrel{\stackrel{\sim}{\sim}}{\stackrel{\sigma}{\sigma}}$ & $\begin{array}{l}\text { م } \\
\text { N- }\end{array}$ \\
\hline ــ & $\bar{\xi}$ & $\stackrel{\infty}{\infty}$ & $\stackrel{\stackrel{\infty}{\infty}}{\stackrel{-}{-}}$ & ৪ & $\stackrel{\stackrel{\leftrightarrow}{\Omega}}{=}$ & $\begin{array}{l}8 \\
\text { }\end{array}$ & $\stackrel{\text { L }}{\circ}$ & $\stackrel{\circ}{\sim}$ & $\stackrel{\llcorner 0}{\sim}$ \\
\hline
\end{tabular}




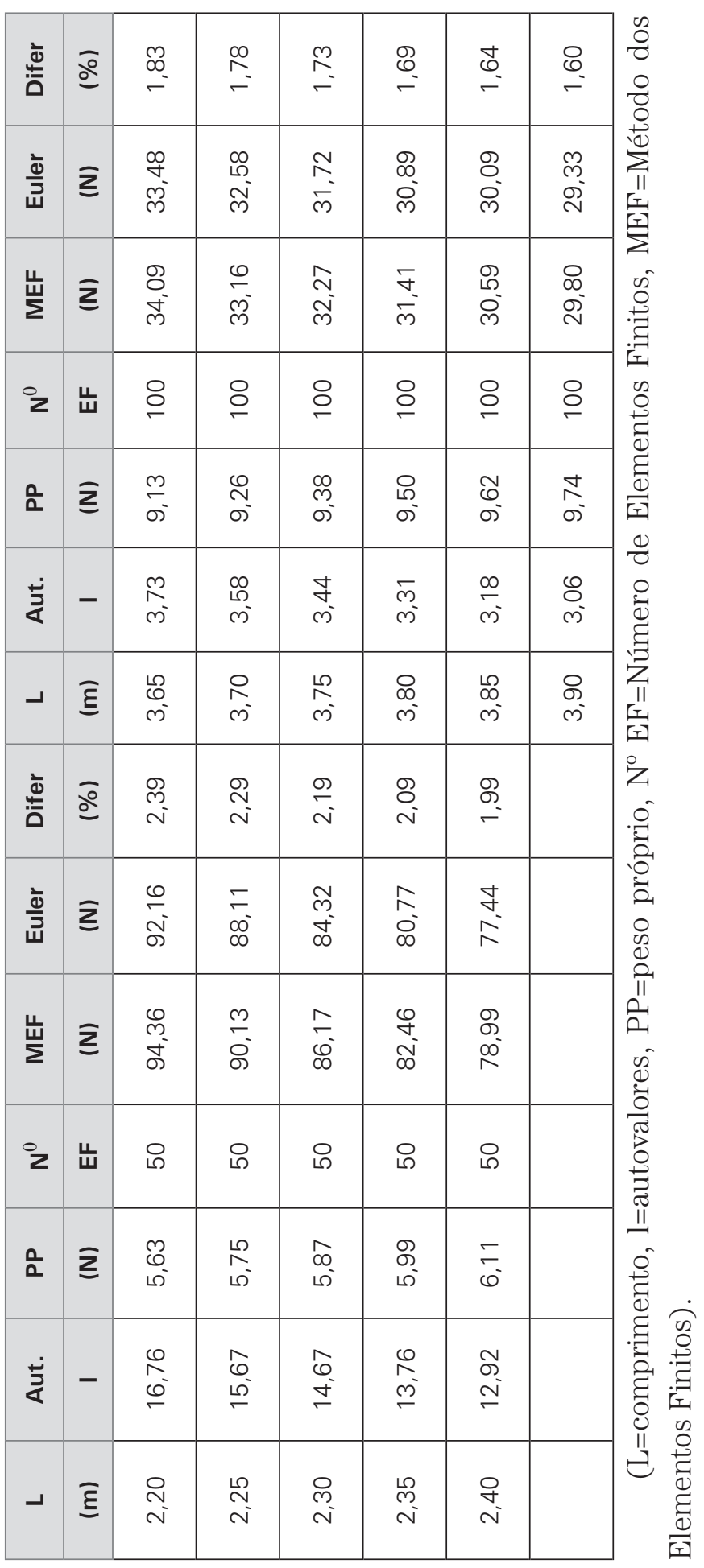




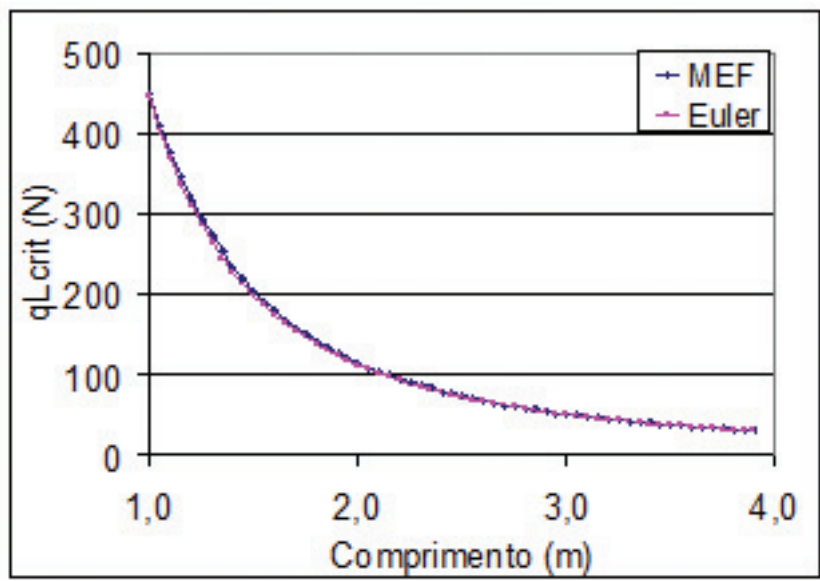

Figura 5.22 - Euler e Elementos Finitos: exclusivamente o peso próprio.

Quando se analisa sob a hipótese de pequenos deslocamentos, a influência do peso próprio na carga crítica de flambagem, verifica-se que, quando o valor $q L$ supera o valor dado pela expressão (3.1) $P_{\mathrm{Cr}}$ torna-se negativo, o que pode ser apreciado pela Figura 5.23.

Por regressão de potência chega-se a uma equação que representa os resultados pelo processo estático do MEF $\left(457,79 \mathrm{~L}^{-2,0059}\right)$. Essa é 2,7\% superior à da formulação de Euler-Greenhill $\left(445,49 \mathrm{~L}^{-2}\right)$.

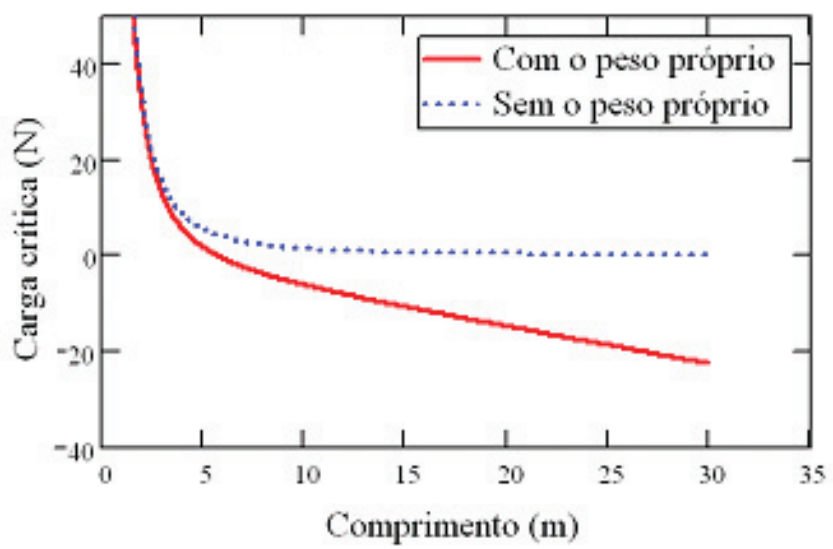

Figura 5.23 - Solução de Euler-Greenhill. 
Uma outra forma de se obter a carga crítica de flambagem é por meio da expressão da rigidez generalizada total, desenvolvida no capítulo 4. A expressão (4.25) quando igualada a zero fornece a equação para o valor para a carga crítica de flambagem, Eq. (5.2),

$$
\mathrm{qL}_{\text {crit }}=\frac{8,298 \mathrm{EI}}{\mathrm{L}^{2}}
$$

que é 5,17 \% maior que a solução de Euler-Greenhill da Eq. (3.4).

O comprimento crítico de flambagem, com os parâmetros da barra testada, pela solução de Euler-Greenhill, quando se leva em conta o peso próprio na carga crítica de Euler, é de 5,8 m. Pela solução desenvolvida neste trabalho chega-se ao mesmo resultado, porem é necessário retirar a massa do acelerômetro da formulação, como foi mencionado no início desta seção, pois a força axial correspondente não pôde ser contemplada por meio do equacionamento de Euler-Greenhill, apresentado no capítulo 3.

Os traçados correspondentes aos comprimentos críticos pelos dois processos podem ser observados na Figura 5.24. Esses resultados reforçam a validade da formulação proposta com a função de forma escolhida. Em suma, a consideração do peso próprio dos elementos estruturais pela Eq. (3.5) na carga de crítica de flambagem da Eq. (3.1) é o equivalente à consideração da rigidez geométrica nas análises não-lineares, quer sejam dinâmicas ou estáticas. 


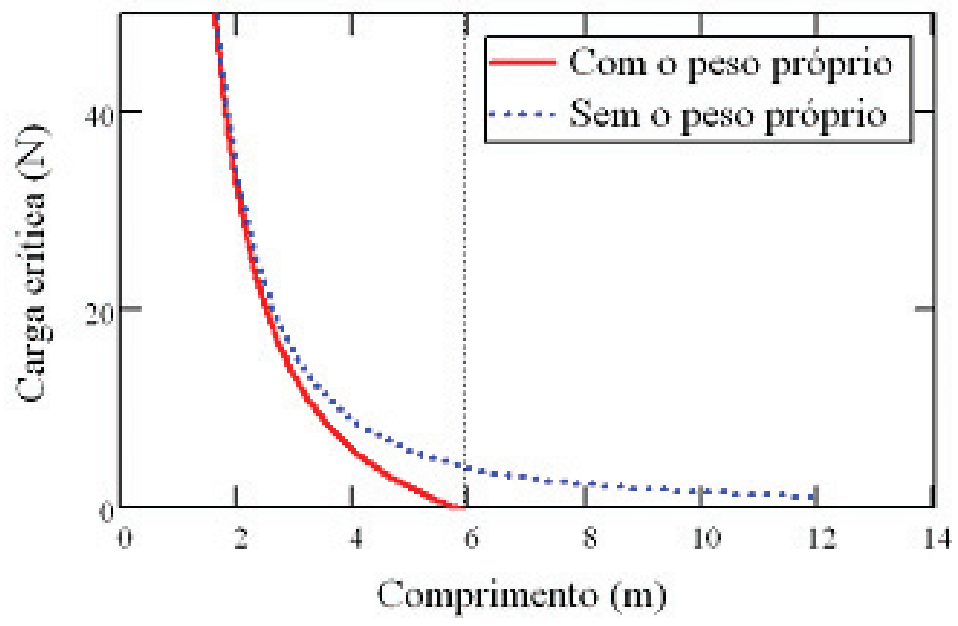

(a) Euler: $5,8 \mathrm{~m}$.

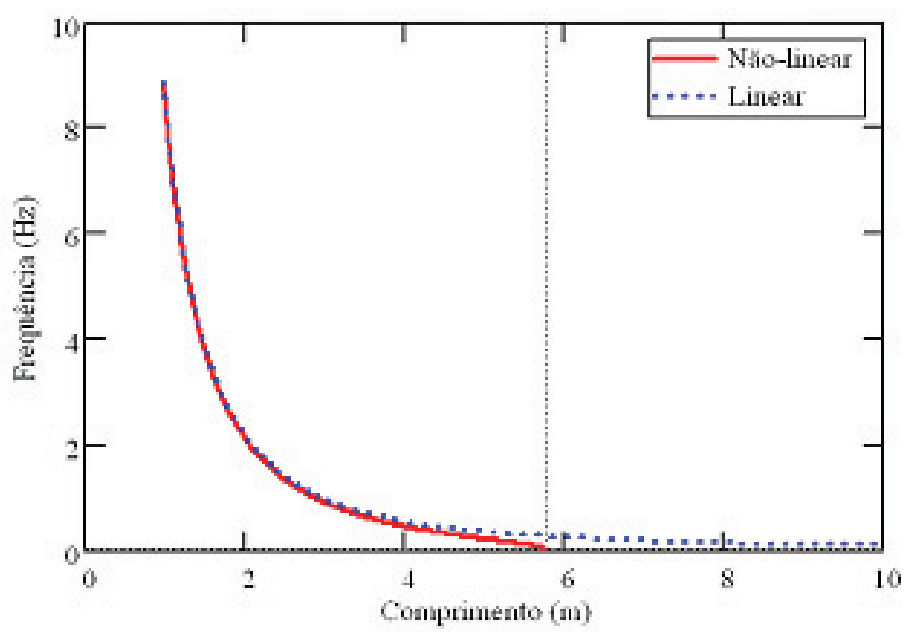

(b) Método proposto: $5,8 \mathrm{~m}$.

Figura 5.24 - Comprimento crítico de flambagem.

\subsection{RESUMO}

O conjunto de ensaios dinâmicos conduzidos em laboratório permitiu comprovar experimentalmente a influência da carga 
axial na frequência natural de vibração dos sistemas estruturais. Em um primeiro grupo de ensaios foi aplicada uma massa concentrada na extremidade da barra e três posições de testes foram adotadas, uma para o esforço de compressão, outra para o esforço de tração e uma terceira para a ausência do esforço normal. Esperava-se encontrar três valores distintos para as frequências, o que foi confirmado.

Um segundo grupo de testes foi conduzido levando em conta modelos sujeitos exclusivamente ao seu peso próprio, visando simular sistemas com reduzida força axial externa aplica. A aferição da solução proposta neste trabalho foi feita dinamicamente e também pelo método estático para a determinação da carga crítica de flambagem, tanto pela solução de Euler-Greenhill quanto a solução do Método dos Elementos Finitos.

É possível concluir, portanto, que, dentro do intervalo de validade adotado para a equação (4.19), os resultados experimentais confirmaram:

- $\quad$ primeiramente, o caráter não-linear geométrico de sistema esbeltos;

- $\quad$ segundo, a validade do método proposto; e;

- $\quad$ por último, o cálculo correto da frequência do primeiro modo de vibração, propiciado pela solução desenvolvida neste trabalho.

Em outras palavras, a formulação elaborada nesta Tese, para o cálculo da frequência fundamental de estruturas em balanço, pôde ser avaliada por meio de análises dinâmicas e estáticas, sendo possível validar seus resultados.

As análises feitas utilizando como referência os modelos físicos de laboratório levaram à comprovação de que a consideração do esforço normal na rigidez dos sistemas estruturais modifica as suas frequências de vibração.

No capítulo 7 será investigada a aplicabilidade da solução proposta à estruturas reais e as repercussões que as frequências calcu- 
ladas sob não-linearidade geométrica trazem ao cálculo da ação dinâmica do vento.

Ainda no capítulo 7, será apresentada uma investigação experimental de campo, realizada sobre uma estrutura real, para avaliação do método e da solução proposta neste trabalho.

No capítulo seguinte serão apresentados os modelos para o cálculo da ação do vento segundo a NBR 6123/88 - Forças devidas ao vento em edificações. 